DoD Corrosion Prevention and Control Program

\title{
Demonstration of Smart Fluorescent and Self- Healing Coatings for Severely Corrosive Environments at Vehicle Wash Facilities
}

Final Report on Project FAR-02 for FY06

Ashok Kumar, Dr. L. D. Stephenson, Timothy D. Race,

August 2009

and Tony Bochniak 



\section{Demonstration of Smart Fluorescent and Self- Healing Coatings for Severely Corrosive Environments at Vehicle Wash Facilities}

Final Report on Project FAR-02 for FY06

Dr. Ashok Kumar and Dr. L. D. Stephenson

Construction Engineering Research Laboratory

U.S. Army Engineer Research and Development Center

2902 Newmark Drive

Champaign, IL 61822

Timothy D. Race

Corrosion Control Consultants and Labs, Inc.

135 Addison Avenue, Suite 108

Elmhurst, IL 60126

Tony Bochniak

Manta Industrial, Inc.

5233 Hohman Avenue

Hammond, IN 46320-1721

Final report

Approved for public release; distribution is unlimited.

Prepared for Office of the Secretary of Defense (OUSD(AT\&L))

3090 Defense Pentagon

Washington, DC 20301-3090

Under Military Interdepartmental Purchase Request MIPR6FCERB1020, 20 Mar 06;

MIPR6H6AG3CPC1, 15 May 06; and MIPR6HMBHDE097, 31 May 06 


\begin{abstract}
This project demonstrated the following cost-effective paint maintenance procedures: utilization of smart coatings containing fluorescing compounds, self-healing microcapsules, and purpose-formulated surface tolerant coatings to overcoat existing paints. Smart coatings incorporate microcapsules, and fluorescing compounds which are mixed into paint at the time of application. Microcapsules instill the coating with selfhealing, corrosion resistance, and passive sensing capabilities. Fluorescing compounds improve the coating service life by faster and better inspections, early identification of problems, and timely repairs. The overcoating process does not require extensive surface preparation, and can be significantly less expensive than other maintenance practices, particularly when the existing coating contains lead or other hazardous materials.
\end{abstract}

The smart coatings were demonstrated on pipes used in a water-handling system for a central vehicle wash facility. The overcoating procedure was demonstrated on two types of structures: steel tanks and corrugated steel hangars. It is recommended that these technologies be implemented as standard practice for coating of steel structures for the Army and DoD.

DISCLAIMER: The contents of this report a re n ot to be u sed for a dvertising, publication, or promotional purposes. Citation of trade names does not constitute an official endorsement or approval of the use of such commercial products. All product names and trademarks cited are the property of their respective owners. The findings of this report are not to be construed as an official Department of the Army position unless so designated by other authorized documents. 


\section{Contents}

List of Figures and Tables.........................................................................................................

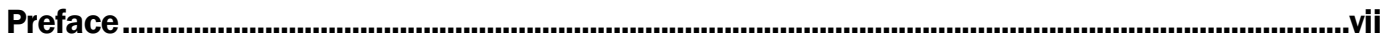

Executive Summary ......................................................................................................................................... viii

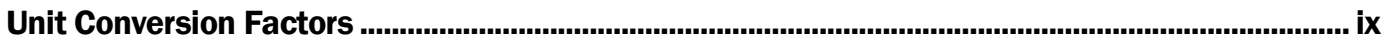

1 Introduction

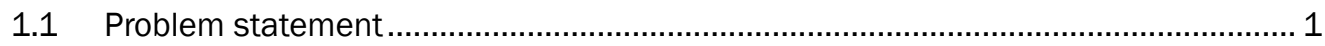

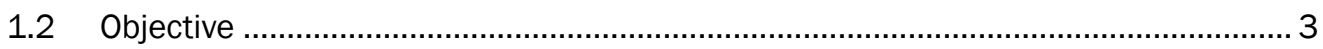

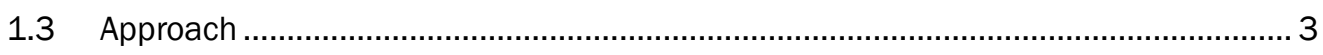

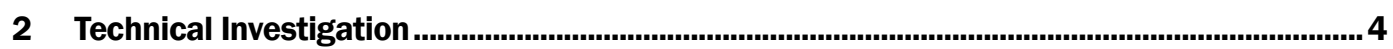

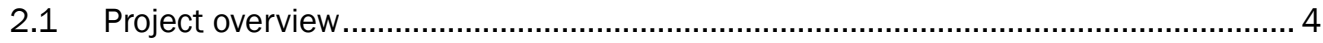

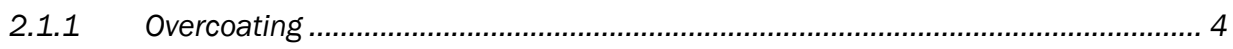

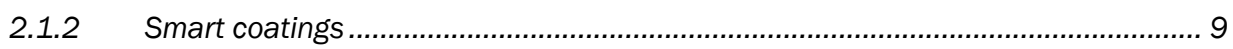

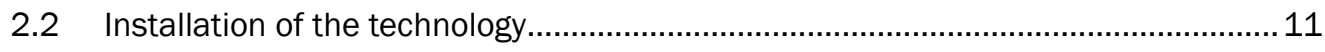

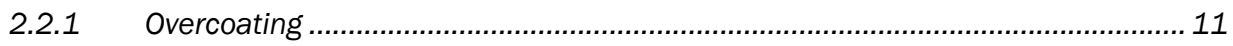

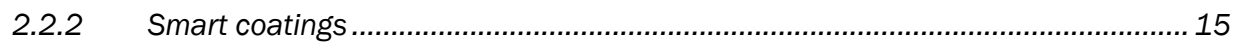

2.3 Technology operation and monitoring …….................................................... 16

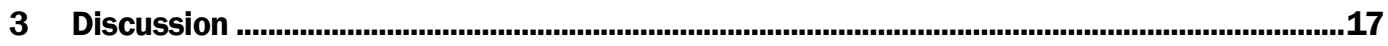

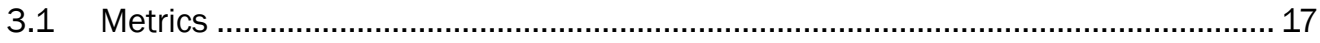

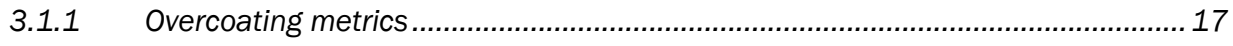

3.1.2 Smart coatings metrics................................................................................... 17

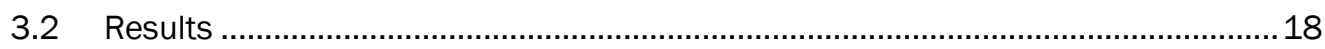

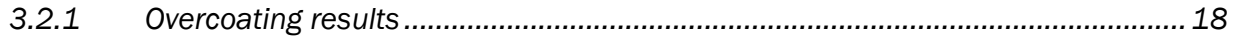

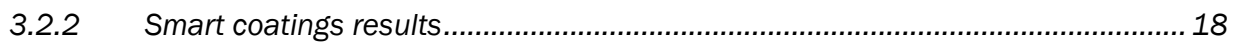

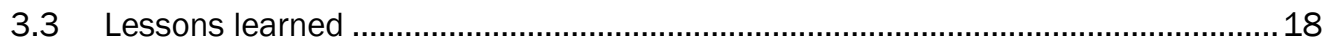

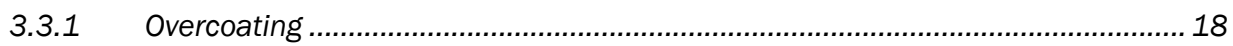

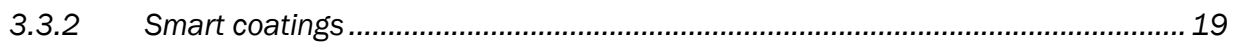

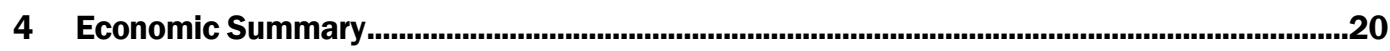

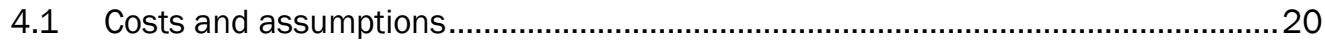

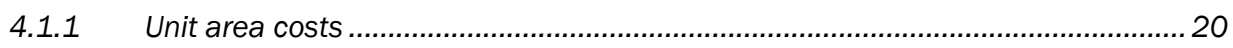

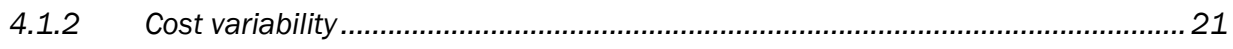

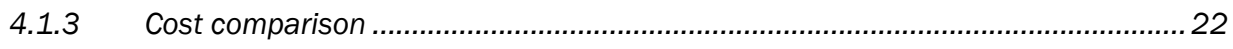

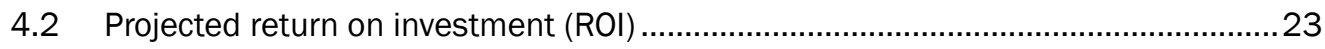

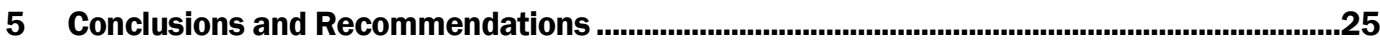

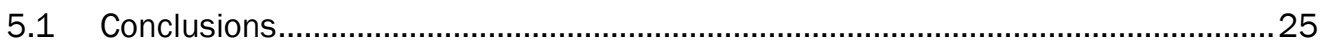

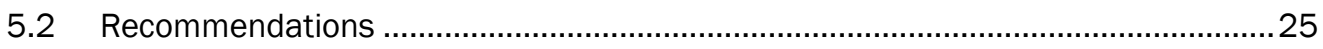




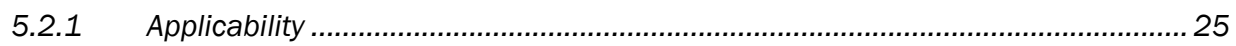

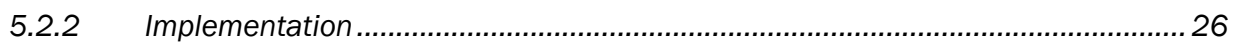

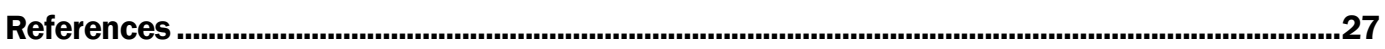

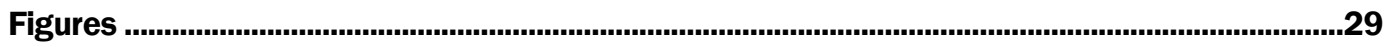

Appendix A: Project Management Plan for CPC Project FAR-02 .....................................................1

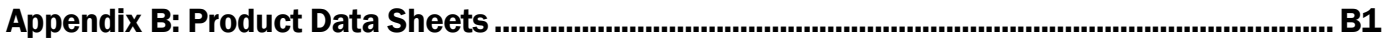

Appendix C: Economic Analysis of Overcoating and Smart Coatings........................................ C1

Appendix D: Environmental, Health, and Safety Information .................................................... D1

Appendix E: Suggested Implementation Guidance ............................................................................E1

Appendix F: Smart Fluorescent and Self-Healing Coatings for Steel Utilities at Army

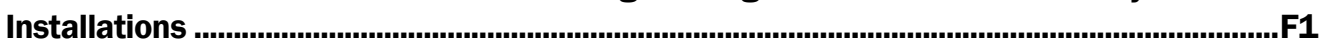

Appendix G: Smart Coatings Condition Assessment Report ..................................................... G1

Report Documentation Page 


\section{List of Figures and Tables}

\section{Figures}

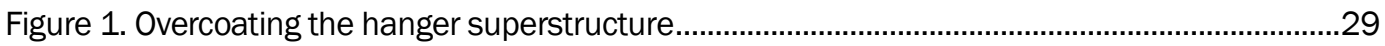

Figure 2. Deluge Tank No. 2 before painting.

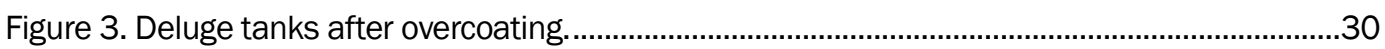

Figure 4. Simmons AAF hangar after overcoating has been completed. ............................................30

Figure 5. Simmons AAF hangar work in progress.............................................................................30

Figure 6. Simmons AAF hangar before painting. …………………………………………………....31

Figure 7. Simmons AAF hangar before painting..............................................................................

Figure 8. Simmons AAF hangar doors after overcoating. ...............................................................31

Figure 9. Simmons AAF hangar before painting. .........................................................................32

Figure 10. Simmons AAF hangar before painting, showing masking of utility line. ..........................32

Figure 11. Simmons AAF hangar after first MCU coat, showing protective covers and

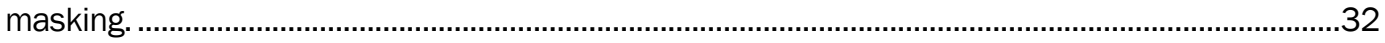

Figure 12. Simmons AAF hangar during overcoating....................................................................33

Figure 13. Simmons AAF hangar during overcoating..........................................................................33

Figure 14. Simmons AAF hangar during power washing to remove dirt, chalk, and loose

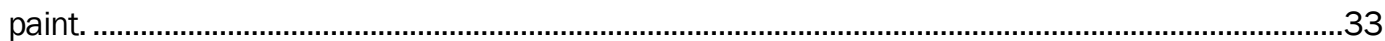

Figure 15. Simmons AAF hangar before overcoating....................................................................34

Figure 16. Simmons AAF hangar during overcoating. ………………………………………....34

Figure 17. Simmons AAF hangar superstructure after power washing...............................................34

Figure 18. Inspecting the paint thickness on a deluge tank.........................................................35

Figure 19. Smart coatings on pipe at CVWF grit basin. .....................................................................35

Figure 20. Before applying smart coatings....................................................................................35

Figure 21. Applying smart coating system to pipe.......................................................................

Figure 22. Abrasive blasting the pipe before applying smart coatings.................................................36

Figure 23. Pipe before abrasive blasting showing corrosion. ………………………….....................36

Figure 24. Pipe before abrasive blasting showing corrosion....................................................................37

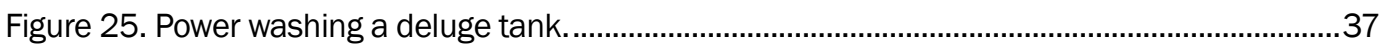

Figure 26. Mixing the coal tar epoxy with UVITEX OB fluorescent pigment.........................................37

Figure 27. Scaffolding in preparation for work on hangar superstructure. ........................................38

Figure 28. Condition of hangar superstructure before work began..................................................38

Figure 29. Painting the hangar superstructure

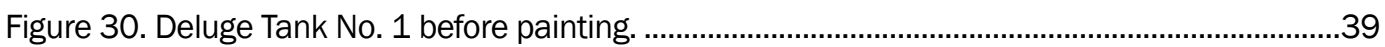

Figure 31. Applying aliphatic polyurethane topcoat to deluge tank.................................................39

Figure 32. Work in progress showing the overcoat primer, an MCU (Rust Grip). ..............................39

Figure 33. Priming a deluge tank.......................................................................................................40 


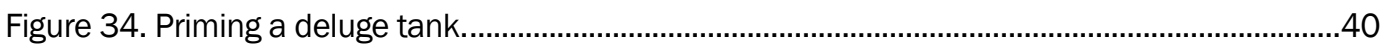

Figure 35. Inspecting the deluge tank paint thickness before starting work. .................................40

Figure 36. Deluge tank with newly completed overcoat system. .......................................................4 41

Figure 37. Applying topcoat to tank roof using a power roller...............................................................4 41

\section{Tables}

Table 1. Summary of recommended overcoating practices. ............................................................... 7

Table 2. Composition of microcapsules for self-healing paint. .............................................................10

Table 3. Structures overcoated - Simmons Army Airfield. ................................................................11

Table 4. Simmons AAF Hangar and deluge tanks. ...........................................................................14

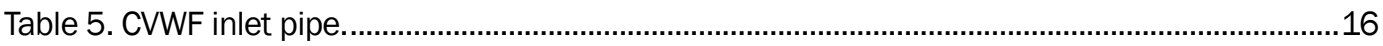

Table 6. Structures overcoated - Simmons Army Airfield. ..................................................................18

Table 7. CVWF inlet pipe treated with smart coatings ......................................................................18

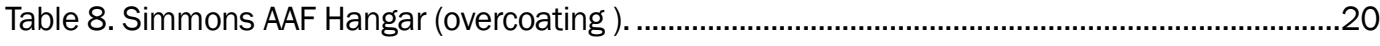

Table 9. Simmons AAF Deluge Tank 1 (overcoating) ............................................................................20

Table 10. Simmons AAF Deluge Tank 2 (overcoating). .....................................................................21

Table 11. Central vehicle wash facility (smart coatings) ...................................................................21 


\section{Preface}

This demonstration was performed for the Office of the Secretary of Defense (OSD) under Department of Defense (DoD) Corrosion Control and Prevention Project FAR-02, "Smart Fluorescent and Self-Healing Coatings for Severely Corrosive Environments at Vehicle Wash Facilities at Fort Bragg"; Military Interdepartmental Purchase Requests MIPR 6FCERB1020, dated 20 Mar 06; MIPR6H6AG3CPC1, dated 15 May o6; andMIPR 6HMBHDE097, dated 31 May 06. The proponent was the U.S. Army Office of the Assistant Chief of Staff for Installation Management (ACSIM), and the stakeholder was the U.S. Army Installation Management Command (IMCOM). The technical monitors were Daniel J. Dunmire (OUSD(AT\&L)Corrosion), Paul M. Volkman (IMPW-E), and David N. Purcell (DAIM-FDF).

The work was performed by the Engineering and Materials Branch (CEERD-CF-M), Facilities Division (CF), U. S. Army Engineer Research and Development Center - Construction Engineering Research Laboratory (ERDC-CERL), Champaign, IL. The ERDC-CERL Project Manager was Dr. Ashok Kumar and the Associate Project Manager was Dr. L. D. Stephenson. The stakeholder was Mr. Russell Hayes (Fort Bragg DPW POC). The customer was Mr. Jason Lyons, Acting Chief, Maintenance Division, Fort Bragg. The painting contractor was Manta Industrial. The Project Manager for Manta Industrial was Mr. Tony Bochniak. Mr. Craig Meier (Corrosion Control, Inc.) performed quality assurance testing for the government.

At the time this report was prepared, the Chief of the ERDC-CERL Materials and Structures Branch was Vicki L. Van Blaricum (CEERD-CF-M), the Chief of the Facilities Division was L. Michael Golish, (CEERD-CF), and the Technical Director for Installations was Martin J. Savoie (CEERDCV-ZT). The Deputy Director of ERDC-CERL was Dr. Kirankumar Topudurti and the Director was Dr. Ilker Adiguzel.

The Commander and Executive Director of the U.S. Army Engineer Research and Development Center was COL Richard B. Jenkins and the Director was Dr. James R. Houston. 


\section{Executive Summary}

This OSD Corrosion Prevention and Control project demonstrated costeffective paint maintenance procedures including utilization of paints containing fluorescing compounds and self-healing microcapsules as well as purpose-formulated surface tolerant coatings to overcoat existing paints. Overcoating is defined as the practice of painting over existing coatings to extend the service life. Maintenance painting of this type does not require extensive surface preparation. Overcoating can be significantly less expensive than other maintenance practices particularly when the existing coating contains lead or other hazardous materials. Moisture cured polyurethanes (MCU) are a popular and successful group of overcoat materials. MCU are tolerant of relatively poor application conditions and generally can be applied at very high humidity and low temperatures.

Smart coatings incorporate microcapsules and fluorescing compounds, which are mixed into paint at the time of application. Microcapsules instill the coating with special properties, including self-healing, corrosion resistance, and passive sensing. Fluorescing paints improve and speed the identification of application defects, such as holidays, pinholes and thin spots, thus improving the performance of the coating system.

The technology demonstrated in this project at Fort Bragg validates the use of surface tolerant paints for overcoating and smart fluorescing and self-healing coatings to enhance corrosion protection.

The surface tolerant overcoating technology is recommended for corrosion protection of steel structures that meet established overcoating criteria. The technology is applicable for multiple regions and installations, especially those in hot and humid environments locations where atmospheric corrosion is of concern.

Smart coatings containing microcapsules are recommended for surfaces subject to impact and abrasion, but only if the microcapsules become less expensive/more cost effective or for critical structures. Smart fluorescing coatings are recommended for critical service items including storage tanks and pipes. 


\section{Unit Conversion Factors}

\begin{tabular}{|l|c|l|}
\hline Multiply & By & To Obtain \\
\hline degrees Fahrenheit & $($ F-32)/1.8 & degrees Celsius \\
\hline feet & 0.3048 & meters \\
\hline gallons (U.S. liquid) & $3.785412 \mathrm{E}-03$ & cubic meters \\
\hline inches & 0.0254 & meters \\
\hline mils & 0.0254 & millimeters \\
\hline square feet & 0.09290304 & square meters \\
\hline
\end{tabular}




\section{Introduction}

\subsection{Problem statement}

An inspection of steel structures at Fort Bragg indicated problems with atmospheric corrosion. Protective coatings used on steel and galvanized steel are susceptible to peeling and other deterioration, caused by the combined effects of sunlight, moisture, and temperature cycles. This problem is not unique to Fort Bragg, but exists at all DoD facilities.

In the past, hexavalent chromium and lead-containing paints were used as a matter of routine. Today it is well understood that these types of coatings are hazardous to workers and the environment. Containment and disposal of surface preparation debris, worker protection, and other regulatory compliance costs combine to make removal of hazardous paints very expensive. In today's market the cost of repainting structures with lead paint costs about $\$ 8-15 / \mathrm{ft}^{2}$. Prices quotes as high as $\$ 20$ to $\$ 40 / \mathrm{ft}^{2}$ are not unheard of.

Overcoating can be significantly less expensive than other maintenance practices particularly when the existing coating contains lead or other hazardous materials. Typical costs in today's market are $\$ 3-6 / \mathrm{ft}^{2}$.

Coatings in critical service must be carefully inspected in order to ensure that the coatings will perform as intended. Critical service includes water and POL tanks and pipes for service and waste water as well as fuel and other chemicals. Coating defects such as pinholes and holidays can result in early failure especially on interior surfaces, but also on exterior surfaces. Early coating failure at defects can result in localized failures including perforation which can result in leakage and loss of service. Traditional means of identifying coating film defects are relatively slow. Low and high voltage pinhole testers are effective tools. However, low voltage detectors do not work for coatings greater than 20 mils thick. For higher thicknesses high voltage detectors are used. These instruments if used incorrectly can damage the paint. Neither detector can be used after the coating has been in service, doing so will result in false positives and possibly coating damage. Fluorescing coatings can be useful for scheduled inspections of tank interiors as well as pipe and tank exteriors providing early detection of coating erosion, cracks, and intercoat blistering. A fluorescing coating used 
as a prime or other coat allows the areas that differ from thinner coats, holidays, etc to fluoresce differently and therefore show up by simple visual inspection using a black light. Fluorescing paints have been used successfully by Naval Sea Systems Command (NAVSEA) as ballast tank linings.

Inspecting for paint film defects on surfaces in critical service is time consuming. Low voltage detectors can be operated effectively at $30 \mathrm{ft}^{2} / \mathrm{min}$. Inspection of fluorescing coatings can be accomplished at $150 \mathrm{ft}^{2} / \mathrm{min}$. Significant cost savings can be realized just in inspection. Low voltage testing costs about $\$ 0.05 / \mathrm{ft}^{2}$ while UV-light or LED pocket light inspection of fluorescing paints can be accomplished for about $\$ 0.01 / \mathrm{ft}^{2}$. Significant cost savings can be expected from improved application and acceptance inspection as well as periodic inspection. The design life of coating systems for lining potable water storage tanks is 40 -years for a two coat epoxy system. Owners are inured to accepting service lives of just 10 to 15 years. In other words there is a great disparity between the service received and the potential service of the coating. Improved inspection can go a long way towards narrowing that gap.

The traditional coatings used to prevent corrosion of steel where the topcoat has been breached are the inorganic and organic zinc rich primers. These coatings will sacrifice through galvanic action to protect the steel substrate. However, once the zinc is locally consumed, zinc rich primers cease to be effective deterrents to corrosion. Self-healing coatings containing microcapsules can both inhibit corrosion at films breaks, as well as heal the localized topcoat failure. A more in-depth description of how microcapsules and fluorescent coatings work and respective laboratory tests on them is presented in Appendix 1.

During a prior project in 2002, a deluge tank was coated with a moisture cure polyurethane coating system similar to the coating system used in this project (Race et al. 2003). The coating system on that deluge tank has performed well during the past 5 years. During another project in 2005, a deluge tank was coated with a moisture cure polyurethane coating system similar to the coating system used in this project (CPC Project AR-F-320 Interim Report). Comparison to these structures can be used to demonstrate longer-term performance. 


\subsection{Objective}

The objective of this research was to implement cost-effective paint maintenance procedures at Fort Bragg including overcoating lead-coated steel buildings and steel deluge tanks, applying self-healing coatings to selected items, and fluorescing coating to pipes in critical service. The maintenance procedures include surface preparation, environmental protection, and paint application.

\subsection{Approach}

Candidate steel structures and appurtenances requiring maintenance painting were identified. The structures were assessed using established techniques to determine the suitability of various paint maintenance procedures. Overcoat materials, surface preparation methods, and environmental controls were specified. Overcoating, self-healing paint, and fluorescing paint were implemented. The Project Management Plan for this CPC project is contained in Appendix A. Product data sheets are presented in Appendix B. An economic analysis of applying the subject coatings is provided in Appendix C. Environmental health and safety information is presented in Appendix D. Suggested language for implementation guidance is provided in Appendix E. A more in-depth technical description of how microcapsules and fluorescent coatings work and respective laboratory tests on them is presented in Appendix F. 


\section{Technical Investigation}

\subsection{Project overview}

\subsubsection{Overcoating}

Overcoating practices

The process of overcoating generally includes the following: low-pressure water washing or hand washing to remove surface contaminants; abrasive blasting or power or hand tool cleaning to remove corrosion products and loose paint; dust removal; and application of overcoat materials. Recommended practices are discussed below and summarized in Table 1.

\section{Contaminant removal}

Surface contaminants must be removed prior to overcoating the aged coating. Contaminants such as loose paint, chalk, dirt, grease, oil, and mildew may interfere with the adhesion of the overcoat material to the aged coating. Contaminants may be removed by power washing or hand washing.

Industry practices include power washing with water at pressures as low as 60opsi to as high as 7500 psi Pressures between 5000 and 7500 psi are capable of removing significant amounts of loose coating as well as minor quantities of relatively adherent coating. Such pressures are higher than required to remove surface contaminants and as such are more appropriately described as a surface preparation method than as cleaning. In any case cleaning at higher pressures will almost certainly require the collection and testing of the waste water for lead contamination. Intermediate pressures are more generally accepted as appropriate for removal of surface contaminants. In practice water pressure is generally specified as a range, because of variability in operator technique and the degree of adherence and nature of surface contaminants. A biodegradable detergent is often added to the cleaning water. Cleaning water is usually applied at lower pressures in the 400 to 600 psi range. Rinse water pressures are generally higher, usually in the 1500 to 4000 psi range.

Waste water from pressure washing should be tested. Water that exhibits the hazardous characteristic must be disposed of as a hazardous waste. Filtering the solids from collected water may be sufficient to reduce the hazardous characteristic. Some facility owners do not specify that the wash 
water must be collected. Collection of wash water from elevated structures may be difficult. Generally nets or screens are used to collect dislodged particulate and the water is allowed to spill onto the ground. Enforcement and interpretation of regulations governing such operations are highly variable. Waste water from power washing averages 100 to 200 gallons per $1000 \mathrm{ft}^{2}$ of surface cleaned. Production rates for power washing average about $1000 \mathrm{ft}^{2} /$ hour.

Removal of surface contaminants may also be performed by hand washing the surface. Washing is generally performed using mild detergents. Bleach may be added to help eliminate mildew. The cleaning solution is applied and the surface is scrubbed with a non-woven abrasive pad. Clean water is applied with rags or sponges to rinse the surface. The method is quite effective at removing tenacious contaminants such as chalk and mildew. Ground tarps are sufficient for collecting the minimal quantities of debris and waste water produced. Waste water from hand washing averages 10 to 20 gallons per $1000 \mathrm{ft}^{2}$ of surface cleaned. Production rates for hand washing average about $150 \mathrm{ft}^{2} /$ hour.

Both power washing and hand washing techniques are recommended for contaminant removal on projects. The technique to be utilized should be selected by the specifier.

\section{Surface preparation}

Surface preparation methods should be selected to minimize damage to the aged coating while providing a clean surface free of loose corrosion and loose paint. Sweep and brush-off blasting may disrupt the adhesion or fracture the aged coating and may lead to subsequent failures of the overcoat system. Similarly, spot or zone cleaning using an abrasive method, may result in blast media impingement damage to adjacent coated areas. Again, this may lead to adhesive failures of the overcoat system.

Power washing followed by power tool cleaning is used by several state departments of transportation for preparing surfaces for overcoating. Power washing removes surface contaminants including dirt, chalk, and salt. Power tools are then used to spot clean corroded areas and to remove loose coating. Depending on the nature of the structure, several types of power tools may be required to prepare the surface. Typical power tools used include needle guns, abrasive wheel or disc sanders, and rotary impact tools. Rotary impact tools or needle guns are needed to remove thick 
deposits of rust scale. Rotary tools such as wheel and disc sanders equipped with non-woven abrasive pads are well suited to cleaning broad flat areas.

Two levels of cleanliness may be specified using power tools, SSPC-SP 3 Power Tool Cleaning and SSPC-SP 11 Power Tool Cleaning to Bare Metal. SSPC-SP 11 is significantly more expensive than SSPC-SP 3 and produces a higher degree of cleanliness than is necessary for overcoating. SSPC defines the degree of cleanliness in SP 3 as the removal of all loose mill scale, loose rust, loose paint, and loose detrimental matter. Furthermore it is not intended that adherent mill scale, rust, and paint be removed by this method. The SP 3 written standard is supplemented by a visual standard, SSPC-VIS 3, Visual Standard for Power- and Hand-Tool Cleaned Steel. Surfaces suitable for overcoating are most accurately depicted by Condition E of VIS 3. Condition E depicts mostly intact paint applied over blastcleaned steel. Condition $\mathrm{G}$ is applicable to a lesser degree and shows a thoroughly weathered, blistered, and stained paint applied over a mill scale bearing steel. SSPC-SP 3 implies that the entire surface is cleaned with the power tools. However, from a practical standpoint it is more cost-effective to minimize the surface area that is cleaned with power tools. Surfaces resembling Condition E of VIS 3 will be adequately prepared if only areas with visible spots of corrosion or loose paint are power tool cleaned. Surfaces resembling Condition $\mathrm{G}$ should be power tool cleaned in their entirety. Some specifiers have gone as far as to specify a minimum size corrosion spot which requires power tool cleaning. This may also be a cost-effective practice as it avoids the need to clean areas with pinpoint or small spots of corrosion which may be readily overcoated without cleaning. Another important aspect of power tool cleaning is the need to remove loose paint back to sound paint and to feather edges. This practice will help prevent lifting of the aged coating and will provide a better appearance.

SSPC-SP 2 Hand Tool Cleaning provides the same definition for degree of cleanliness as SP 3 Power Tool Cleaning. Research performed by the New England regional coalition of state departments of transportation (NEPCOAT) has shown that the performance of overcoat materials applied over SP 2 cleaned surfaces is significantly poorer than the same materials applied over SP 3 cleaned surfaces. These results were based on tests performed over surfaces contaminated with road de-icing salts. SP 2 can be used provided that the surfaces to be overcoated are not contaminated with soluble salts. 


\section{Dust removal}

Residual dust produced during power tool cleaning must be removed from the surface prior to overcoating. Common dust removal methods recommend in SSPC-SP 3 include brushing, blow off, and vacuuming. Brushing and blow off methods should be avoided because they may introduce leadcontaining dust into the air. Wiping down surfaces with rags wet with water or solvent is the recommended practice. Rags wet with water reduce worker exposures to airborne dust. Solvent wiping also reduces airborne dust exposure and may also dry faster and remove more contaminants than water wiping. Solvent wiping with clean white rags wet with a high flash solvent is the preferred method.

\section{Overcoat application techniques}

Corroded areas and areas of loose paint that have been prepared by power tool cleaning should receive a coat of the specified primer. Areas of eroded topcoat where the original primer is exposed or shadows are visible should also be primed. In cases where corrosion spots and SP 2 or SP 3 cleaned areas are uniformly dispersed and numerous, it may be more cost-effective to apply the primer to the entire surface. Spot priming numerous individual rust spots by brush may be more time consuming than priming the entire surface using a roller. The primer and or the first full coat of the overcoat system should be applied by brush or roller. Subsequent coats may be applied by spray, brush, or roller.

Table 1. Summary of recommended overcoating practices.

\begin{tabular}{|l|l|}
\hline Procedure & Description \\
\hline $\begin{array}{l}\text { Contaminant } \\
\text { Removal }\end{array}$ & $\begin{array}{l}\text { (a) Power Wash - mild detergent solution at 400-600 psi; rinse at 1500-4000 } \\
\text { psi } \\
\text { (b) Hand Wash - mild detergent and bleach solution with abrasive pad; rinse } \\
\text { with clean water }\end{array}$ \\
\hline Surface Preparation & $\begin{array}{l}\text { SP 2 or SP 3 Hand or Power Tool Clean - to remove loose corrosion and } \\
\text { coating; feather edges }\end{array}$ \\
\hline Dust Removal & Hand wipe surfaces with clean rags wet with water or high flash solvent \\
\hline Overcoat Application & Brush and roll to spot prime; brush, roll, or spray topcoats \\
\hline
\end{tabular}

\section{Overcoat materials}

Overcoat materials should have good penetration and wetting characteristics. They should be relatively low build materials with good flexibility and 
should not contain strong solvents. Some commercially available coatings have been specifically formulated for overcoating. Certain products have been validated in use as overcoats and should be considered as candidates. Types of products marketed by paint manufacturers for overcoating include acrylic latex, calcium sulfonate, alkyd, epoxy, oil and oil-modified alkyd, fluoropolymer, polyurethane, polyester, wax, petrolatum tape, urethane-latex, and epoxy-urethane coatings.

Based on research performed by the New England regional coalition of state departments of transportation (NEPCOAT), solvent borne overcoat materials are generally superior to water-borne products. However, coating materials containing strong solvents or those with a high degree of internal stress should not be used for overcoating. Strong solvents may have a tendency to lift the old coating or to cause resin or plasticizer migration in the aged coating. Overcoats with a high degree of internal stress will transfer their strong internal forces to the underlying aged coating which may cause spontaneous delamination of the entire system.

Steel structures are typically painted with alkyd, epoxy, and polyurethane coatings. Historically the Army used lead-containing primers with alkyd or oleo resinous topcoats. Most industrial maintenance coating systems are designed for adhesion over clean steel surfaces. However, some coatings are more tolerant of minimally prepared steel surfaces which have adherent mill scale and rust. These types of products are generally preferred for overcoating painted steel structures.

Moisture cured polyurethanes (MCU) are a popular and successful group of overcoat materials. They are available in a wide range of colors and pigmentations. MCU are tolerant of relatively poor application conditions and generally can be applied at very high humidity and low temperatures. They are quite versatile and performed well in the NEPCOAT overcoat study. MCU overcoat systems have been recommended for use on Corps of Engineers projects.

MCU overcoat systems were previously demonstrated and validated under the Environmental Security Technology Certification Program. Aluminum pigmented MCU was tested on a complex steel lattice railroad bridge at Holston Army Ammunition Plant. The projected service-life of the MCU overcoat repair was reported to be 12 to 18 years. The projection was based on the pre-overcoat condition of the original paint system, the durability of 
the overcoat materials, and the severity of the exposure environment. MCU systems were applied to the exterior of steel deluge tanks and galvanized steel hangars at Fort Campbell. The projected service-life of the overcoat repair on the tanks was reported to be 15 to 25 years. Both projects successfully validated the cost performance of MCU overcoat systems.

\subsubsection{Smart coatings}

Self-healing coatings

Self-healing coatings have been developed by ERDC/CERL. These coatings incorporate microcapsules, which are mixed into paint as a dry powder at the time of application. Microcapsules may instill the coating with special properties including self-healing, corrosion resistance, and passive sensing.

Army research has established that constituents of microcapsules can be released when they are ruptured by damage to the coating in which they are contained. The investigated microcapsules exhibited long-term stability in dried paint films, only releasing active constituents when ruptured.

The optimum microcapsules were found to have nominal diameters in the range of 60 to 150 microns. Large diameter microcapsules are better at delivering their functional constituents. However, microcapsules diameters should not be greater than the paint thickness.

Because of its resistance to many of the commonly used paint solvents, urea formaldehyde (UF) was found to be the best shell material for containing the functional compounds for self-healing and corrosion resistance. UF shells also have good resistance to the functional compounds which they contain and exhibit long-term stability in dried paint films. UF shells are relatively easy to break and allow release of their constituents as needed. Microcapsules were supplied by Thies Technology, Inc., Henderson, NV. The composition of the microcapsules is given in Table 2. 
Table 2. Composition of microcapsules for self-healing paint.

\begin{tabular}{|l|l|}
\hline $\begin{array}{l}\text { Microcapsule } \\
\text { Description }\end{array}$ & $\begin{array}{l}\text { EM000808A } \\
\text { (urea-formaldehyde shell, 60-150 micron diameter) }\end{array}$ \\
\hline Diluent & $\begin{array}{l}\text { Therminol } 66 \text { (modified partially hydrogenated terphenol) } \\
18.5 \text { Percent by Weight }\end{array}$ \\
\hline Diluent & $\begin{array}{l}\text { Santicizer 148 } \\
\text { (Isodecyl diphenyl phosphate) } \\
19.4 \text { Percent by Weight }\end{array}$ \\
\hline Film-Former & $\begin{array}{l}\text { phenolic varnish } \\
55.3 \text { Percent by Weight }\end{array}$ \\
\hline Antioxidant & $\begin{array}{l}\text { butylated hydroxytoluene (BHT) } \\
0.43 \text { Percent by Weight }\end{array}$ \\
\hline Anticorrosion Agent & $\begin{array}{l}\text { Irgacor 153 } \\
\text { (alkylammonium salt of (2-benzothiazolylthio) succinic acid in xylene } \\
\text { preparation } \\
6.1 \text { Percent by Weight }\end{array}$ \\
\hline
\end{tabular}

\section{Fluorescent coatings}

Commercially available fluorescent coatings contain additives that fluoresce under ultraviolet (UV) light. Fluorescent coatings can be used as primer coatings or other coatings where their fluorescing capabilities aid inspection and identification of problems. Inspection can reveal areas where coatings have pinholes, holidays, incomplete coverage, and areas where corrosion has initiated under the coating. The fluorescent coating produces a visual condition that dramatically increases a worker or inspectors ability to "see" paint film defects. Fluorescence is accomplished by incorporating a photo-luminescent pigment into the coating. Illumination under ultraviolet light allows easy location of film defects at welds, corners, edges, and crevices. Under-film corrosion can be detected by the visual emphasis of surface contours.

Fluorescent additives in coating systems are used in the marine industry to extend the life of ballast tanks. Fluorescent coatings are also used for lining potable water storage tanks in compliance with NSF Standard 61. They are used to enhance inspection of applied coatings both during and after application. An applicator or inspector can estimate paint film thickness during application by visually identifying areas of high and low luminosity. Viewing a topcoat over a fluorescent primer can reveal pinholes, holidays, and thin spots in the topcoat. Defects appear as areas of brighter luminosity than surrounding areas. 
The average worker with $20 / 20$ vision can usually locate a defect $0.5 \mathrm{~mm}$ in size. UV fluorescence allows the same worker to locate defects $0.1 \mathrm{~mm}$ in size or smaller, in both low and normal-light conditions.

The fluorescing material or optically active pigment selected for use was Ciba UVITEX ${ }^{\circledR} \mathrm{OB}^{\circledR}$ manufactured by Ciba Specialty Chemicals. UVITEX ${ }^{\circledR}$ $\mathrm{OB}^{\circledR}$ (2, 5-thiophenediylbis (5-tert- 1, 3-benzoxazole)) is a fluorescing optical brightener. As a marker in paints the recommended addition of UVITEX ${ }^{\circledR} \mathrm{OB}^{\circledR}$ is 2 to $4 \%$ based on the weight of paint resin. The product data sheep for UVITEX ${ }^{\circledR} \mathrm{OB}^{\circledR}$ is in Appendix B.

\subsection{Installation of the technology}

Environmental, health and safety information related to surface preparation and application of overcoating and smart coatings is presented in Appendix D.

\subsubsection{Overcoating}

\section{Structures selected for overcoating}

The structures evaluated and selected for overcoating are described in Table 3 below.

Table 3. Structures overcoated - Simmons Army Airfield.

\begin{tabular}{|l|l|l|l|}
\hline Name & Building No. & Surface Area & Overcoating \\
\hline Hangar & P-3262 & $66,315 \mathrm{SF}$ & $\begin{array}{l}\text { Moisture cure } \\
\text { polyurethane and } \\
\text { aliphatic polyurethane } \\
\text { topcoat }\end{array}$ \\
\hline Deluge Tank & $\# 1$ & $4757 \mathrm{SF}$ & $\begin{array}{l}\text { Moisture cure } \\
\text { polyurethane and } \\
\text { aliphatic polyurethane } \\
\text { topcoat }\end{array}$ \\
\hline Deluge Tank & $\# 2$ & $6585 \mathrm{SF}$ & $\begin{array}{l}\text { Moisture cure } \\
\text { polyurethane and } \\
\text { aliphatic polyurethane } \\
\text { topcoat }\end{array}$ \\
\hline Total Area Overcoated & & $77,657 \mathrm{SF}$ & \\
\hline
\end{tabular}

Overcoating risk assessment: Initial condition of structures

The initial condition of the structures selected for maintenance painting at Fort Bragg is detailed below. Structures were rated for corrosion, flaking, 
erosion, and adhesion. The presence of hazardous lead was determined. The initial condition is important because it has a direct bearing on what work practices are employed as well as the extent and therefore cost of cleaning and surface preparation. The initial condition is included in this report to help the reader understand the applicability of the work practices employed herein and the relevance of the cost data to other prospective projects. The initial condition of the coated structures is depicted by some of the photographs contained in the Figures section at the end of the report. Data sheets for total hazardous metals measured in the preexisting coatings are shown in Appendix D.

\section{Simmons Army Airfield hangar}

The hangar is a galvanized corrugated steel structure with steel doors and doorframes, steel hangar doors, and structural steel elements. The initial paint condition was generally poor with widespread areas of peeling and cracking on the exterior siding. Areas of exposed galvanizing were rusting. Structural steel elements exhibited areas of active corrosion.

Lead content on various components was: hangar doors $0.20 \%$, metal doors and doorframes $0.63 \%$, CMU non-detectable, corrugated metal siding $0.22 \%$, and structural steel and ladders $22 \%$.

The average dry film thickness on the corrugated siding was 7.1 mils. Coating adhesion on the siding was fair to good.

\section{Simmons AAF deluge tank \#1}

Deluge tank \#1 is a welded plate steel structure. The structure was previously painted in a red and white checkerboard pattern consistent with aviation marking requirements. The original system consisted of abrasive blasting and application of TT-P-86 Type 2 red lead paint and red and white colored alkyd enamel topcoats. The average dry film thickness on the exterior tank shell was 10.0 mils. The average on the tank roof was 12.8 mils.

The tank was in generally poor condition with significant amounts of paint erosion and corrosion. The corrosion rating of the tank shell was about a $2 \mathrm{G}$ (16\% to $33 \%$ - general corrosion). Topcoat erosion was significant with numerous areas of red primer showing. The degree of topcoat erosion was 
No. 4. In some areas the primer had eroded enough for general corrosion to occur. Flaking of the topcoat was not an issue on this structure.

Total lead in one paint chip sample measured a significant $4.5 \%$. Paint adhesion was generally good.

The low coating thickness and good adhesion both indicate that there was not a significant risk associated with overcoating the shell of the tank. However, the percent area corroded (16 to 33\%) may exceed the cut-off point of $17 \%$ where overcoating is not as cost-effective as complete removal and repainting.

\section{Simmons AAF deluge tank \#2}

Deluge tank \#2 is a welded plate steel structure. The original system consisted of abrasive blasting and application of TT-P-86 Type 2 red lead paint and red and white alkyd enamels. The average dry film thickness on the tank shell was 5.2 mils. The average on the tank roof was 4.2 mils.

The tank shell was in poor condition with significant amounts of paint erosion and corrosion. The rust rating for the tank was 1 (>50\%). Active corrosion was noted on the bottom ring of the tank. The degree of topcoat erosion on the tank shell was No. 1.

Total lead in the existing paint measured a significant 5.8\%. Paint adhesion was generally good.

The low coating thickness and good adhesion indicated that the risk associated with overcoating the shell of this tank was negligible. However, the extent of corrosion $(\sim 60 \%)$ was high, indicating that the economics of overcoating the shell were not predicted to be good.

Overcoat project specifications

The painting specifications are summarized in Table 4. SSPC is The Society for Protective Coatings. HPW is high pressure washing. DFT is dry film thickness. LBP is lead-based paint. 
Table 4. Simmons AAF Hangar and deluge tanks.

\begin{tabular}{|l|l|}
\hline \multicolumn{2}{|l|}{ Work Process } \\
\hline $\begin{array}{l}\text { Surface Preparation and } \\
\text { Cleaning }\end{array}$ & $\begin{array}{l}\text { HPW @ 3500 psi - to remove loose paint, chalk, and dirt. } \\
\text { Spot clean SSPC-SP 2 Hand Tool Clean to remove rust and loose } \\
\text { paint. }\end{array}$ \\
\hline Environmental Controls & $\begin{array}{l}\text { Impermeable ground tarps overlaid with semi-permeable ground } \\
\text { tarps }\end{array}$ \\
\hline Primer & $\begin{array}{l}\text { Rust Grip } \\
3.5-4.5 \text { mils DFT }\end{array}$ \\
\hline Finish Coat & $\begin{array}{l}\text { Enamo Grip } \\
3.0-4.0 \text { mils DFT }\end{array}$ \\
\hline
\end{tabular}

Overcoating work practices

Overcoating work practices including cleaning, surface preparation, environmental controls, and paint application are depicted in photographs contained in the Figures section at the end of the report.

\section{Containment and surface preparation}

Prior to power washing the ground was covered with 4-mil thick plastic sheeting extending 8-feet from the exterior walls of the hangar. PVC pipe was rapped in the plastic to form a dam and prevent water from spilling on the ground. In addition to plastic sheeting perforated tarps were laid over the impermeable plastic to collect paint chips while simultaneously allowing water to pass through. Collected water was evaporated. At the completion of power washing paint chips and plastic sheeting were disposed of as hazardous waste.

\section{Surface preparation}

All exterior siding was power washed at 3500 psi to remove dirt, loose paint, oxidation and other contaminants per the specification. After power washing, areas that showed surface rust and remaining loose paint were prepared according to SSPC-SP2 hand tool cleaning. All signage was removed and reinstalled after the final coat was applied. 
Installation of coating system

After surface preparation, one coat of Superior Coatings Rust Grip was applied by brush and roll application to an average dry film thickness of 4 mils. After the primer was applied and allowed to cure in accordance to manufacture's requirements, one coat of Superior Coatings Enamo Grip a two-component aliphatic polyurethane was applied to an average dry film thickness of 3.5 mils. The product data sheets for Enamo Grip and Rust Grip are in Appendix B.

\subsubsection{Smart coatings}

Items selected for painting

Fort Bragg identified severe corrosion at its Central Vehicle Wash Facility (CVWF). The 3-foot diameter by 200 feet long inlet pipe to the grit settling pond was severely corroded and in need of maintenance. The existing coating was badly eroded and chalky. Approximately $60 \%$ of the surface was rusty. Critical areas such as welds and elbows had cracked coating. Coupling flanges, bolts and pipe stands were badly corroded. The existing coating was tested for lead and found not to have a significant quantity.

Base coating for smart additives

Pipes used in a water handling system for the central vehicle wash facility were selected for application of smart coatings. The pipes are exposed to precipitation and sunlight as well as periodic condensation. Coal tar epoxy (SSPC Paint No. 16) is commonly used to coat larger diameter water pipes and was selected for use at Fort Bragg.

Coal tar epoxy (Amercoat 78HS) loaded with microcapsules, as described in section 2.1.2, table 3, was used to stripe coat welds, bolts, and edges. Coal tar epoxy loaded with UVITEX ${ }^{\circledR} \mathrm{OB}^{\circledR}$ was used to prime the pipe. Coal tar epoxy without additives was used as a topcoat. The product data sheet for Amercoat $78 \mathrm{HS}$ is in Appendix B.

Project specifications

The painting specifications are summarized in Table 5 . 
Table 5. CVWF inlet pipe.

\begin{tabular}{|c|c|}
\hline \multicolumn{2}{|l|}{ Work Process } \\
\hline $\begin{array}{l}\text { Surface Preparation and } \\
\text { Cleaning }\end{array}$ & $\begin{array}{l}\text { SSPC-SP } 10 \text { White Metal Blast Cleaning (incorporating SP } 1 \text { to } \\
\text { remove all dirt, oil and grease deposits - using low pressure water } \\
\text { cleaning) to a blast profile of } 2-3 \text { mils }\end{array}$ \\
\hline Environmental Controls & NA \\
\hline Stripe Coat & $\begin{array}{l}\text { Brush and roll a stripe coat of Amercoat } 78 \mathrm{HS}+30 \% \mathrm{BV} \\
\text { Microcapsules to all welds, edges, and bolts at } 5-8 \text { mils DFT }\end{array}$ \\
\hline Primer & $\begin{array}{l}\text { Brush and roll a prime coat of Amercoat } 78 \mathrm{HS}+1 \% \mathrm{BV}^{\mathrm{UVITEX}}{ }^{\circledR} \mathrm{OB}^{\circledR} \\
\text { at } 5-8 \text { mils DFT }\end{array}$ \\
\hline Finish Coat & Brush and roll a topcoat of Amercoat $78 \mathrm{HS}$ at $5-8$ mils DFT \\
\hline
\end{tabular}

Project work practices

The CVWF grit chamber inlet pipe was cleaned prior to blasting using low pressure water to remove dirt, oil, and grease in accordance with SSPC-SP 1 Solvent Cleaning. The dried assembly was abrasive blasted in conformance with SSPC-SP 10 White Metal Blast Cleaning, using 20/40 coal slag grit (Reed Minerals) achieving a 2 to 3 mils blast profile. The prepared pipe assembly was stripe coated using a blend of Amercoat $78 \mathrm{HS}$ plus 30 percent by volume of dry microcapsules. Stripe coating with the field mixed self-healing coating was performed on all welds, edges, and bolts. The stripe coated pipe was coated with Amercoat 78HS containing 1percent by volume of dry UVITEX ${ }^{\circledR} \mathrm{OB}^{\circledR}$. The primed pipe was topcoated with one coat of Amercoat $78 \mathrm{HS}$. All coatings were applied with brushes and rollers. Each coat of paint was inspected with a DFT gage as well as by visual inspection using a portable UV light.

\subsection{Technology operation and monitoring}

Protective coatings by their very nature are passive forms of corrosion protection. Inspectors were used to monitor the installation of overcoating, self-healing, and fluorescent paint. Coating performance is generally monitored over very long time periods. Monitoring will be performed by performing site inspections of the installed coating systems after one year. Performance indicators include visible corrosion and coating degradation (ASTM D1654-05) as well as adhesion (ASTM D3359 or ASTM D6671-07). 


\section{Discussion}

\subsection{Metrics}

\subsubsection{Overcoating metrics}

Incorporated into technology

- $\quad$ SSPC-SP 3 Power Tool Cleaning

- SSPC-VIS 3, Visual Standard for Power- and Hand-Tool Cleaned Steel

- SSPC-SP 2 Hand Tool Cleaning

Performance metrics

- ASTM D1654-05 Standard Test Method for Evaluation of Painted or Coated Specimens Subjected to Corrosive Environments

- ASTM D3359-07 Standard Test Methods for Measuring Adhesion by Tape Test

- ASTM D6677-07 Standard Test Method for Evaluating Adhesion by Knife

\subsubsection{Smart coatings metrics}

Incorporated into technology

- SSPC-SP 10 White Metal Blast Cleaning

- SSPC Paint No. 16 Coal Tar Epoxy

Performance metrics

- ASTM D1654-05 Standard Test Method for Evaluation of Painted or Coated Specimens Subjected to Corrosive Environments

- ASTM D3359-07 Standard Test Methods for Measuring Adhesion by Tape Test

- ASTM D6677-07 Standard Test Method for Evaluating Adhesion by Knife 


\subsection{Results}

\subsubsection{Overcoating results}

Approximately 78,00o $\mathrm{ft}^{2}$ of steel surfaces were successfully overcoated at Fort Bragg. Overcoats were applied to two distinct types of structures steel tanks and corrugated steel hangers. These structures are listed in the following table.

Table 6. Structures overcoated - Simmons Army Airfield.

\begin{tabular}{|l|l|l|l|}
\hline \multicolumn{1}{|c|}{ Name } & Building No. & Surface Area & Overcoating \\
\hline Hangar & P-3262 & $66,315 \mathrm{SF}$ & $\begin{array}{l}\text { Moisture cure } \\
\text { polyurethane and } \\
\text { aliphatic polyurethane } \\
\text { topcoat }\end{array}$ \\
\hline Deluge Tank & $\# 1$ & $4757 \mathrm{SF}$ & $\begin{array}{l}\text { Moisture cure } \\
\text { polyurethane and } \\
\text { aliphatic polyurethane } \\
\text { topcoat }\end{array}$ \\
\hline Deluge Tank & $\# 2$ & $6585 \mathrm{SF}$ & $\begin{array}{l}\text { Moisture cure } \\
\text { polyurethane and } \\
\text { aliphatic polyurethane } \\
\text { topcoat }\end{array}$ \\
\hline Total Area Overcoated & & $77,657 \mathrm{SF}$ & \\
\hline
\end{tabular}

\subsubsection{Smart coatings results}

Approximately $2000 \mathrm{ft}^{2}$ were successfully coated with smart coatings. The 3 -foot diameter by 200 feet long inlet pipe to the grit settling pond, which is part of the water handling system for the Central Vehicle Wash Facility (CVWF), was chosen as the surface to receive the smart coatings. The smart coatings were applied as indicated in the following table.

Table 7. CVWF inlet pipe treated with smart coatings

\begin{tabular}{|l|l|}
\hline Stripe Coat & $\begin{array}{l}\text { Brush and roll a stripe coat of Amercoat } 78 \mathrm{HS}+30 \% \mathrm{BV} \\
\text { Microcapsules to all welds, edges, and bolts at 5-8 mils DFT }\end{array}$ \\
\hline Primer & $\begin{array}{l}\text { Brush and roll a prime coat of Amercoat } 78 \mathrm{HS}+1 \% \mathrm{BV} \mathrm{UVITEX}^{\circledR} \text { OB }^{\circledR} \\
\text { at 5-8 mils DFT }\end{array}$ \\
\hline Finish Coat & Brush and roll a topcoat of Amercoat $78 \mathrm{HS}$ at 5-8 mils DFT \\
\hline
\end{tabular}

\subsection{Lessons learned}

\subsubsection{Overcoating}

- Collection of wash water from elevated structures may be difficult. 
- Residual dust produced during power tool cleaning must be removed from the surface prior to overcoating.

- Spot priming numerous individual rust spots by brush may be more time consuming than priming the entire surface using a roller.

- Power washing pressures should be limited such that substantial amounts of lead-containing paint are not removed.

- Filtering the solids from collected water may be sufficient to reduce the hazardous characteristic.

\subsubsection{Smart coatings}

Although most of the procedures followed are standardized, the use of selfhealing microcapsules and fluorescent additive requires attention to several additional details, primarily selection of the proper self-healing microcapsules and fluorescent additive, accurate measurement and mixing of the microcapsules and additive, and selection of the method of application. For example, it was found that the primer with the microcapsules and fluorescent additives should be brushed or rolled onto the substrate rather than sprayed.

In order for the CVWF to remain operational while the recoating process was carried out, only one side of the grit settling chamber was shut down at a time. Also, it was found the following surface preparation process should be followed: (1) low-pressure water washing to remove surface contaminants; (2) abrasive blasting to remove all existing coating material and corrosion; and (3) application of coating systems with fluorescent additives and self healing microcapsules mixed in at the time of application, rather than premixed, in order to avoid damage of additive and microcapsules by paint solvents.

The analysis of the images under fluorescent illumination requires some practice, and the use of such coatings with known defects is strongly suggested. Dust and other small particles on the surface of the coatings fluoresces brightly, and one must learn to differentiate from actual defects in the coatings.

A follow-on inspection of the coated inlet pipe at the CVWF grit settling chamber was performed in April 2009. A report of the inspection findings is included as Appendix G. 


\section{Economic Summary}

\subsection{Costs and assumptions}

\subsubsection{Unit area costs}

Unit area costs for overcoating are summarized in Tables 8 through 11. Costs are calculated using a blended wage rate of $\$ 26.55 / \mathrm{h}$, based on the prevailing wage rates for a certified industrial painter, foreman, and supervisor in North Carolina plus fringe benefits.

Table 8. Simmons AAF Hangar (overcoating ).

\begin{tabular}{|l|c|c|r|}
\hline \multicolumn{1}{|c|}{ Work Phase } & Hours & Production $\left(\mathrm{ft}^{2} / \mathrm{h}\right.$ & Cost $\left(\$ / \mathrm{ft}^{2}\right)$ \\
\hline Mobilization/demobilization & 132 & NA & 0.053 \\
\hline Health and raining & 172 & NA & 0.069 \\
\hline Setup/cleanup & 442 & NA & 0.177 \\
\hline Power wash/hand tool clean & 500 & 133 & 0.200 \\
\hline Paint application & 1860 & 36 & 0.745 \\
\hline Materials & NA & NA & 0.273 \\
\hline Miscellaneous & NA & NA & 0.369 \\
\hline Total & & & 1.855 \\
\hline
\end{tabular}

Table 9. Simmons AAF Deluge Tank 1 (overcoating).

\begin{tabular}{|l|c|c|r|}
\hline \multicolumn{1}{|c|}{ Work Phase } & Hours & Production $\left(\mathrm{ft}^{2} / \mathrm{h}\right.$ & Cost $\left(\$ / \mathrm{ft}^{2}\right)$ \\
\hline Mobilization/demobilization & 13 & NA & 0.073 \\
\hline Health and raining & 17 & NA & 0.095 \\
\hline Setup/cleanup & 75 & NA & 0.419 \\
\hline Power wash/hand tool clean & 71 & 67 & 0.396 \\
\hline Paint application & 120 & 40 & 0.670 \\
\hline Materials & NA & NA & 0.315 \\
\hline Miscellaneous & NA & NA & 0.500 \\
\hline Total & & & 2.468 \\
\hline
\end{tabular}


Table 10. Simmons AAF Deluge Tank 2 (overcoating).

\begin{tabular}{|l|c|c|r|}
\hline \multicolumn{1}{|c|}{ Work Phase } & Hours & Production $\left(\mathrm{ft}^{2} / \mathrm{h}\right.$ & Cost $\left(\$ / \mathrm{ft}^{2}\right)$ \\
\hline Mobilization/demobilization & 20 & NA & 0.081 \\
\hline Health and raining & 24 & NA & 0.105 \\
\hline Setup/cleanup & 139 & NA & 0.560 \\
\hline Power wash/hand tool clean & 91 & 72 & 0.367 \\
\hline Paint application & 220 & 30 & 0.887 \\
\hline Materials & NA & NA & 0.289 \\
\hline Miscellaneous & NA & NA & 0.568 \\
\hline Total & & & 2.857 \\
\hline
\end{tabular}

Table 11. Central vehicle wash facility (smart coatings).

\begin{tabular}{|l|c|c|r|}
\hline \multicolumn{1}{|c|}{ Work Phase } & Hours & Production $\left(\mathrm{ft}^{2} / \mathrm{h}\right.$ & \multicolumn{1}{c|}{ Cost $\left(\$ / \mathrm{ft}^{2}\right)$} \\
\hline Mobilization/demobilization & 18 & NA & 0.230 \\
\hline Health and raining & 24 & NA & 0.307 \\
\hline Setup/cleanup & 66 & NA & 0.844 \\
\hline Abrasive blast clean & 63 & 33 & 0.806 \\
\hline Paint application & 251 & 20 & 3.212 \\
\hline Materials & NA & NA & 7.699 \\
\hline Miscellaneous & NA & NA & 1.638 \\
\hline Total & & & 14.736 \\
\hline
\end{tabular}

\subsubsection{Cost variability}

The average cost of overcoating at Fort Bragg was $\$ 1.98 / \mathrm{ft}^{2}$. The average cost for the deluge tanks was $\$ 2.70 / \mathrm{ft}^{2}$. The average cost of overcoating two similar deluge tanks at Fort Campbell was $\$ 3.63 / \mathrm{ft}^{2}$. The cost of overcoating the Simmons AAF hangar was $\$ 1.89 / \mathrm{ft}^{2}$. The average cost of overcoating similar hangars at Fort Campbell was $\$ 2.47 / \mathrm{ft}^{2}$. The cost for overcoating tanks and hangars at Fort Bragg was about $75 \%$ of the cost at Fort Campbell.

An analysis was performed to assess cost variability for overcoating. The major cost variables are mobilization/demobilization, health and training, surface preparation, paint application, expendable materials, and miscellaneous expenses. The cost of mobilization/demobilization ranged from $\$ 0.053 / \mathrm{ft}^{2}$ to $\$ 0.081 \mathrm{ft}^{2}$. The cost of health and training ranged from 
$\$ 0.069 / \mathrm{ft}^{2}$ to $\$ 0.1051 \mathrm{ft}^{2}$. The cost of non-productive labor (setup and cleanup) ranged from $\$ 0.177 / \mathrm{ft}^{2}$ to $\$ 0.5601 / \mathrm{ft}^{2}$. The cost of surface preparation ranged from $\$ 0.200 / \mathrm{ft}^{2}$ to $\$ 0.396 / \mathrm{ft}^{2}$. The cost of paint application ranged from $\$ 0.670 \mathrm{ft}^{2}$ to $\$ 0.887 / \mathrm{ft}^{2}$. The cost of paint and expendable materials ranged from $\$ 0.273 \mathrm{ft}^{2}$ to $\$ 0.315 / \mathrm{ft}^{2}$. Miscellaneous costs ranged from $\$ 0.369 / \mathrm{ft}^{2}$ to $\$ 0.5681 / \mathrm{ft}^{2}$. Based on the available data from Fort Bragg the low and high costs of overcoating are calculated to be $\$ 1.81 / \mathrm{ft}^{2}$ and $\$ 2.91 / \mathrm{ft}^{2}$ respectively. The median calculated cost of overcoating at Fort Bragg was $\$ 2.36 / \mathrm{ft}^{2}$. The cost variability is $\pm \$ 0.55 / \mathrm{ft}^{2}$ or $\pm 23 \%$.

An analysis was performed to assess cost variability for smart coating applications. The major variable is the cost of microcapsules. Microcapsules used in this project are manufactured to specifications as a special batch order item. The future cost of commercially manufactured microcapsules could be as low as $\$ 470 / \mathrm{lb}$ as compared to the present cost of $\$ 4700 / \mathrm{lb}$. If microcapsules at the lower cost had been available for use at Fort Bragg, the unit area cost would have been just $\$ 8.67 / \mathrm{ft}^{2}$ as compared to the actual cost of $\$ 14 \cdot 74 / \mathrm{ft}^{2}$.

\subsubsection{Cost comparison}

The cost of overcoating the structures at Fort Bragg can be compared to the cost of complete coating removal and repainting.

The paint system used for overcoating is similar to, or the same as those that may have been used to repaint the structures had all of the preexisting paint been removed prior to painting. Therefore application and material costs would have been similar or the same as for overcoating. The primary cost differential between overcoating and complete paint removal and repaint is surface preparation.

The hangar could not be abrasive blasted because blasting creates dust that is incompatible with the functions of the hangar. Additionally, the best alternative to abrasive blasting these structures is ultra high pressure (UHP) water blasting. Assuming production rates in the range 80 to 100 $\mathrm{ft}^{2} / \mathrm{h}$, the added labor cost of complete coating removal on the hangars would have been $\$ 0.11 / \mathrm{ft}^{2}$ to $\$ 0.24 / \mathrm{ft}^{2}$. Additional costs associated with mobilization/demobilization, equipment, health and safety, containment, water filtering, and waste disposal would add an estimated $\$ 6-8 / \mathrm{ft}^{2}$. The estimated cost of repainting the hanger using UHP water blasting and a 
similar two coat paint system would be about $\$ 9-11 / \mathrm{ft}^{2}$ as compared to the overcoating cost of $\$ 2.85 / \mathrm{ft}^{2}$.

The deluge tanks could have been contained and dry abrasive blasted to remove the existing coating prior to repainting. Assuming production rates in the range 150 to $200 \mathrm{ft}^{2} / \mathrm{h}$, the cost of complete coating removal on the tanks would have been about $\$ 0.40 / \mathrm{ft}^{2}$ to $\$ 0.8 \mathrm{o} / \mathrm{ft}^{2}$ less in terms of production labor. However, the additional costs of mobilization/demobilization, equipment, materials, containment, worker protection, and waste disposal would have increased the cost by about $\$ 6 / \mathrm{ft}^{2}$ to $\$ 8 / \mathrm{ft}^{2}$. Overall the cost of abrasive blasting and repainting would have been about $\$ 8 / \mathrm{ft}^{2}$ to $\$ 10 / \mathrm{ft}^{2}$ as compared to an overcoating cost of $\$ 1.89 / \mathrm{ft}^{2}$.

The cost of implementing smart coatings at Fort Bragg can be compared to the cost of the same job without smart coatings. Assuming that the identical procedures were used and the cost of microcapsules was $\$ 470 / \mathrm{lb}$, then the same job without self-healing properties would have been $\$ 8.00 / \mathrm{ft}^{2}$ and the same job without either self-healing of fluorescent additives would have been $\$ 7.63 / \mathrm{ft}^{2}$ as compared to the projected commercial cost of the smart coating installation at $\$ 8.67 / \mathrm{ft}^{2}$. The installation of the smart coating system is projected to cost just $\$ 1.04 / \mathrm{ft}^{2}$ more than the regular paint system.

\subsection{Projected return on investment (ROI)}

Alternative 1: The Fort Bragg Central Vehicle Wash (CVWF) inlet pipe to the grit settling chamber will require replacement 8 years from now, at a cost of $\$ 15.8 \mathrm{M}$, plus the materials cost of coating the new pipe with smart fluorescent-self-healing coatings ( $\$ 410 \mathrm{~K})$, as shown under Baseline Costs as $\$ 16.21 \mathrm{M}$ in Year 8. Average annualized maintenance costs of the system is $\$ 35 \mathrm{~K}$, as shown under Baseline Costs. Additional costs are damage to Army vehicles due to corrosion, and downtime at $\$ 50 \mathrm{~K}$ from year 1 to year 8. Also included in year 8 , as additional costs, is the $\$ 8.5 \mathrm{M}$ in corrosion of vehicles due to non-availability of the CVWF, therefore the total cost shown under New System Benefits/Savings in Year 8 is $\$ 8.55 \mathrm{M}$.

Alternative 2: Recoating the existing inlet pipes and components using smart self-healing-fluorescent based coatings in year 1 at a project cost of $\$ 1 \mathrm{M}$ is projected to extend the lives of the original coating systems by another 30 years. These coatings will show when maintenance is needed 
via fluorescence. Generally, they require very little maintenance $(\$ 2,500)$ as shown under New System Costs. The downtime cost for coating the pipe in year 1 is minimal $(\$ 10 \mathrm{~K})$, as shown under New System Costs.

The additional cost of replacement of the inlet pipes and other components due to corrosion, and downtime (resulting in corrosion of vehicles) are avoided, as shown under New System Benefits/ Savings. The structures will again need recoating in year 38 . After Year 8 , the maintenance costs are the same, so no further analysis is needed.

Comparing the two alternatives, the potential return-on-investment (ROI) for Alternative 2 is projected to be 14.85 .

\section{Return on Investment Calculation}

Investment Required

Return on Investment Ratio

Net Present Value of Costs and Benefits/Savings
14.85

21,938
Percent

$14,868,402 \quad 14,846,465$

G New System Costs
E Benefits/Savings
Present Value Costs
H

Total Present Value

\begin{tabular}{r|r|r|r|r|r|r|}
\hline 35,000 & & 10,000 & 50,000 & 9,346 & 79,441 & 70,095 \\
\hline 35,000 & & 2,500 & 50,000 & 2,184 & 74,239 & 72,056 \\
\hline 35,000 & & 2,500 & 50,000 & 2,041 & 69,386 & 67,345 \\
\hline 35,000 & & 2,500 & 50,000 & 1,907 & 64,847 & 62,939 \\
\hline 35,000 & & 2,500 & 50,000 & 1,783 & 60,605 & 58,823 \\
\hline \\
\hline
\end{tabular}




\section{Conclusions and Recommendations}

\subsection{Conclusions}

Implementation of overcoating and smart coatings will provide the benefits of restoring structures to their optimum operating conditions, as well as reducing maintenance costs, and increasing safety. For example, fire suppression systems utilizing deluge tanks will remain operational and therefore training and operations flights will not be grounded. Safety is increased when smart coatings help protect failure critical components. Timely maintenance utilizing surface tolerant coatings for overcoating will reduce overall maintenance costs compared to total coating removal and replacement.

All of these coating technologies are commercially available and ready for implementation as solutions to the corrosion problems on hangars, flight control towers, POL tanks, potable water tanks, piping, deluge tanks, metal buildings and other types of steel structures.

\subsection{Recommendations}

\subsubsection{Applicability}

Overcoating

The surface tolerant coating technology demonstrated under this project is advocated for corrosion protection of steel structures that meet established overcoating criteria. The technology is applicable for multiple regions and installations, especially those in hot and humid environments where atmospheric corrosion is a concern. Overcoating with surface tolerant coatings, such as those described, can also be a useful solution to problems with lead hazard control due to lead based paints.

Smart coatings

Self-healing coating technology demonstrated under this project is advocated for corrosion protection of steel surfaces where the coating is subject to physical damage caused by impact and abrasion. The technology is applicable to all geographic locations and types of installations. Low areas of 
structures and appurtenances are likely to be contacted and are especially good candidates for self-healing coatings.

Fluorescing coating technology demonstrated under this project is advocated for corrosion protection of steel surfaces in critical service including pipes, tanks, and vessels. The technology is applicable to all geographic locations and types of installations.

\subsubsection{Implementation}

Overcoating

Overcoating is currently referred to in UFGS-09900 under Division 5 for exterior metal, ferrous and non-ferrous paint. "For overcoating existing alkyd, latex or epoxy systems refer to the Evaluation Section of MPI Repaint Manual." It is suggested that overcoating also be referenced at the beginning of section 3.5 on preparation of metal surfaces with reference to the MPI manual. A draft potential UFGS for overcoating is attached in Appendix E.

\section{Smart coatings}

Self-healing coatings are recommended for implementation if the ROI can justify their use. They are currently fairly expensive due to the high cost of manufacturing the microcapsules. Production scale up is necessary to reduce the cost of the microcapsules. At least one manufacturer, a major chemical producer, has expressed interest in a license to make the microcapsules. A cost reduction of $90 \%$ would make self-healing coatings cost effective.

Fluorescing coating technology should be incorporated into UFGS-09 97 13.16 (January 2007), Interior Coating of Welded Steel Water Tanks; and UFGS-09 9713.17 (January 2007), Three Coat Epoxy Interior Coating of Welded Steel Petroleum Fuel Tanks. The recommended revisions are contained in Appendix E. 


\section{References}

Burkhurst, M., and Bowry, E. 2005. Paper T-44: An Optically Active Coating System for Coatings Ballast Tanks, The Paint \& Coatings Expo 2005, Pittsburgh, PA: SSPC: The Society for Protective Coatings.

Johnson, R. E., and Agarwala, V. S., Rajan, K. S., Singh, A., Durrett, M. 1999. Fluorescent Materials Utilized as Early Warning Sensors for Corrosion of Aluminum Alloy Surfaces, CORROSION/99, Paper 505, National Association of Corrosion Engineers (NACE), Houston, TX.

Kumar, Ashok and Stephenson, L. D. 2003. Accelerated Testing of Self-Healing Coatings, Corrosion 2003, Paper No. 03221, National Association of Corrosion Engineers (NACE) Conference, San Diego, CA.

Kogler, R.A., Ault, J.P., and Farschon, C.L. 1997. Environmentally Acceptable Materials for the Corrosion Protection of Steel Bridges, Federal Highway Administration Technical Report, FHWA-RD-06-058.

Kumar, Ashok and Stephenson, L. D. 2002. Self Healing Coatings, Proceedings: Corrosion 2002, Paper No. 02158, National Association of Corrosion Engineers Conference, Denver, CO.

Kumar, Ashok, and Stephenson, Larry D. 2004. Self-Healing Coatings Using Microcapsules and Nanocapsules, Conference Proceedings, National Association of Corrosion Engineers, Houston, TX.

Race, Timothy D. , Kumar, Ashok, Weber Robert A., and Stephenson, L. D. 2003. Overcoating of Lead-Based Paint on Steel Structures Cost and Performance Report, Technical Report, USACERL, Report Number ERDC/CERL TR-03-5, Champaign, IL.

Race, Timothy D., Stephenson, L. D., and Kumar, Ashok 2003. Decision Tree for LeadBased Paint Hazard Control and Abatement for Steel Structures, Technical Report, USACERL, Report Number ERDC/CERL TR-03-3, Champaign, IL.

Stephenson, L. D. and Kumar, Ashok 2004. Technology Demonstration of Self-Healing Coatings for In-Place Management of Lead-Based Paint Hazards, Technical Report, USACERL, Report Number ERDC/CERL TR-03-29, Champaign, IL.

Stephenson, L. D., Kumar, Ashok, Race, Timothy D., and Williams, Steve 2007. SurfaceTolerant Coatings for Aircraft Hangars, Flight Control Tower, and Deluge Tanks at Fort Campbell, ERDC/CERL TR-07-24, U. S. Army Engineer Research \& Development Center (ERDC) Construction Engineering Research Laboratory (CERL) Champaign, IL.

SSPC-TU 11 2006. Society for Protective Coatings Technology Update No. 11, Inspection of Fluorescent Coating Systems.

United States Patent: 2006. Self-Healing Coatings Using Microcapsules, Pub Number US 2006/0042504A1. 
United States Patent no. 7,192,993, March 20, 2007, Self-healing coating and microcapsules to make same, Ashok Kumar, et.al,

MIL-PRF-23236C: Performance Specification: Coatings Systems for Ship Structures, U. S. Dept of Defense (2003) (http://assist.daps.dia.mil). 


\section{Figures}

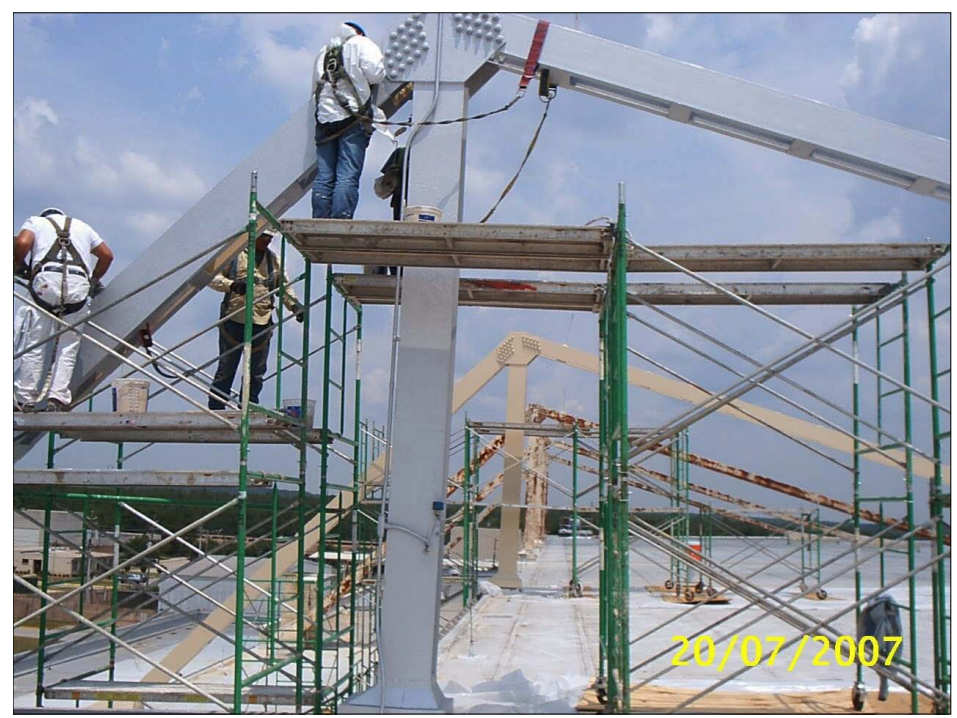

Figure 1. Overcoating the hanger superstructure (working from scaffolding and appropriately tied off).

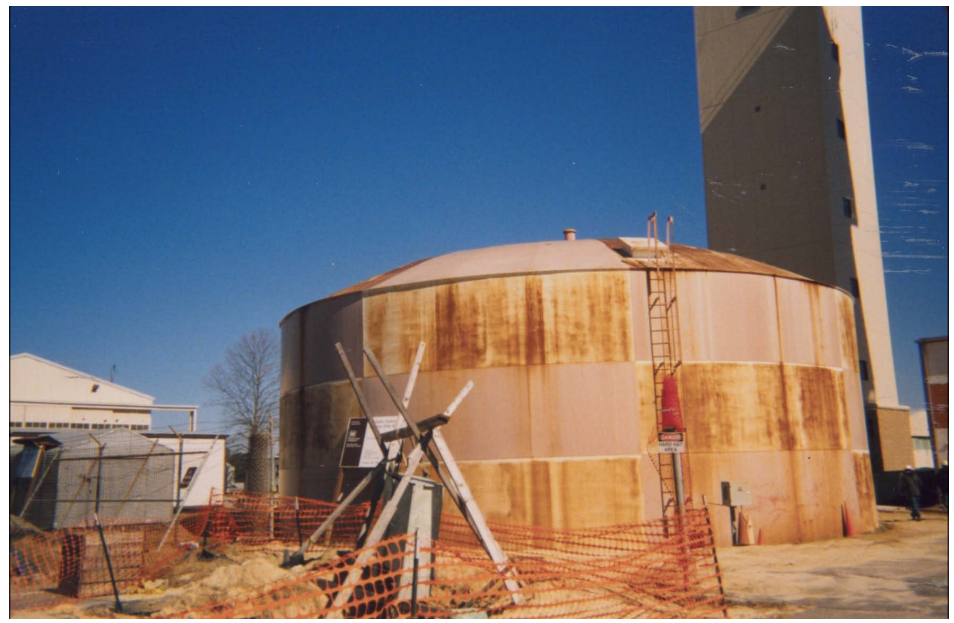

Figure 2. Deluge Tank No. 2 before painting. 


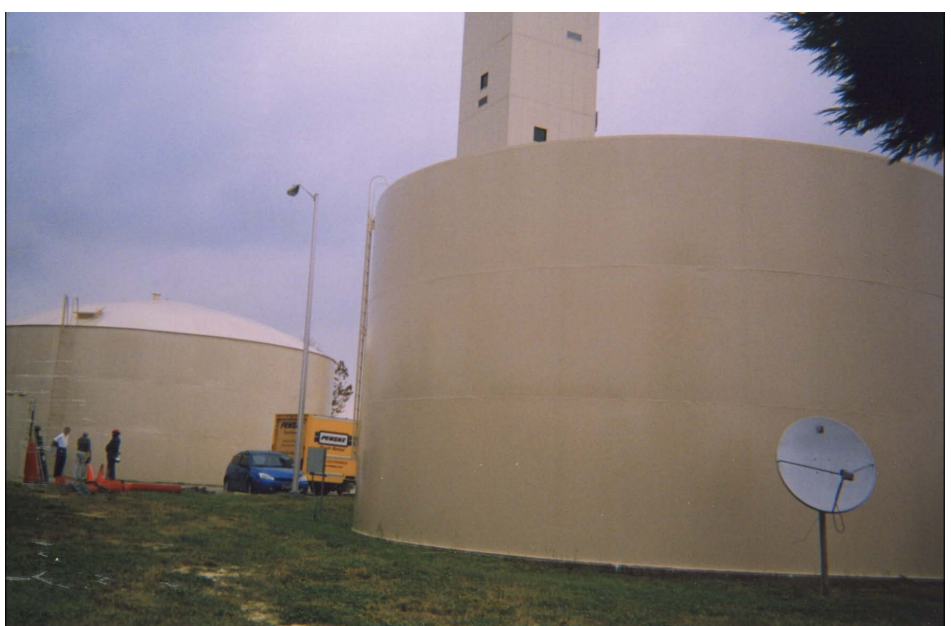

Figure 3. Deluge tanks after overcoating.

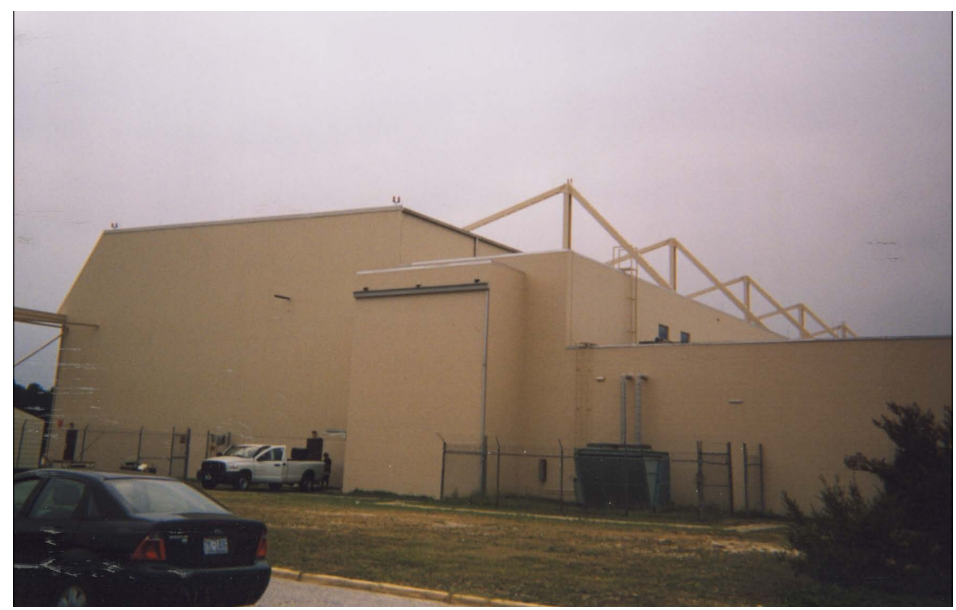

Figure 4. Simmons AAF hangar after overcoating has been completed.

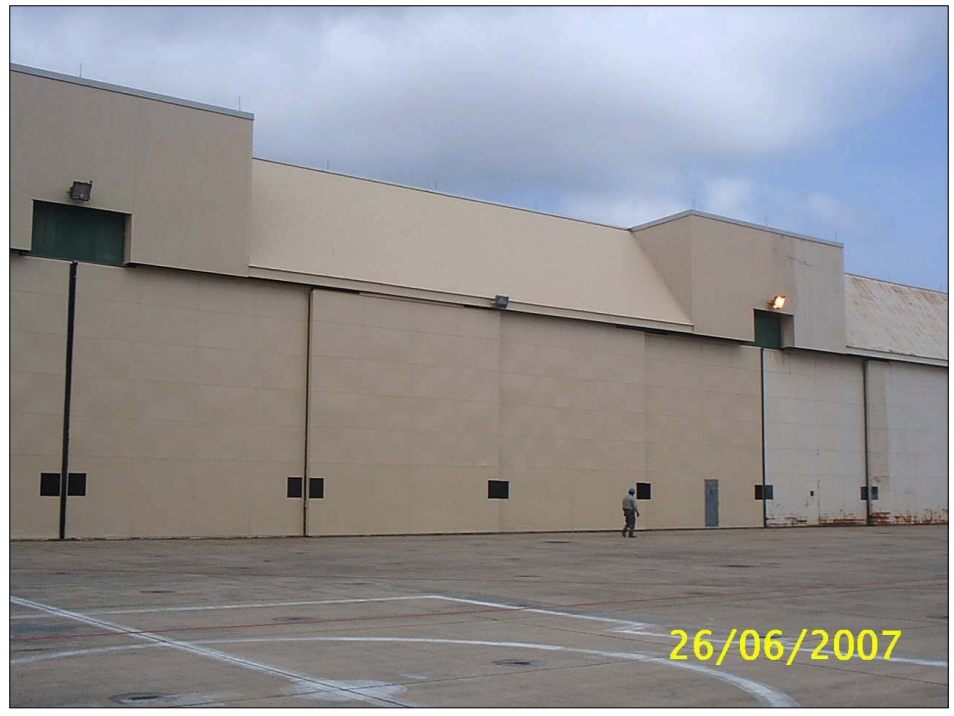

Figure 5. Simmons AAF hangar work in progress. 


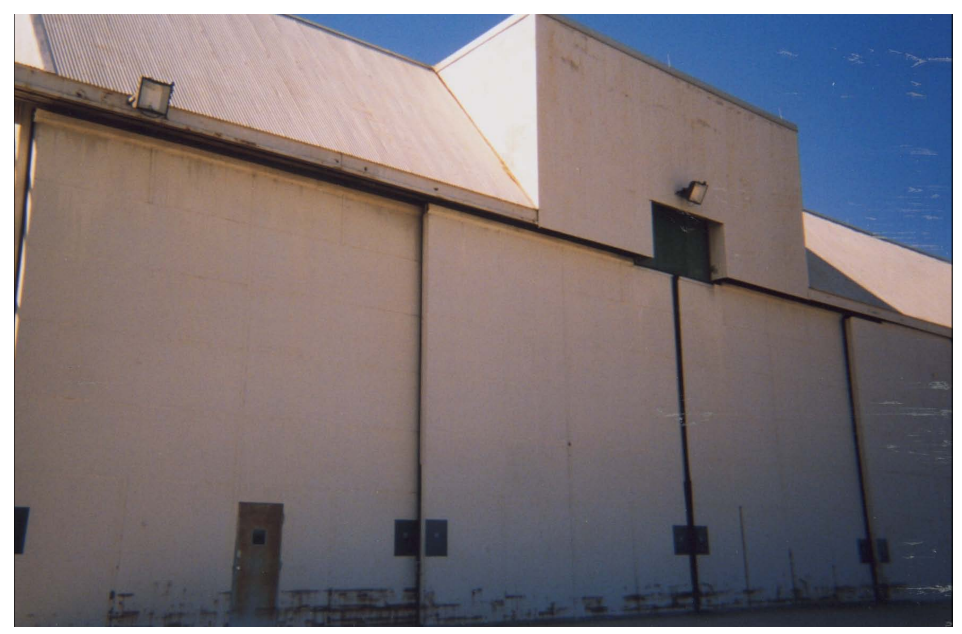

Figure 6. Simmons AAF hangar before painting.

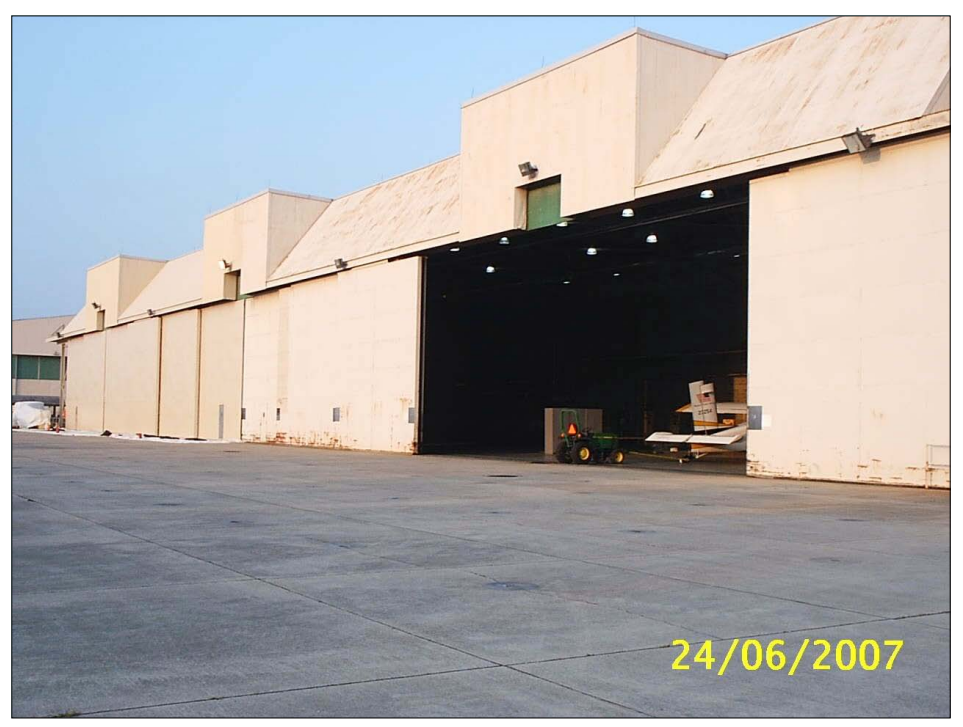

Figure 7. Simmons AAF hangar before painting.

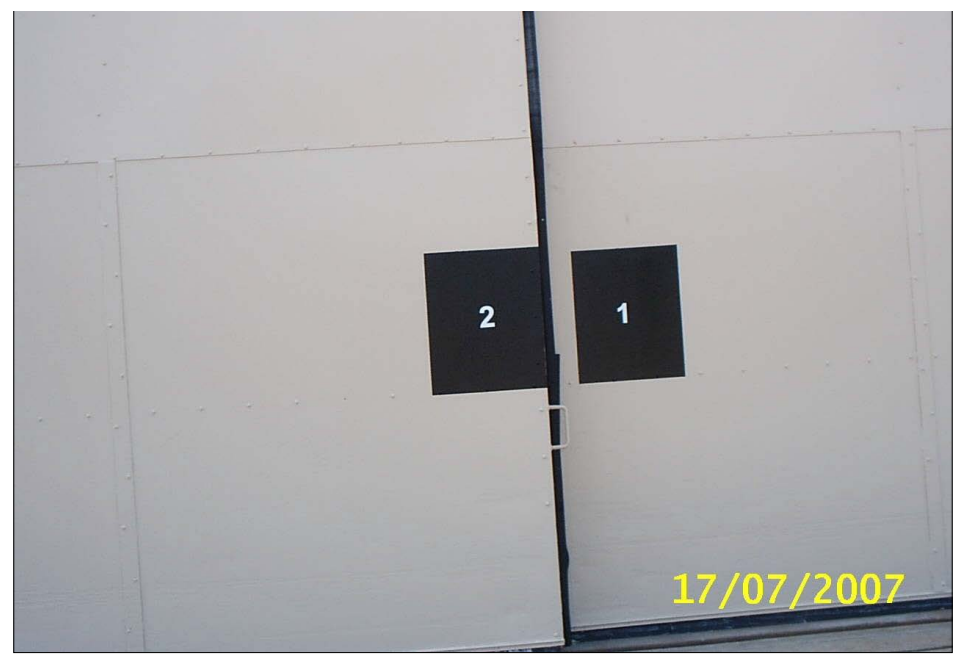

Figure 8. Simmons AAF hangar doors after overcoating. 


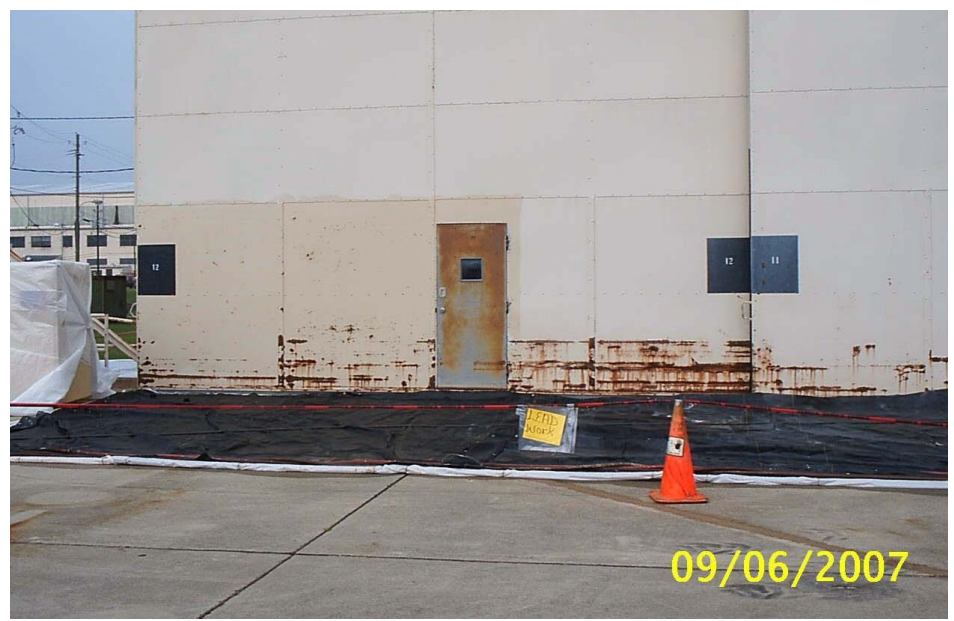

Figure 9. Simmons AAF hangar before painting.

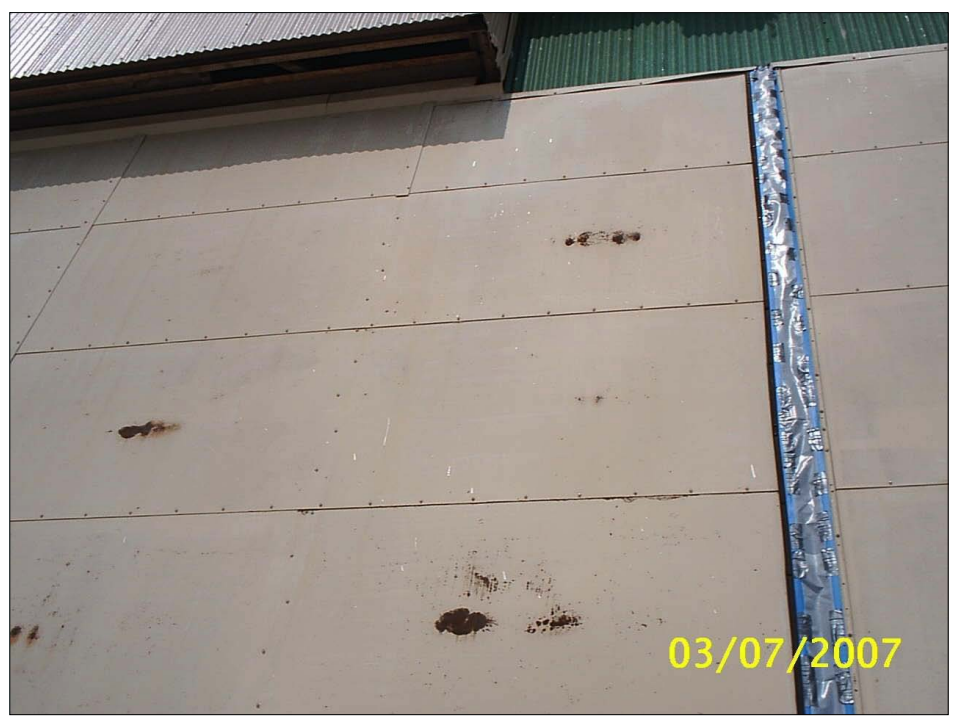

Figure 10. Simmons AAF hangar before painting, showing masking of utility line.

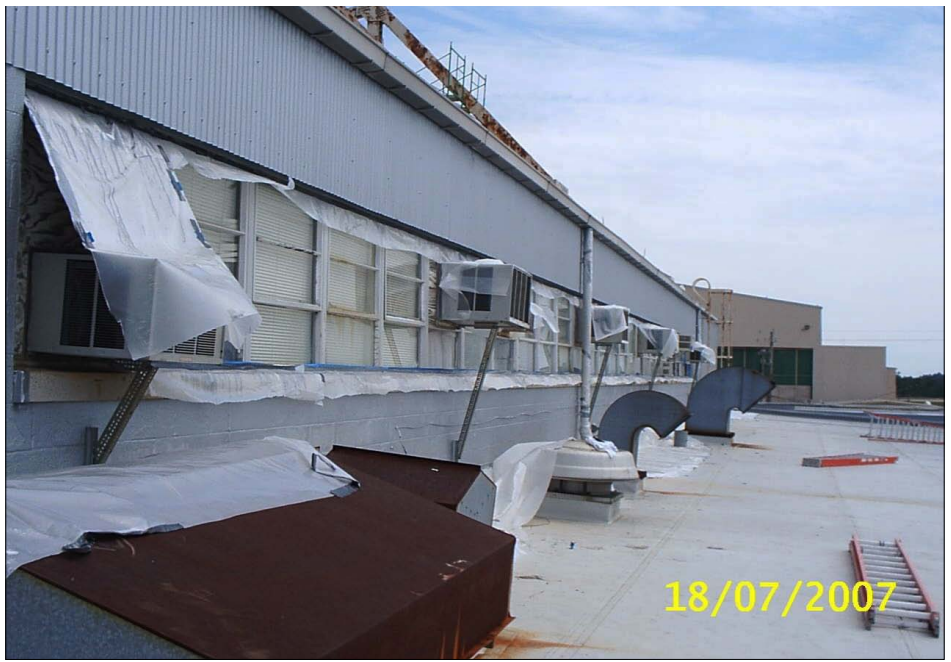

Figure 11. Simmons AAF hangar after first MCU coat, showing protective covers and masking. 


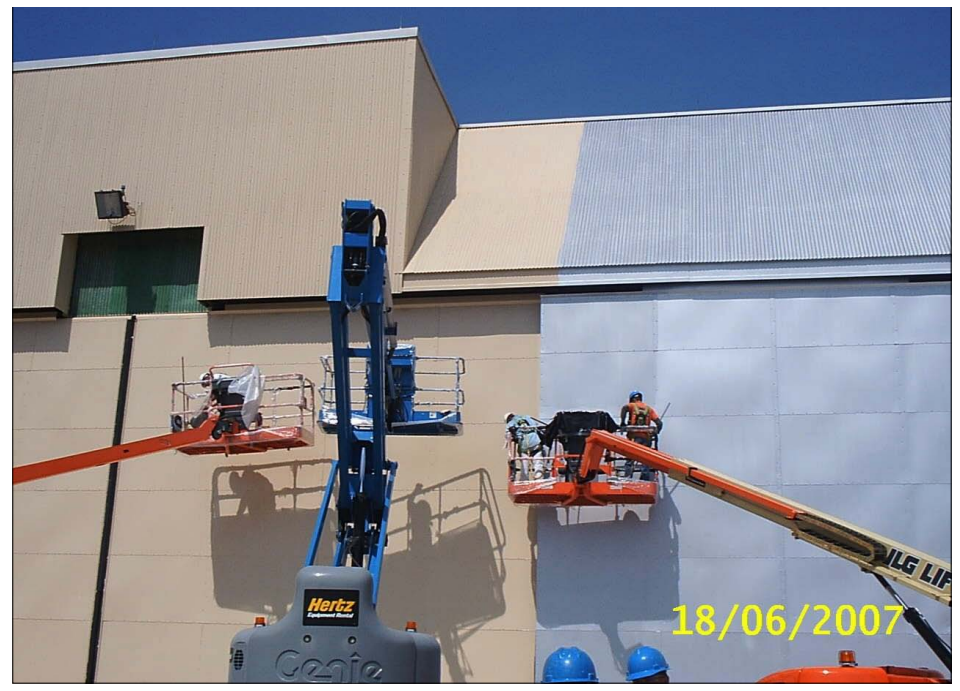

Figure 12. Simmons AAF hangar during overcoating.

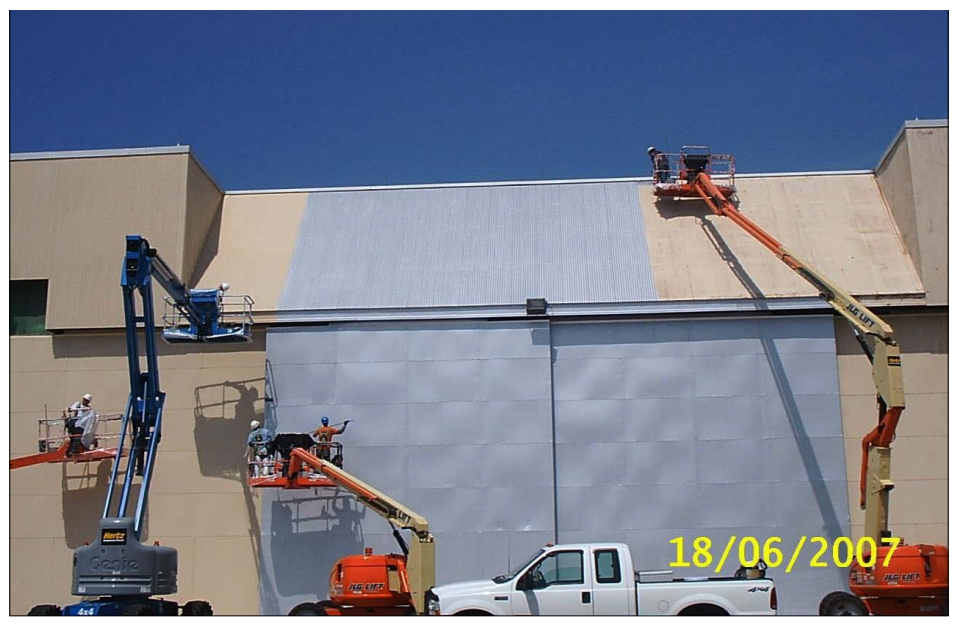

Figure 13. Simmons AAF hangar during overcoating.

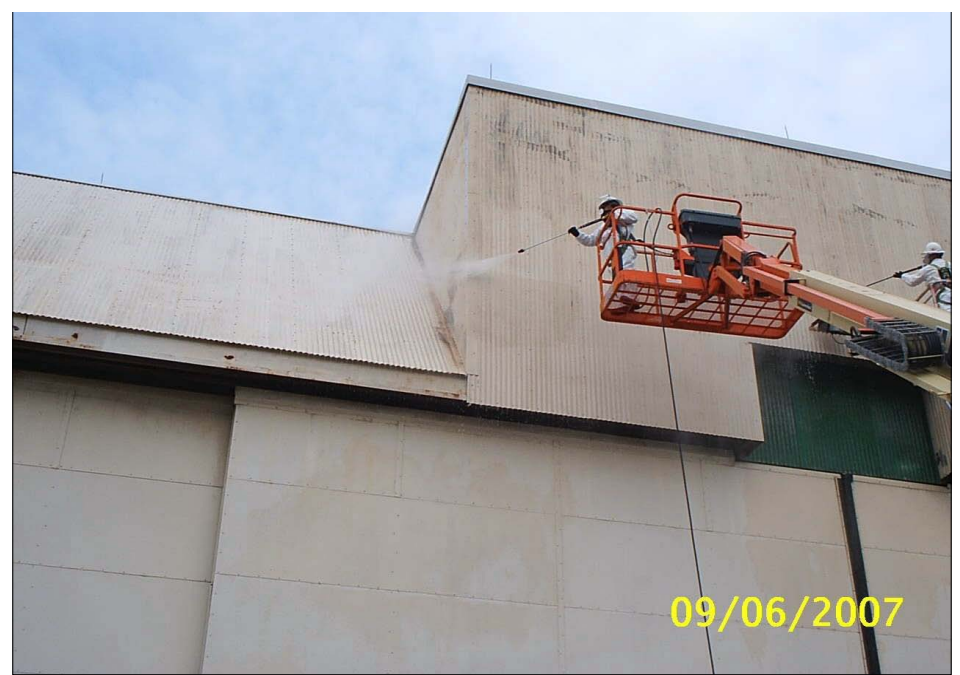

Figure 14. Simmons AAF hangar during power washing to remove dirt, chalk, and loose paint. 


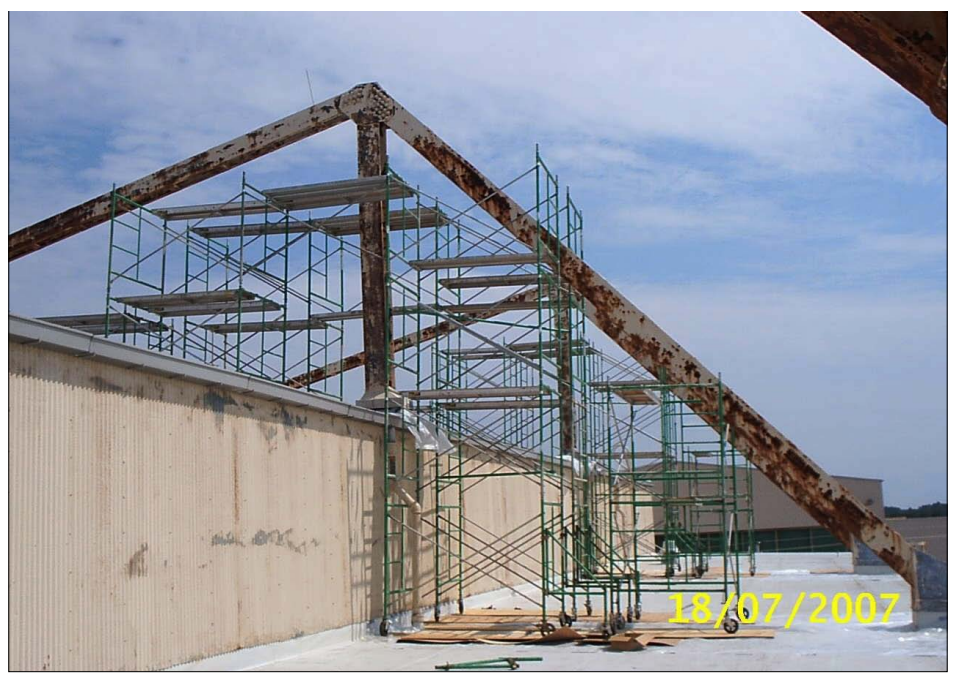

Figure 15. Simmons AAF hangar before overcoating. Note the extent of rust on the steel superstructure and metal siding.

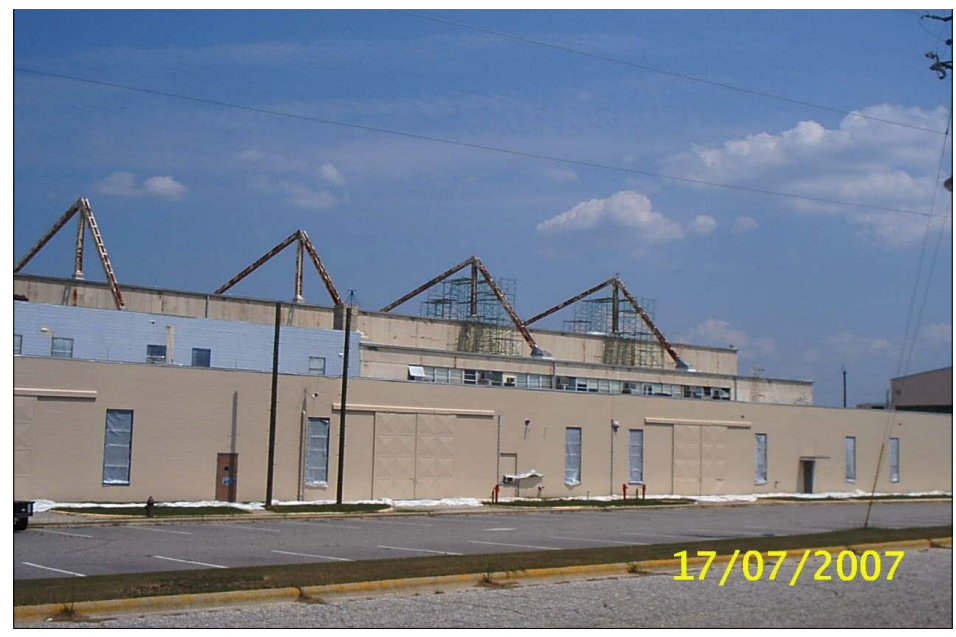

Figure 16. Simmons AAF hangar during overcoating.

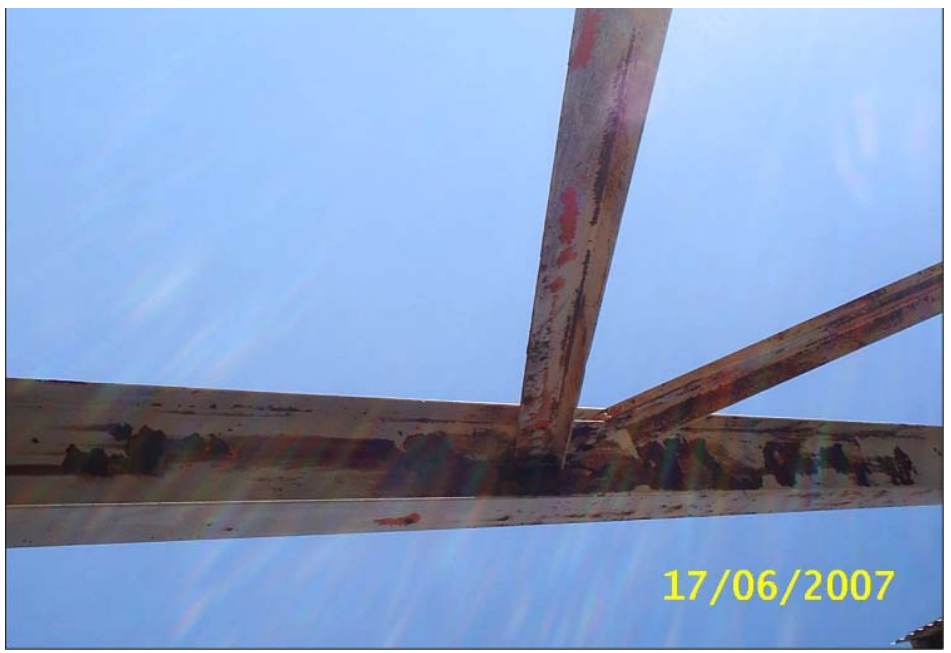

Figure 17. Simmons AAF hangar superstructure after power washing. 


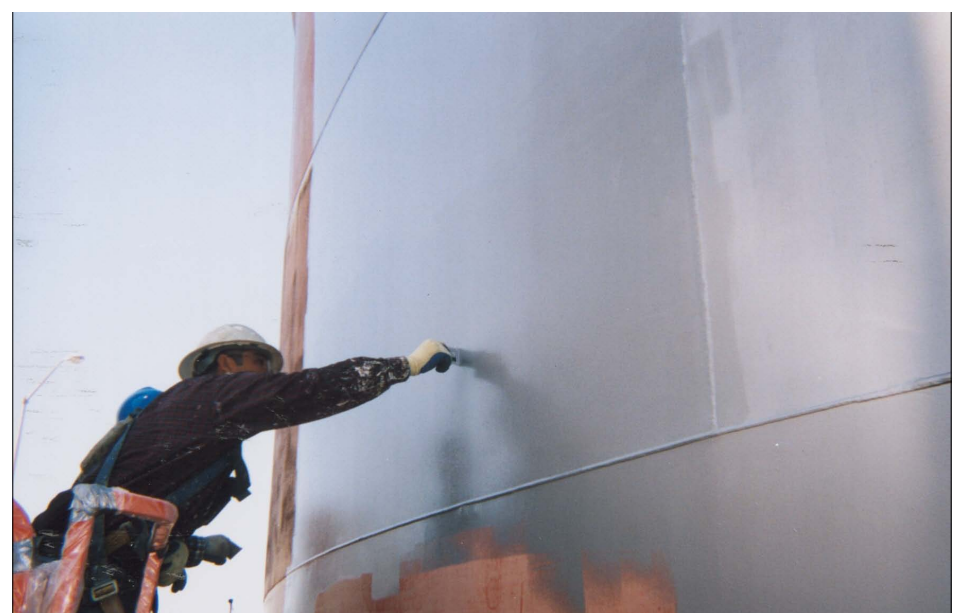

Figure 18. Inspecting the paint thickness on a deluge tank.

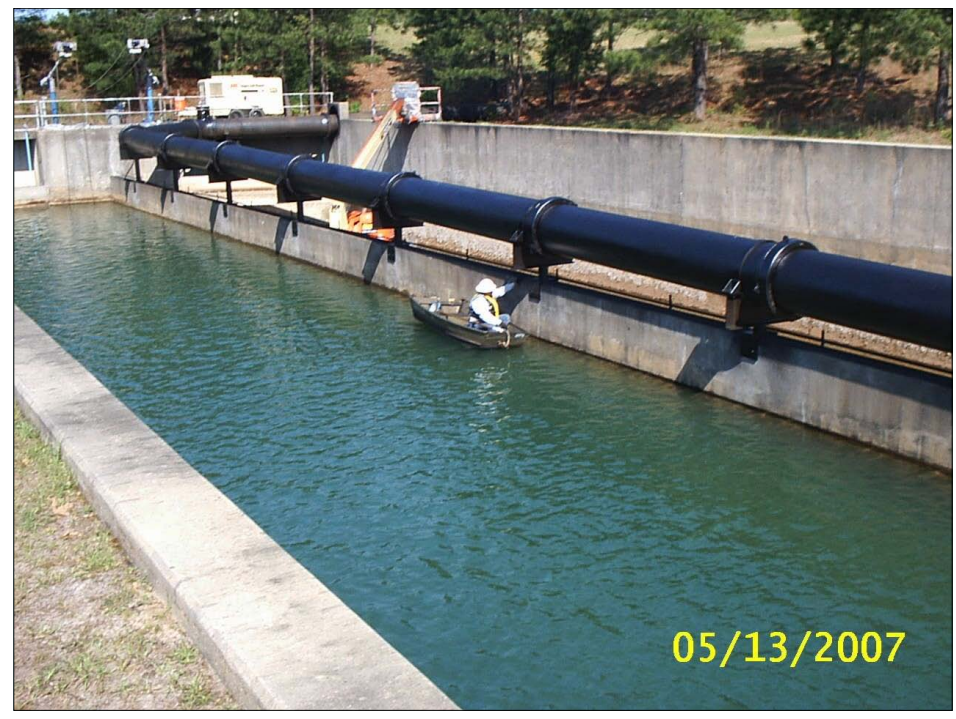

Figure 19. Smart coatings on pipe at CVWF grit basin.

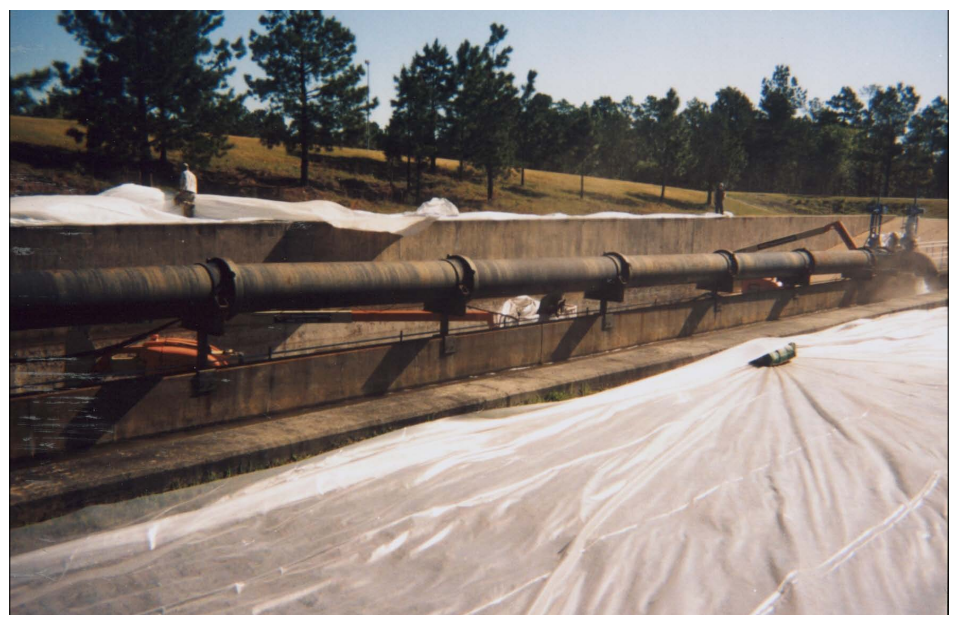

Figure 20. Before applying smart coatings (note ground tarps for environmental protection). 


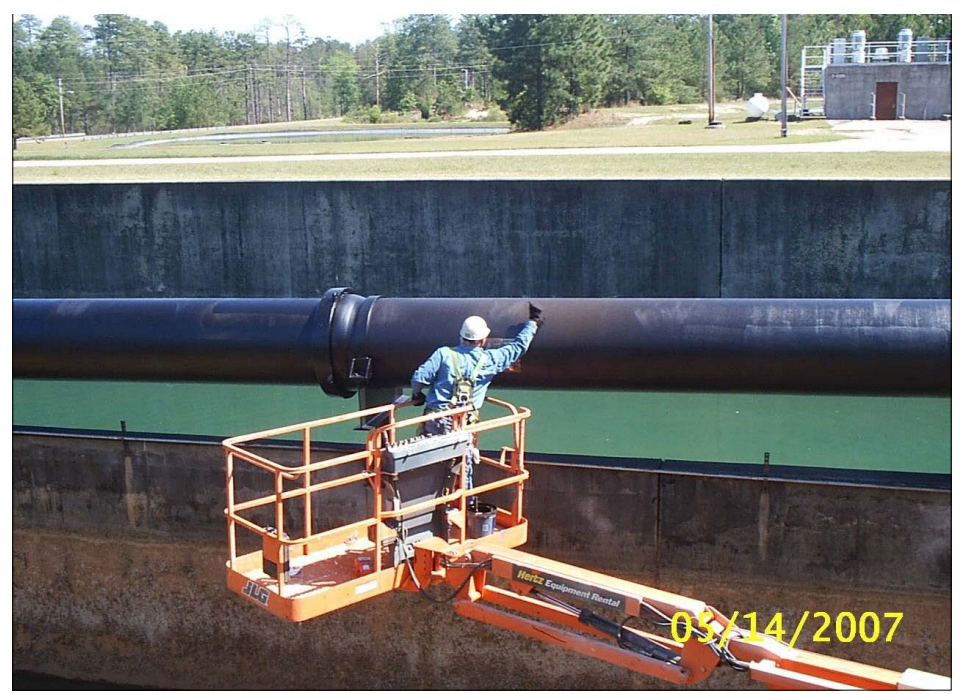

Figure 21. Applying smart coating system to pipe.

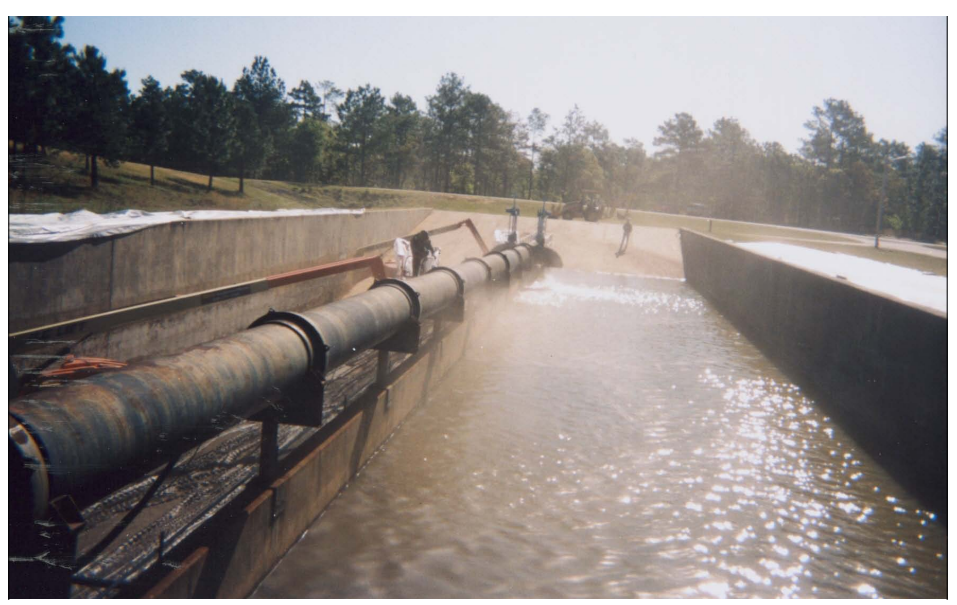

Figure 22. Abrasive blasting the pipe before applying smart coatings.

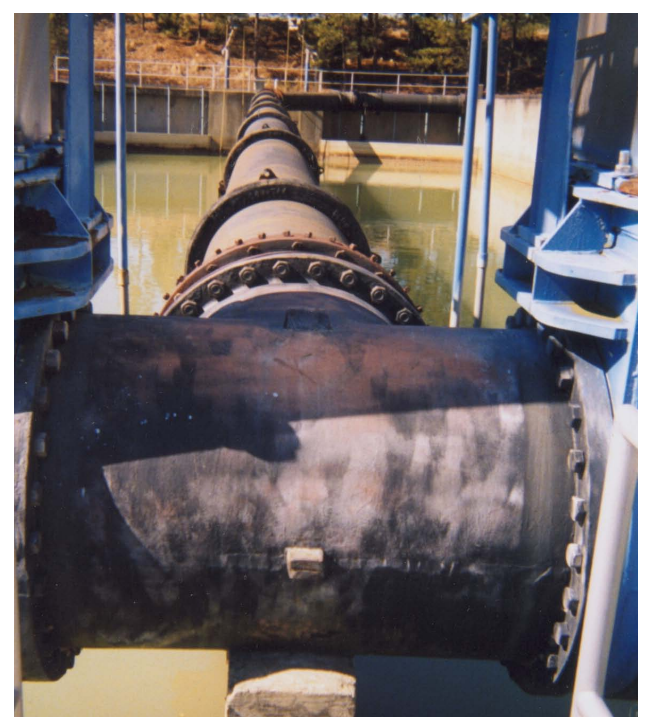

Figure 23. Pipe before abrasive blasting showing corrosion. 


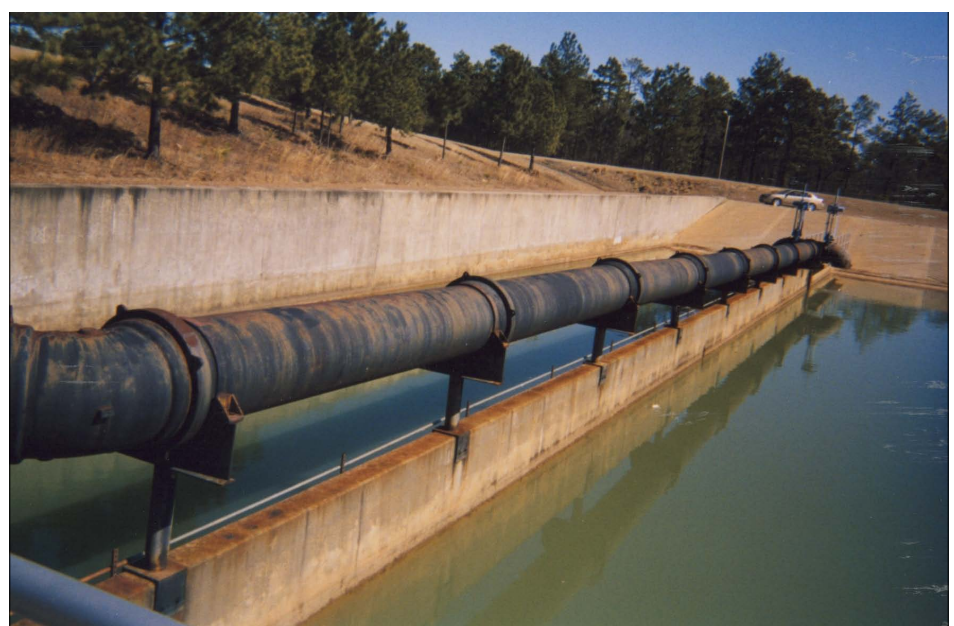

Figure 24. Pipe before abrasive blasting showing corrosion.

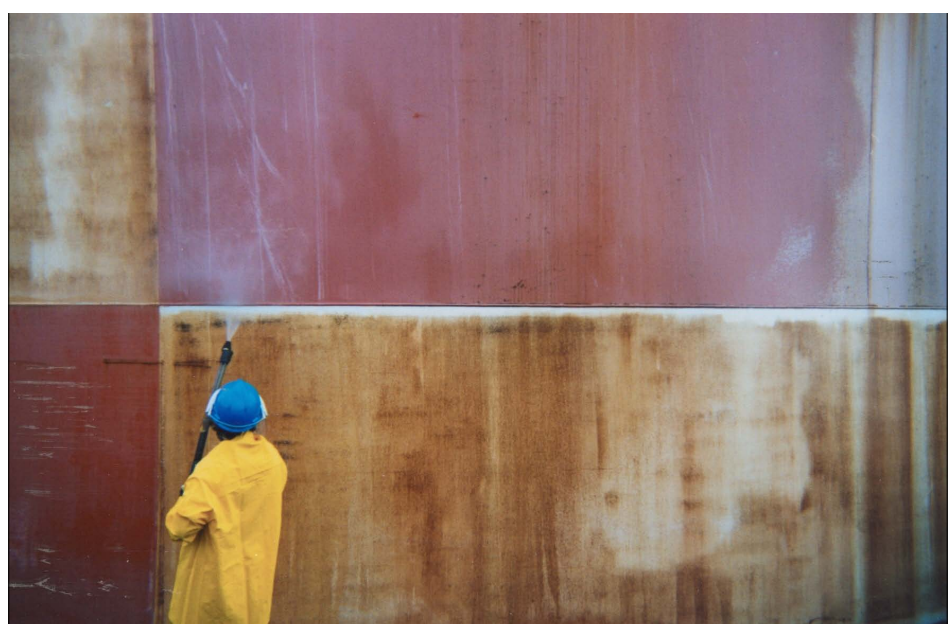

Figure 25. Power washing a deluge tank.

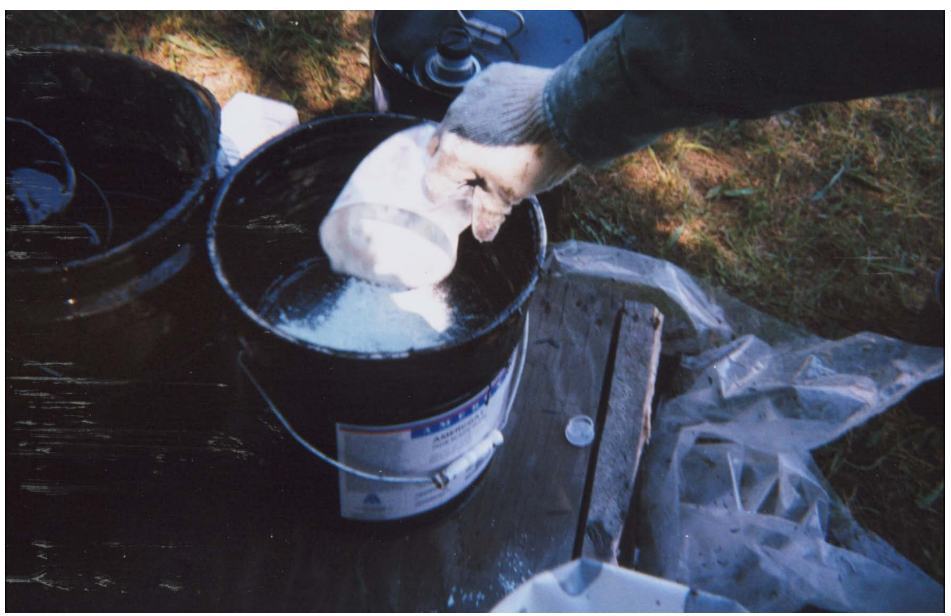

Figure 26. Mixing the coal tar epoxy with UVITEX OB fluorescent pigment. 


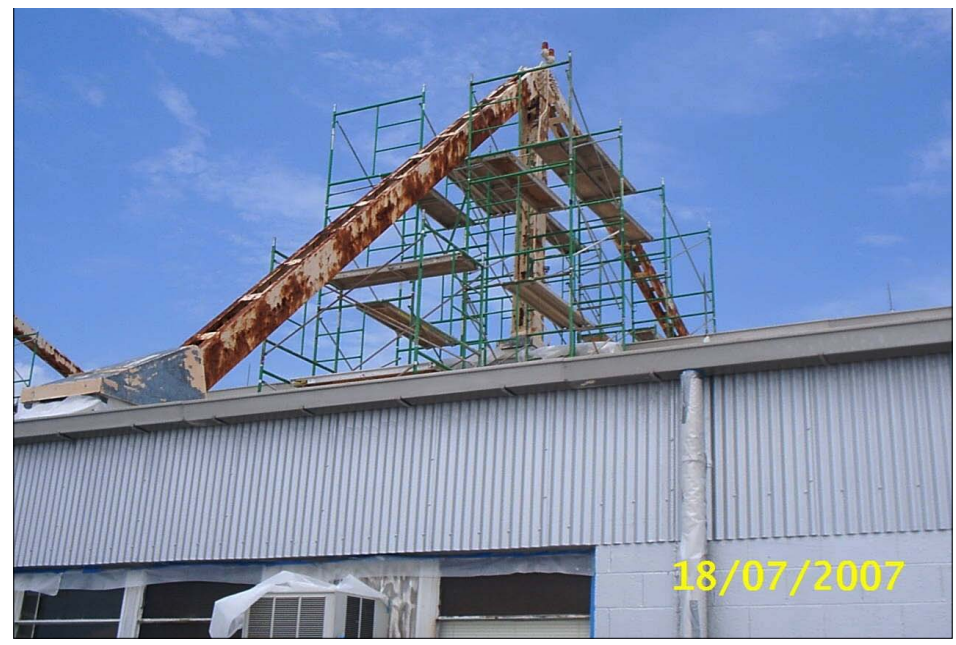

Figure 27. Scaffolding in preparation for work on hangar superstructure.

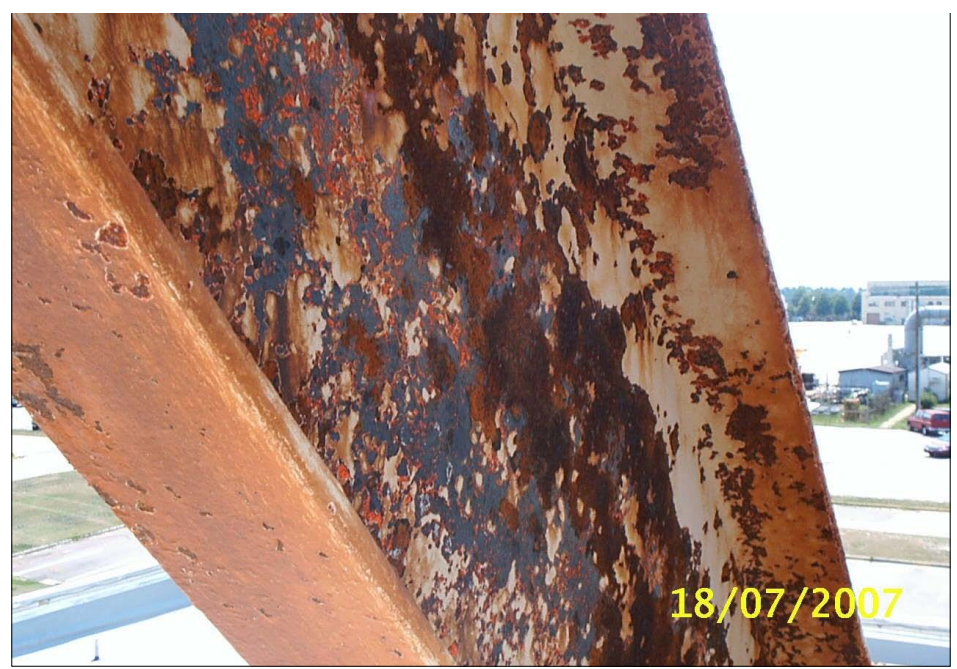

Figure 28. Condition of hangar superstructure before work began.

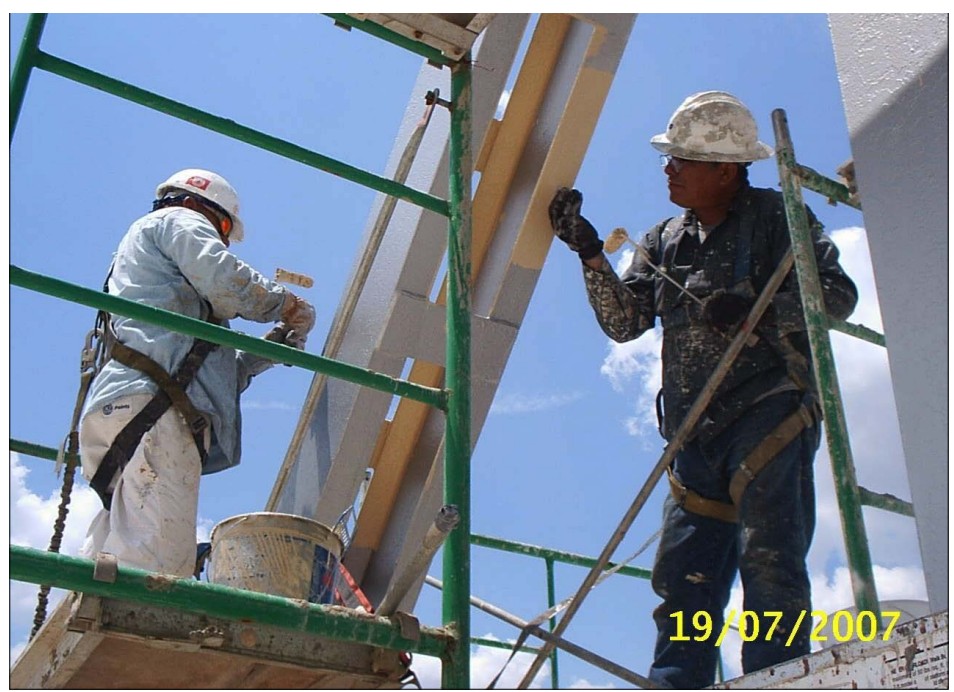

Figure 29. Painting the hangar superstructure. 


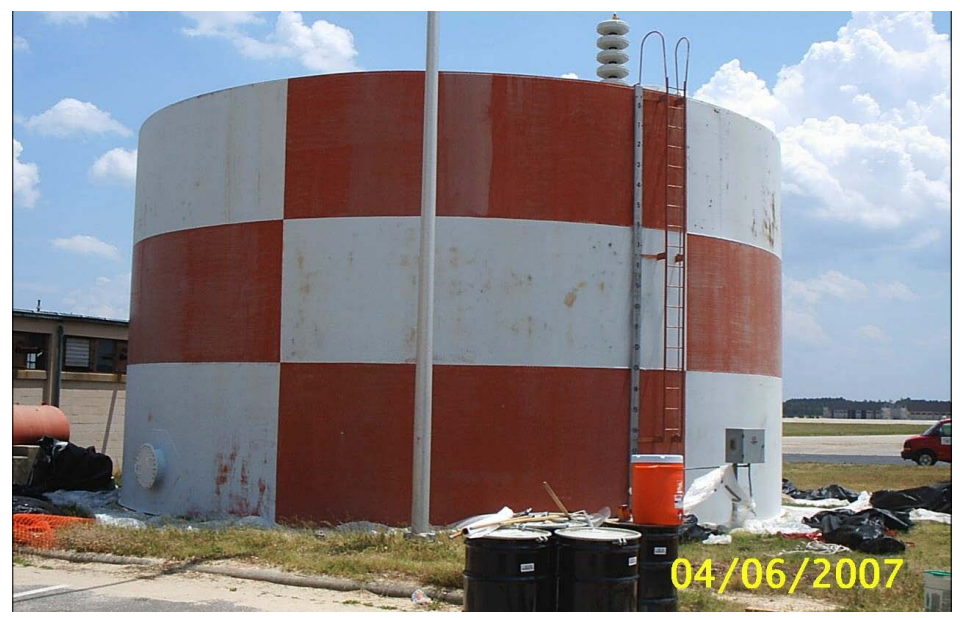

Figure 30. Deluge Tank No. 1 before painting.

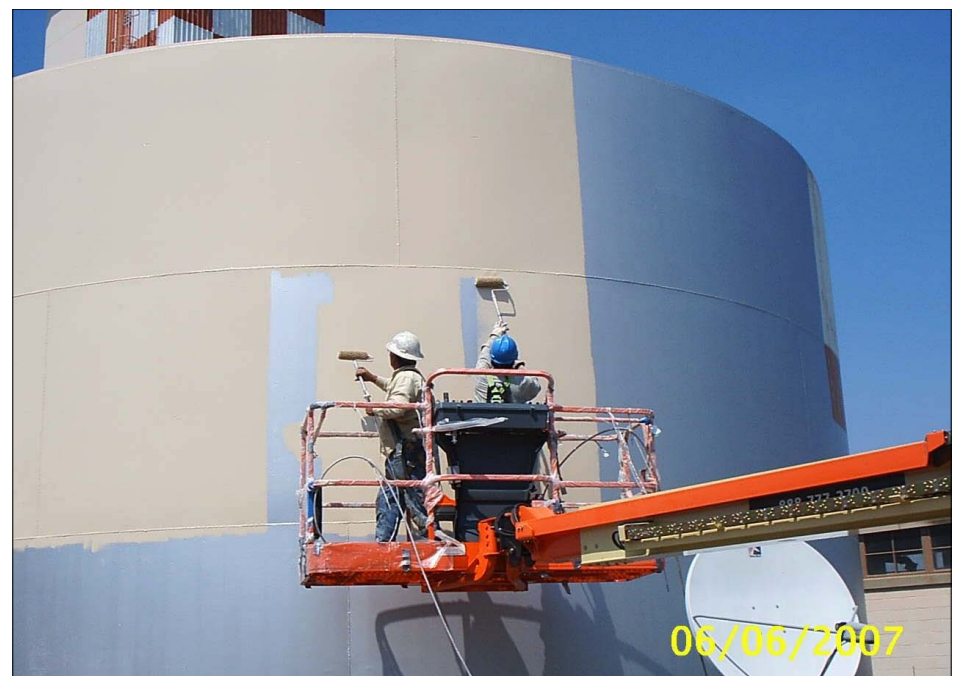

Figure 31. Applying aliphatic polyurethane topcoat to deluge tank.

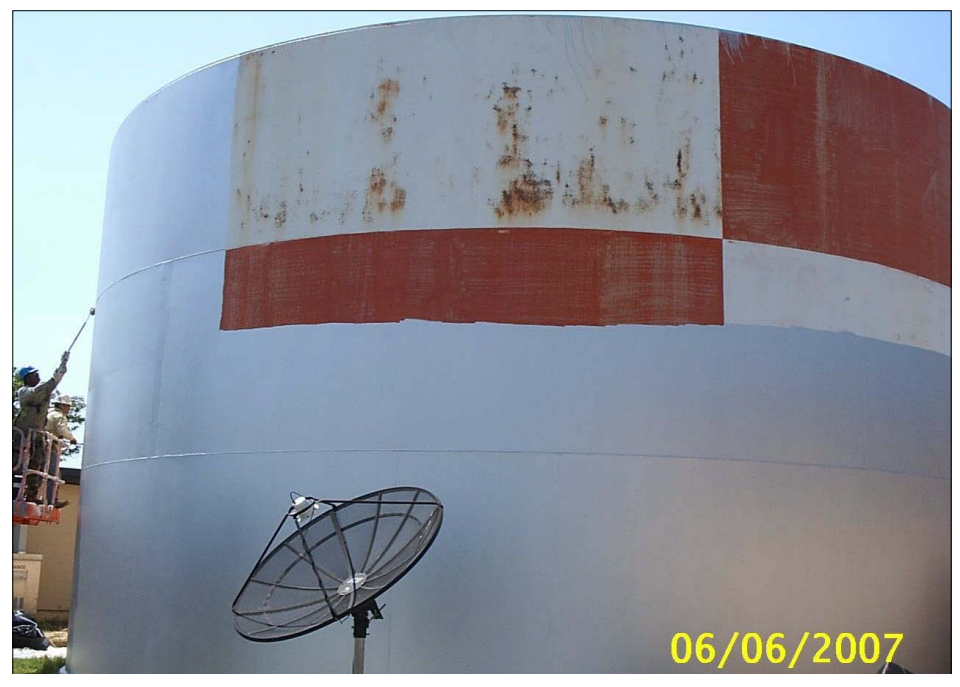

Figure 32. Work in progress showing the overcoat primer, an MCU (Rust Grip). 


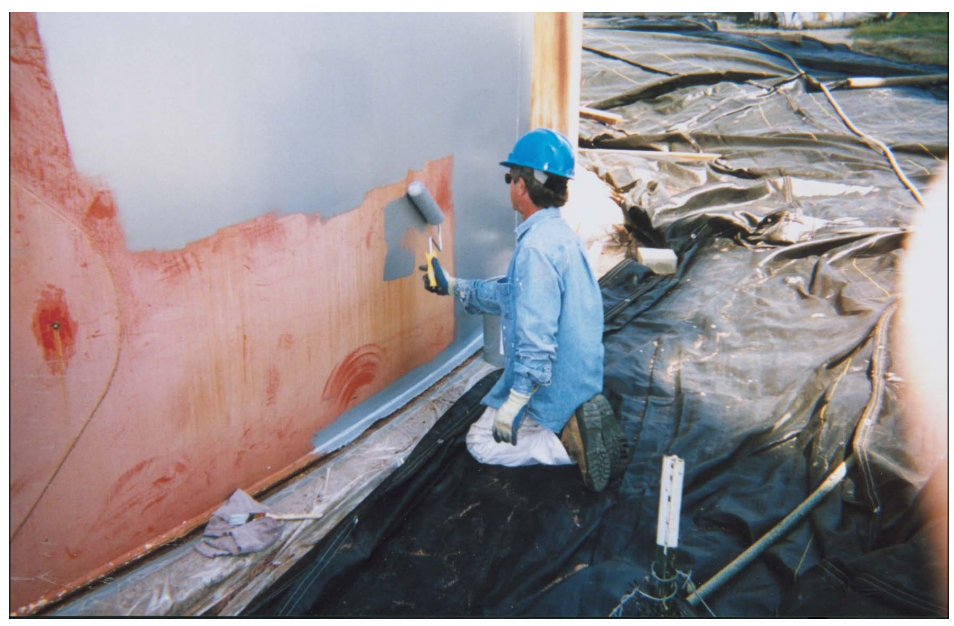

Figure 33. Priming a deluge tank.

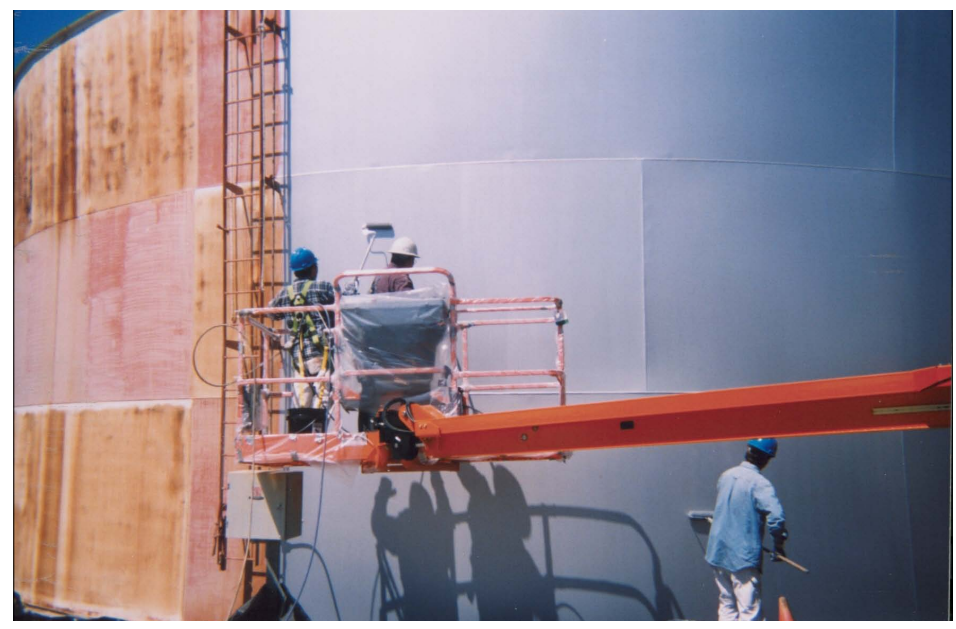

Figure 34. Priming a deluge tank.

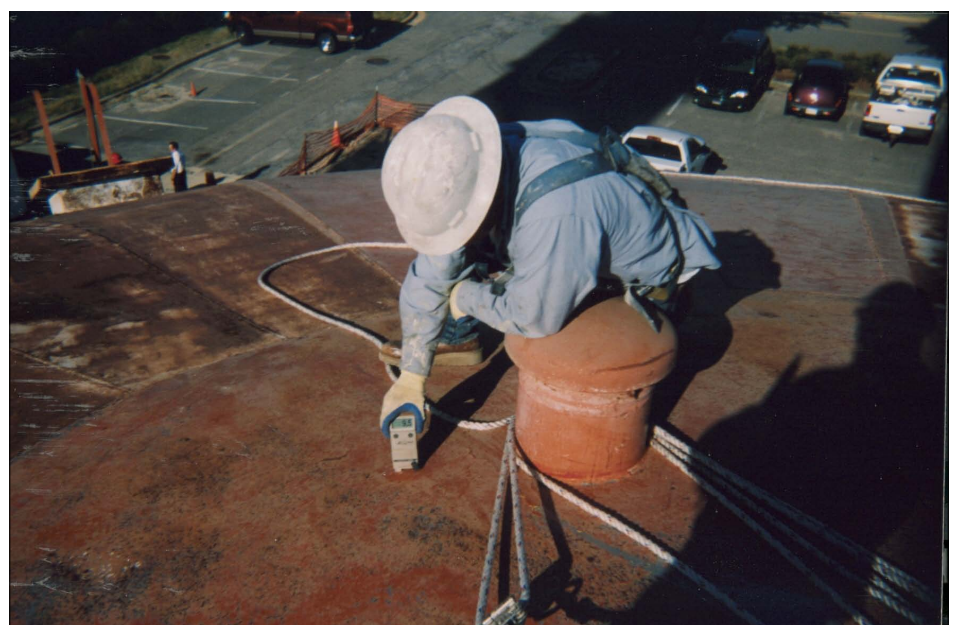

Figure 35. Inspecting the deluge tank paint thickness before starting work. 


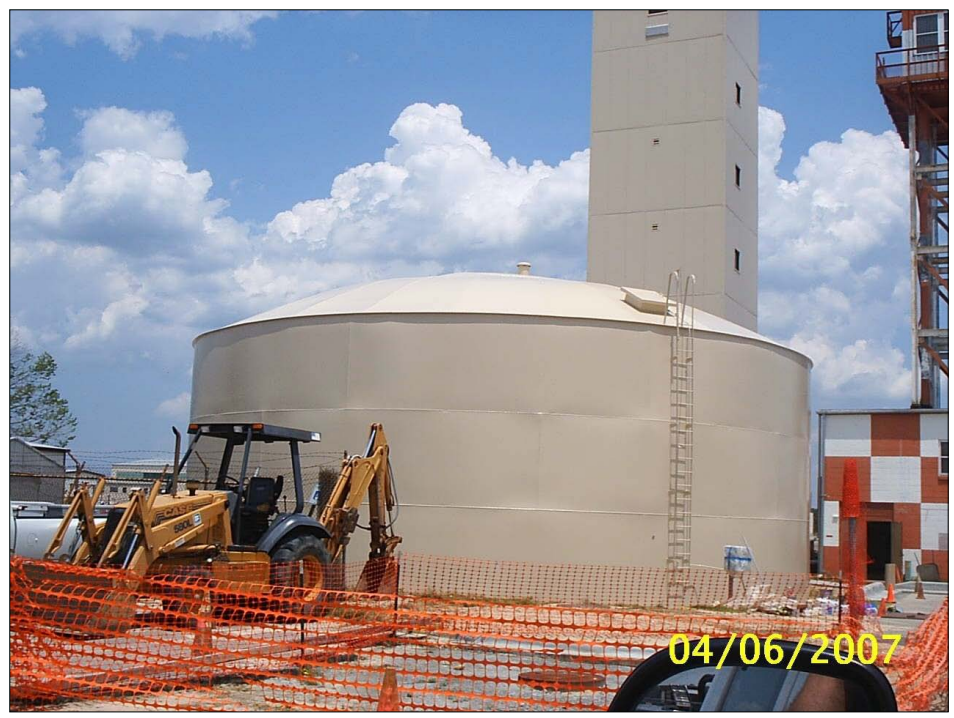

Figure 36. Deluge tank with newly completed overcoat system.

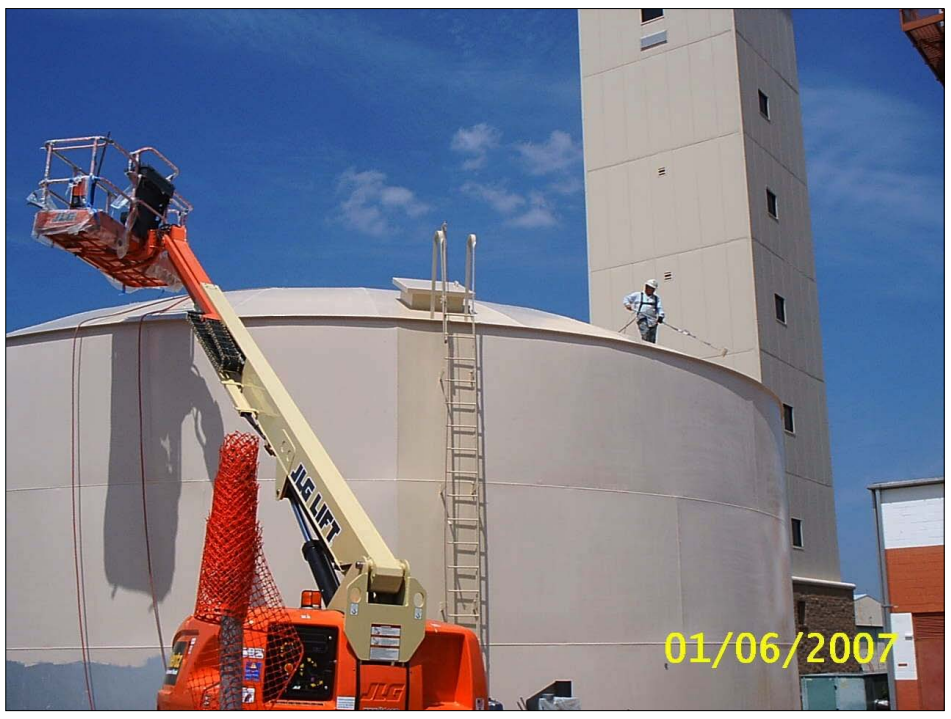

Figure 37. Applying topcoat to tank roof using a power roller. All work was performed by brush and roll to prevent overspray damage to vehicles and facilities. 


\title{
Appendix A: Project Management Plan for CPC Project FAR-02
}

\author{
TRI SERVICE PROGRAM \\ ARMY FACILITIES \\ CORROSION PREVENTION AND CONTROL PROJECT PLAN
}

Smart Fluorescent and Self-healing Coatings for Severely Corrosive

Environments at Vehicle Wash Facilities

at Fort Bragg (RDT\&E, FY06)

15 June 2005

Submitted By:

Ashok Kumar

U. S. Army Engineer Research \& Development Center (ERDC)

Construction Engineering Research Laboratory (CERL)

Comm: $217-373-7235$

(Project Number to be assigned by OSD when approved) 


\author{
TRI SERVICE PROGRAM \\ ARMY FACILITIES \\ CORROSION PREVENTION AND CONTROL PROJECT PLAN \\ Smart Fluorescent and Self-healing Coatings for Severely Corrosive Environments at Vehicle \\ Wash Facilities \\ at Fort Bragg (RDT\&E. FY06)
}

\title{
1. STATEMENT OF NEED
}

PROBLEM STATEMENT: Fort Bragg has identified severe corrosion problems at Central Vehicle Wash Facility (CVWF). The 2-ft. diameter inlet pipe for the grit chamber is being severely corroded due to its proximity to the water in the wash basin. If left uncorrected, the pipe will be destroyed by corrosion. About 20 other Army Installations have similar facilities that suffer similar problems. In addition, similar corrosion problems are present at vehicle wash facilities at other installations in the Tri-services. Maintenance delays will eventually result in pitting, which occurs when complete coating failure has occurred and irreversible corrosion damage has begun. There is a need for coatings that detect areas where corrosion can initiate or has occurred due to holidays that allow moisture and other corrodants to seep underneath the film, and cause debonding.

IMPACT STATEMENT: If this project is not funded, the Fort Bragg Central Vehicle Wash Facility (CVWF) components will continue to deteriorate, and the facility will be forced to shut down more frequently for repairs, in which case the benefits of washing vehicles to enhance their resistance to corrosion will not be realized. Since there is no other similar facility available at Ft. Bragg, Army vehicles will not be able to have mud removed underneath. In this case, concentration cell corrosion will develop, because the corrodants are held next to the metal of the vehicle. Removal of mud by the CVWF prevents this from happening. Thus, the proposed project has far-reaching impact, since the removal of mud from vehicles mitigates corrosion. The unavailability of the CVWF may result in further corrosion of the vehicles.

In order to address these problems, smart fluorescent self-healing coatings will be used that have dual functionality built into the primer and topcoat. These coatings can simultaneously: (1) provide warning of where the coating has been damaged via fluorescence and release of marker dyes, and (2) self-repair the damaged areas. The advanced technologies proposed for demonstration and validation (dem/val) have been demonstrated in the laboratory and require demonstration and validation in the field in operational environments. The use of these smart fluorescent and self-healing coatings would provide the benefits of making inspection easier and restoring the CVWF to its optimum operating condition, as well as reduced maintenance, and increased safety not only for the CVWF, but for the vehicle that use the facility.

This project has the potential for far-reaching impact across the Army and the Triservices, as well. The calculated return on investment (ROI) for this project, which is based on current best practices, projected maintenance and rehab cost, is 14.85 . If these technologies are not implemented, these benefits for the Tri-services will not be realized. 


\author{
TRI SERVICE PROGRAM \\ ARMY FACILITIES \\ CORROSION PREVENTION AND CONTROL PROJECT PLAN \\ Smart Fluorescent and Self-healing Coatings for Severely Corrosive Environments at Vehicle \\ Wash Facilities \\ at Fort Bragg (RDT\&E, FY06)
}

\title{
2. PROPOSED SOLUTION
}

\section{TECHNICAL DESCRIPTION:}

The components of the Ft. Bragg Central Vehicle Wash Facility (CVWF) are shown in Fig.1 and Fig. 2. After a training exercise, vehicles go through the pools and water cannons remove the mud and other debris. The mud that is removed is flushed out of the systems into a grit settling chamber. The inlet pipe to the grit chamber is a 200 -ft long 2 $\mathrm{ft}$. diameter pipe of low carbon steel that is susceptible to corrosion. The pipe and other components at the CVWF are exposed to a high humidity environment that is often hot in the summer. In addition, these components generally experience corrosion from the combined effect of the atmosphere and splash from the water. Damage resulting from these natural conditions can be compounded by the following application problems, such as: (1) inadequate surface preparation, (2) incorrect coating selection, (3) coating misapplication, and (4) absence of quality testing. The coating industry has responded to the demand for reduced maintenance with the development of high performance paint systems. Extended service life is achieved by maximizing barrier function (the use of coating mass to reduce the migration of moisture, oxygen, and other reactive agents to the substrate).

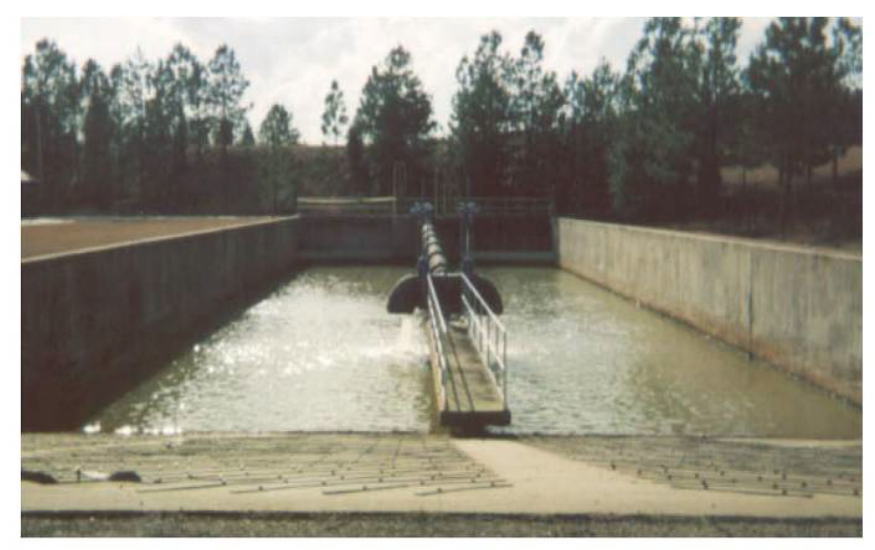

Fig. 1. Fort Bragg Central Vehicle Wash Facility (CVWF) Grit Settling Chamber showing inlet pipe. 


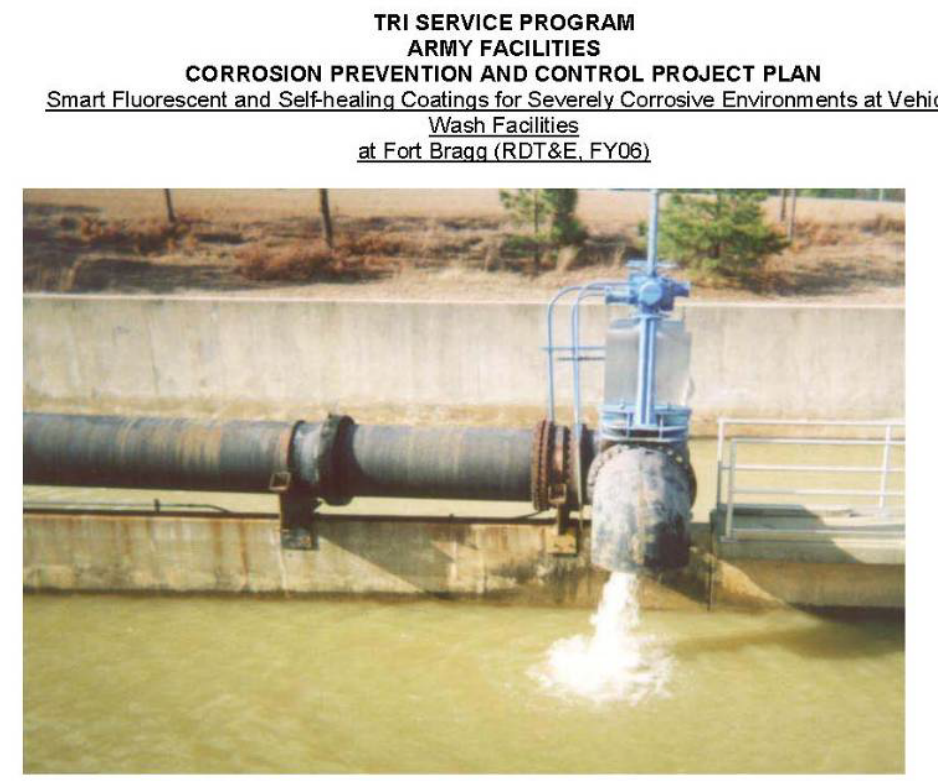

Fig. 2. Close-up of Inlet Pipe ( $2 \mathrm{ft}$. diameter) at Ft. Bragg Central Vehicle Wash Facility (CVWF) showing severe coating degradation

The technology chosen to mitigate the corrosion is a combination fluorescent coatings and self-healing coatings.

These fluorescent coatings are commercially available paints containing additives that, under ultraviolet (UV) light inspection, will fluoresce and reveal areas where coatings have developed holidays, areas of incomplete coverage, and areas where corrosion has initiated underneath the coating. This will allow maintenance personnel to take corrective action, remove the corroded spots and recoat the damaged areas. The use of these coatings results in service life extension of mission-critical structures, and lower life cycle cost, due to early detection and correction of the problem.

The fluorescent coatings have been used in the marine industry to extend the life of ballast tanks. It can be used for the inspection of applied coatings for holidays both during and after application. Coating defects should be visible under UV inspection at a distance of about 3 meters for the following inspections:

(1) Prime coat with pin holes

(2) Prime coat and topcoats with pin holes in topcoat

(3) Prime coat on a weld seam, with cracks in the coating

(4) Prime and topcoats on a weld seam, with cracks in the topcoat 


\author{
TRI SERVICE PROGRAM \\ ARMY FACILITIES \\ CORROSION PREVENTION AND CONTROL PROJECT PLAN \\ Smart Fluorescent and Self-healing Coatings for Severely Corrosive Environments at Vehicle \\ Wash Facilities \\ at Fort Bragg (RDT\&E. FY06)
}

Areas of brighter than normal luminosity will tend to indicate higher than expected dry film thicknesses (DFT), while areas of duller than normal luminosity will tend to indicate lower than expected DFT. Areas where the luminous additive is glowing white indicate paint detachment from the surface. Organic dust and grit will show speckled bright spots under the light. Areas of equal luminosity indicate similar DFT measurements. Under the beam of the UV lamp, areas of black or dark spots indicate low DFT, or areas that have been undercoated.

The use of these fluorescent additives will ensure a longer period of maintenance free service, reduce re-work time and reduce paint usage, which in turn will reduce VOC emission from the site. Easier and improved inspections will allow for identification of defects and repair to the coating system at an early stage. This prevents more expensive repair as the damage would otherwise increase through time.

Also included in some critical areas on the pipe are self-healing coatings with microcapsules that contain film-formers and corrosion inhibitors, which are released when the coating is damaged to repair the damaged areas and prevent further corrosion. Thus, the coating can self-repair in these critical areas. In addition, reporter dyes will be incorporated into the microcapsules that also will be released upon coating damage to help mark the damaged areas in order to enhance the fluorescence detection capabilities. These self-healing microcapsules will be used in critical joints, such as welds.

Technology Maturity: Fluorescent coating and self-healing coatings are advanced technologies, which require demonstration and validation in operational environments.

The Society for Protective Coatings (SSPC) C3 Committee on Inspection has drafted guidance on requirements for the use of fluorescent coatings titled "Inspection of luminescent coating systems." Variations of the techniques have been used recently in industry for inspections of mechanical parts such as landing gears, by using magnetic particles or dye penetrants that fluoresce under UV light and reveal dangerous hairline cracks in the metal.

The fluorescent coating proposed uses a variation of Non-Destructive Testing (NDT) to produce a visual condition that dramatically increases a workers ability to "see" film coverage defects. This is accomplished by the incorporation of a photo-luminescent "tag" or optically active additive in several layers of coatings of an applied system. The ultraviolet (UV) light allows easy location of film defects near weld joints, corners, edges, crevices, or wherever there is a dramatic change in surface contour. Only $0.5 \%$ of the fluorescent tag needs to be added into the paint at the time of application. The average worker with $20 / 20$ vision can usually locate a defect 50 microns in size. A typical UV 


\section{TRI SERVICE PROGRAM \\ ARMY FACILITIES \\ CORROSION PREVENTION AND CONTROL PROJECT PLAN \\ Smart Fluorescent and Self-healing Coatings for Severely Corrosive Environments at Vehicle \\ Wash Facilities \\ at Fort Bragg (RDT\&E, FY06)}

light $250 \mathrm{~W}$ is adequate for inspection. UV fluorescence allows the same worker to locate defects 10 microns in size or smaller even in low light conditions.

The "self-healing"coatings to be incorporated into the smart fluorescent coatings represent a new technology that has been investigated by ERDC-CERL. Self-healing coatings are made by incorporating microcapsules ( $60-150$ microns in diameter) that contain film-formers and corrosion urea formaldehyde inhibitors into commercially available paint primers at the time of coating application. Typical urea formaldehyde (UF) microcapsules ( 60 microns average size) are shown in Fig. 3a. When the coating is scratched or otherwise damaged, the microcapsules break and release their corrosion inhibitors and film formers, which protect the underlying steel substrates from corrosion, and repair some of the coating damage. Also, the smart self-healing coatings will contain conventional dyes that will be released to mark damaged areas, as shown in Fig $3 \mathrm{~b}$.

Two (2) different types of inhibitors/film formers in UF microcapsules were evaluated, as shown in Table 1. The primer and topcoat was a water reducible epoxy, both applied by the drawdown method at 3-5 mils. Figure 4 is an optical micrograph of a transverse section of the self-healing coating on a steel substrate and clearly shows the positional relationship among the microcapsules in the primer layer, and the topcoat, and relative dimensions. It is important that the microcapsules are covered by the primer and topcoat.

Accelerated testing of the self-healing coatings on steel was conducted by scribing them with a razor blade and subjecting them to ASTM D-5894 Standard Practice for Cyclic Salt Fog/UV Exposure of Painted Metal, (Alternating Exposures in a Fog/Dry Cabinet and a UV Condensation Cabinet") testing in the laboratory to simulate the environmental effects of salt spray and ultraviolet (UV) exposure. The test equipment is shown in Fig. 5. The coatings were evaluated as a function of undercutting (underfilm corrosion) as per ASTM D-1654, Standard Test Method for Evaluation of Painted of Coated Specimens Subjected to Corrosive Environments, in which undercutting is determined by measuring the maximum creepage from the scribe.

It was concluded that incorporating self-healing microcapsules into commercially available primers can reduce underfilm corrosion, when the microcapsules are incorporated into the paint at the time of application, as shown in Fig. 6, which compares the performance in the ASTM D-5894 test of one of the coatings with microcapsules to a control coating with no microcapsules. Note that the control coating sample shows pronounced undercutting at the razor scribes, with rust stains originating from the underfilm corrosion at the scribe. Underfilm corrosion is not very visible in the sample containing the microcapsules with camphor and red dye. In term of undercutting, the "A" microcapsules containing camphor and red dye and the "B" coating with the microcapsules, which contained a mixture of spar varnish, tung oil, and iso decyl diphenyl phosphate, showed the lowest undercutting values, $1.4 \mathrm{~mm}$ and $1.5 \mathrm{~mm}$, 


\section{TRI SERVICE PROGRAM}

ARMY FACILITIES

CORROSION PREVENTION AND CONTROL PROJECT PLAN

Smart Fluorescent and Self-healing Coatings for Severely Corrosive Environments at Vehicle

$$
\text { Wash Facilities }
$$

$$
\text { at Fort Bragg (RDT\&E, FY06) }
$$

respectively, compared to the control samples with an undercutting measurement of $4.6 \mathrm{~mm}$ (also see Table 1).

Table1. Self-Healing Coating Test Matrix and Undercutting Results

\begin{tabular}{|c|c|c|c|c|}
\hline $\begin{array}{c}\text { Microcapsule } \\
\text { ID }\end{array}$ & $\begin{array}{c}\text { Microcapsules } \\
\text { Contents }\end{array}$ & $\begin{array}{c}\text { Dry } \\
\text { Thickness, } \\
\text { mils } \\
\text { (microns) }\end{array}$ & $\begin{array}{c}\text { Undercutting } \\
\text { (mm) }\end{array}$ & $\begin{array}{c}\% \text { Reduction } \\
\text { in } \\
\text { Undercutting }\end{array}$ \\
\hline & & & & - \\
\hline Control & N/A & $\begin{array}{c}5.77-6.13 \\
(146-156)\end{array}$ & 4.6 & $69 \%$ \\
\hline A & Camphor/red dye & $\begin{array}{c}7.93-9.40 \\
(201-239)\end{array}$ & 1.4 & $67 \%$ \\
\hline B & $\begin{array}{c}\text { Spar varnish, } \\
\text { Tung Oil, } \\
\text { IsoDecyl } \\
\text { Diphenyl } \\
\text { Phosphate }\end{array}$ & $\begin{array}{c}8.23-12.90 \\
(209-327)\end{array}$ & 1.5 & \\
& & & & \\
\hline
\end{tabular}

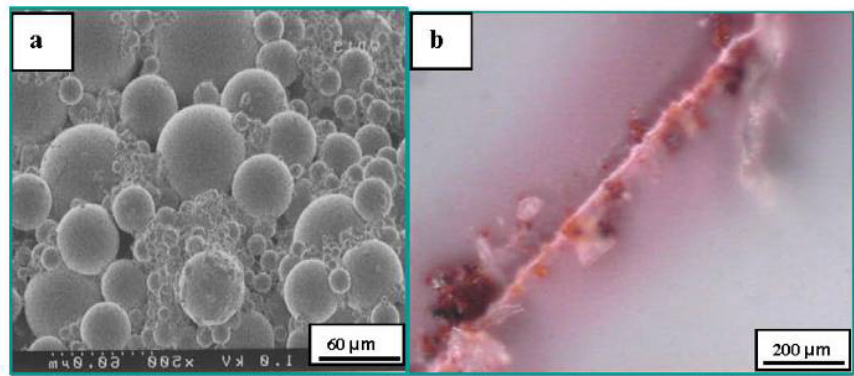

Fig. 3. Micrograph of self-healing coatings: a- Scanning electron micrograph of typical UF microcapsules; b- Optical micrograph of self-healing coating scribed with razor blade, showing red dye release into the damaged area from the microcapsule.

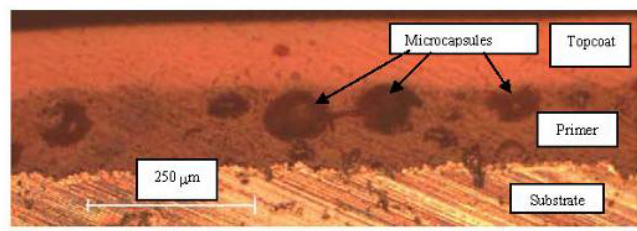

Fig. 4. Optical micrograph of cross section of self-healing coating 

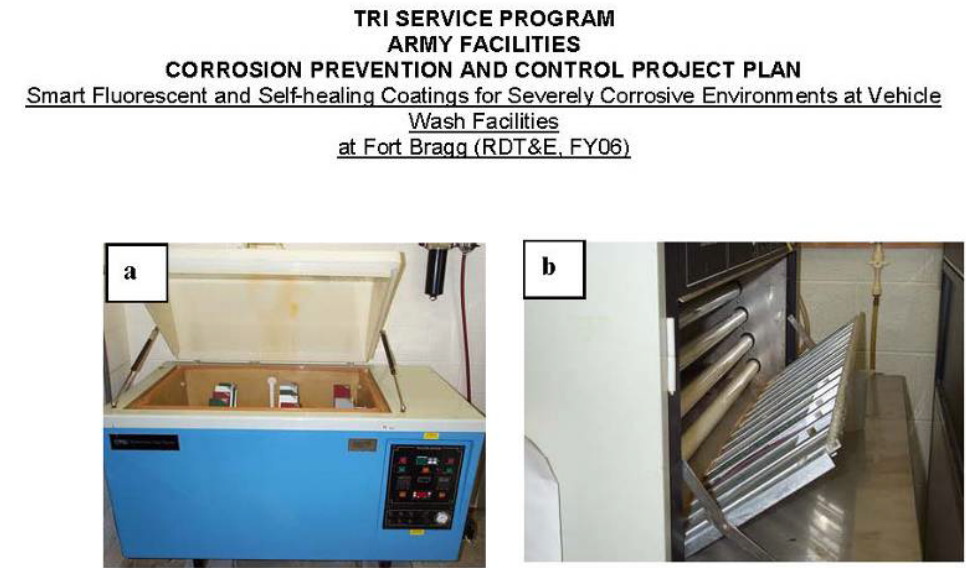

Fig. 5. Laboratory Equipment for ASTM D-5894 Exposure: (a) Salt Spray Chamber; (b) UV-Condensation Test Cabinet

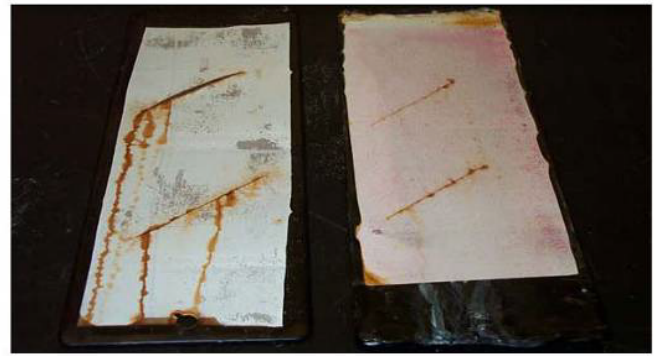

Fig. 6. Samples subjected to ASTM D-5894 ASTM D-5894 StandardPractice for Cyclic Salt Fog/UV Exposure of Painted Metal, (Alternating Exposures in a Fog/Dry Cabinet and a

UV Condensation Cabinet") Exposure for $2016 \mathrm{hr}$.

Left: Control coating (with no microcapsules).

Right: Self-healing coating with microcapsules containing camphor and red dye

\section{$\underline{\text { References }}$}

1. "Accelerated Testing of Self-Healing Coatings," Ashok Kumar and L. D. Stephenson, Corrosion 2003, National Association of Corrosion Engineers (NACE) Conference, San Diego, CA, March 2003. 


\author{
TRI SERVICE PROGRAM \\ ARMY FACILITIES
CORROSION PREVENTION AND CONTROL PROJECT PLAN \\ Smart Fluorescent and Self-healing Coatings for Severely Corrosive Environments at Vehicle \\ Wash Facilities \\ at Fort Bragg (RDT\&E. FY06)
}

2. "Self Healing Coatings," Ashok Kumar and L.D. Stephenson, Proceedings: Corrosion 2002 National Association of Corrosion Engineers Conference, Denver, CO, April 2002.

3. Patent: "Self-Healing Paints" (COE Case \# 558) filed on 04 March 2003

RISK ANALYSIS: The risk for this project is low, as similar advanced technologies for NDT inspection have been used in industry. The self-healing coatings are being field tested on a limited basis at Ft. Campbell for critical areas on deluge tanks. However, this unique combination of smart fluorescent coatings and self-healing coatings has not previously been implemented. The implementation of technologies will not be performed in phases. The CVWF is not being considered for privatization.

EXPECTED DELIVERABLES AND RESULTS/OUTCOMES: The corrosion mitigation needs of the Fort Bragg CVWF will be assessed. The inlet pipe to the grit settling chamber and other components will be cleaned, sandblasted and coated with the fluorescent smart coatings

It is expected that the outcome will be sustainment of the CVWF at its optimum operating condition, as well as reduced maintenance, and increased safety. It is expected that the life of these components are expected be extended by 30 years. This sustainment of the CVWF will ensure that the Army vehicles remain unaffected by corrosion resulting from mud. Where appropriate, Unified Facilities Guide Specifications (UFGS), Engineering Instructions (EI), Technical Instructions (TI), and Technical Manuals (TM), including updates will be developed and posted on the OSD Corrosion Exchange website under "Spec \& Standards" and "Facilities Special Interest Group (SIG)." In addition, a final report will be submitted describing the details and result of the project.

\title{
PROGRAM MANAGEMENT
}

The Project Manager will be: Dr. Ashok Kumar (ERDC/CERL). The Associate Project Manager will be Dr. L. D. Stephenson (ERDC-CERL). Mr. Martin Savoie is Chief of the ERDC/CERL Materials and Structures Branch. The stakeholders will be Ms. Judi Hudson, Ft. Bragg Deputy Director of Public Works), Mr. Steve Smith (Water Champion \& Chief of Public works Operations Offfice), Mr. Steve Jackson (IMA-SERO), Mr. Paul Volkman (HQ-IMA), Mr. David Purcell, (HQ-ACSIM), as well as Triservices WIPT representatives, Ms. Nancy Coleal (AFCESA/CESM), and Mr. Tom Tehada (NFESC).

Customers are: Mr. Steve Smith (Water Champion \& Chief of Public Works Operations Office), Ms. Brenda Audette (Water and Wastewater Plant Supervisor) Mr. Scott Boulton, and Mr. Jason Lyons (all of the Directorate of Public Works Office, Ft. Bragg) Fort Bragg has requested that this project be implemented. The Army has planned to provide matching funds for FY06 for this project through HQ-IMA (See attached 


TRI SERVICE PROGRAM
ARMY FACILITIES
CORROSION PREVENTION AND CONTROL PROJECT PLAN
$\frac{\text { Smart Fluorescent and Self-healing Coatings for Severely Corrosive Environments at Vehicle }}{\text { Wash Facilities }}$
at Fort Bragg (RDT\&E. FY06)

Memorandum from ACSIM Director for Facilities and Housing in Appendix 2). Coordination with the Army Corrosion Program Office will be through Mr. Hilton Mills (AMC).

This is a TriService Project. Funds have been requested for Air Force and Navy representatives to participate in the evaluation of technology implementation. The approach for project performance will include use of Type I -In house, organic capabilities, and Type II Existing Contacts. A Type II Existing Contractual Agreement is expected to be utilized for this project two months after receipt of funds.

\section{COST/BENEFITS ANALYSIS}

a. Funding (\$K):

$\begin{array}{lcc}\text { Funding Source } & \text { OSD } & \text { HQ-IMA Matching } \\ \text { Labor } & 250 & 250 \\ \text { Materials } & 200 & 210 \\ \text { Travel } & 20 & 20 \\ \text { Report } & 20 & 20 \\ \text { Air Force/Navy Participation } & 10 & - \\ \text { TOTAL (\$K) } & \mathbf{5 0 0} & \mathbf{5 0 0}\end{array}$

\section{Development Project Budget}

The $\$ 1 \mathrm{M}$ budget is realistic and adequate for the project scope. This budget has been developed based on a detailed needs assessment for the Central Vehicle Wash Facility in cooperation with the Fort Bragg Directorate of Public Works (DPW) Office, including: Ms. Judi Hudson (Deputy DPW), Mr. Steve Smith (Chief, Public Works Operations Office \& Water Champion), Mr. Jason Lyons and Ms. Brenda Audette, also of the DPW Office. Also, the Army (HQ IMA) has planned to provide matching funds for FY06. ERDC-CERL has conducted a market survey to validate the costs for this project, which have also been extrapolated from ERDC-CERL's extensive previous experience in this area of advanced materials and coatings.

This project has a high potential ROI of 14.85 as shown below.

\section{b. Potential Return-On-Investment Computation}

1) Useful Life Savings (ULS) is equal to the "Net Present Value (NPV) of Benefits and Savings" calculated from the Spreadsheet shown in Appendix 1 that is based on Appendix B of OMB Circular A94. 


\section{TRI SERVICE PROGRAM ARMY FACILITIES \\ CORROSION PREVENTION AND CONTROL PROJECT PLAN \\ Smart Fluorescent and Self-healing Coatings for Severely Corrosive Environments at Vehicle \\ Wash Facilities \\ at Fort Bragg (RDT\&E, FY06)}

ULS $=\$ \mathbf{1 4 , 8 4 6 K}$ (from OMB Spreadsheet in Appendix 1. Assumptions for this calculation are also given in Appendix 1).

2) Project Cost (PC) is shown as "Investment Required" in OMB Spreadsheet in Appendix $1 ; \mathbf{P C}=\mathbf{\$ 1 , 0 0 0 K}$

$$
\text { Potential ROI }=\frac{\mathrm{ULS}}{\mathrm{PC}}=\frac{\$ 14,846 \mathrm{~K}}{\$ 1,000 \mathrm{~K}}=14.85
$$

The calculated ROI for this project, which is based on current best practices, projected maintenance and rehab cost, has the potential to increase over the multiple year implementation due to reduction in down time, which will result in increased indirect savings.

c. Mission Criticality: This project support mission critical systems. Failure of the central vehicle wash facility can compromise the corrosion prevention effort for vehicles, resulting in loss of critical mission support equipment. Failure of the CVWF system during deployment can result in concentration cell corrosion underneath vehicles in critical components where it is difficult to recognize. The operational benefits of implementing advanced corrosion resistant materials selection corrosion control technologies at the CVWF are: (1) increased reliability of the CVWF system, due to early detection and maintenance to mitigate corrosion. (2) enhanced safety and reliability, due to reduced probability of failure of vehicles, and (3) life extension for mission-critical infrastructure.

\section{SCHEDULE}

\section{MILESTONE CHART}

$\begin{array}{lc}\text { Eward Contract } & \begin{array}{c}\text { after receipt of } \\ \text { funds) }\end{array} \\ \begin{array}{l}\text { Select detailed CVWF component needs } \\ \text { Select Smart Fluorescent Coatings }\end{array} & 2 \\ \text { Initiate Implementation of Smart Fluorescent } & 4 \\ \begin{array}{l}\text { Coatings for Inlet Pipe and Other Components } \\ \text { Complete Implementation of Fluorescent }\end{array} & 6 \\ \begin{array}{l}\text { Coatings } \\ \text { Complete Training on maintenance of }\end{array} & 15 \\ \text { advanced materials } & 16 \\ \begin{array}{l}\text { Complete Documentation (includes Final } \\ \text { Report, Procurement Specifications, etc.) }\end{array} & 18\end{array}$




TRI SERVICE PROGRAM
ARMY FACILITIES
CORROSION PREVENTION AND CONTROL PROJECT PLAN
$\frac{\text { Smart Fluorescent and Self-healing Coatings for Severely Corrosive Environments at Vehicle }}{\text { at Fort } \frac{\text { Wash Facilities }}{\text { Bragg (RDT\&E. FY06) }}}$
Complete Potential ROI Validation

a. Note: If project is approved, bi-monthly status report will be a requirement (i.e. starting the first week of the second month after contract award and every two months thereafter until final report is completed). This report will be submitted to the DoD CPC Policy \& Oversight office. The report will include project number, progress summary (and/or any issues), performance goals and metrics and upcoming events.

b. Examples of performance goals and metrics include: achieving specific milestones, showing positive trend toward achieving the forecasted ROI, reaching specific performance quality levels, meeting test and evaluation parameters, or successfully demonstrating a new system prototype.

Development Project Schedule

This materials selection project will be implemented and completed including final report within 18 months. The goals of the project are: sustainment of the restoration of major components central vehicle wash facility to optimum operating conditions using fluorescent smart coating technology. The objectives are: proper selection and implementation of these advanced coatings that will allow quick easy and thorough inspections via ultraviolet and reveal areas where holidays have developed. These coatings will be applied to the inlet pipe of the CVWF grit settling chamber. Detailed milestones are given in the schedule section. Implementation of the coating systems will be provided by Contractors. ERDC-CERL will provide overall management, contract monitoring and provide bi-monthly reports. Existing contract mechanisms, such as IDIQ and BAA will be used. ERDC-CERL will be able to award the contracts within 60 days of receipt of funds. The schedule has been coordinated with Fort Bragg Directorate of Public Works and water treatment and wastewater treatment plants supervisor. Potential contractors have been identified.

\section{IMPLEMENTATION}

a. Transition approach. Where appropriate, Unified Facilities Guide Specifications (UFGS), Engineering Instructions (EI), Technical Instructions (TI), and Technical Manuals (TM), including updates, will be developed. In addition, a final report describing the details and results of the project, will be submitted to OSD. The draft documents will be posted on the OSD Corrosion Exchange website under "Spec \& Standards" and "Facilities SIG."

Coordination with potential users will be an essential part of the transition of the technology. 


\section{TRI SERVICE PROGRAM \\ ARMY FACILITIES \\ CORROSION PREVENTION AND CONTROL PROJECT PLAN \\ Smart Fluorescent and Self-healing Coatings for Severely Corrosive Environments at Vehicle \\ Wash Facilities \\ at Fort Bragg (RDT\&E, FY06)}

It is the intent of the Project Management Plan (PMP) to implement this corrosion prevention and control technology at multiple regions and installations. The UFGS, EIs, TIs, and TMs, including updates to existing guidance documents, developed for Army-wide implementation during this FY06 project, will be utilized in the future to facilitate the planned implementation of corrosion resistant materials for vehicle wash facilities and other corrosion intensive components.

b. Potential ROI validation. The potential ROI will be validated by comparison of CVWF systems operational and maintenance requirements using advanced corrosion resistant materials versus CVWF systems with currently used coatings, during the first two years of implementation. ROI validation methods used will be visual inspection of coatings and the components to which they are applied and corrosion rates for structures, in accordance with National Association of Corrosion Engineers (NACE) standards for which cathodic protection has been implemented. The ROI will be validated by an impartial NACE-certified corrosion expert or similarlyqualified person suggested by NACE Headquarters. In later years, the extension of lifetime of the CVWF and associated components will be used to calculate the potential ROI. The calculated ROI for this project, which is based on current best practices, projected maintenance and rehab cost, has the potential to increase over the multiple year implementation due to reduction in down time, which will result in increased indirect savings.

c. Final Report: A final report will be submitted within 60 days of completion of the project. The report will reflect the project plan format as implemented and will include lessons learned.

\section{Projected Benefits:}

Based on the past record of demonstrating these technologies at Army installations, advanced smart coatings for provide the benefits of restoring the CVWF to its optimum operating condition, as well as reduced, easier and more thorough maintenance.

\section{Operational Readiness}

These coating technologies are commercially available and ready for implementation as solutions to the corrosion problems of the Central Vehicle Wash Facility at Ft. Bragg. Based on previous experience, this project will enhance the performance, reliability of the CVWF and have far reaching impact on the maintenance of Army vehicle needed for Force Projection and safety of the vehicles, all due to reduced corrosion.

\section{Management Support}

This project enjoys the support of the Fort Bragg Directorate of Public Works (DPW)

Office, specifically Ms. Judi Hudson (Deputy DPW), Ms. Brenda Audette (Water Plant 


TRI SERVICE PROGRAM
ARMY FACILITIES
CORROSION PREVENTION AND CONTROL PROJECT PLAN
$\frac{\text { Smart Fluorescent and Self-healing Coatings for Severely Corrosive Environments at Vehicle }}{\text { Wash Facilities }}$
at Fort Bragg (RDT\&E. FY06)

and Wastewater Treatment Plant Supervisor, Ft. Bragg). Signatures have been obtained from representatives of Ft. Bragg DPW and IMA-SERO Region. HQ-IMA and HQ-

ACSIM are supporting this project, as shown on the coordination sheet. Moreover, the Army (HQ-IMA) has planned to provide matching funds for FY06. See attached

Memorandum from ACSIM Director for Facilities and Housing in Appendix 2. 


\section{TRI SERVICE PROGRAM}

ARMY FACILITIES

CORROSION PREVENTION AND CONTROL PROJECT PLAN

Smart Fluorescent Coatings to Detect Corrosion in Severely Corrosive Environments at Vehicle Wash Facilities at Fort Bragg (RDT\&E,FY06)

\section{COORDINATION SHEET}

\section{ORGANIZATION}

Projec1 Manager

ERDC/CERL. Branch Chiet

Instailation DPW POC

IMA Region

HQ IMA

HQ ACSIM

HQ AMC

Tris Service Facilittes WIPT Chair

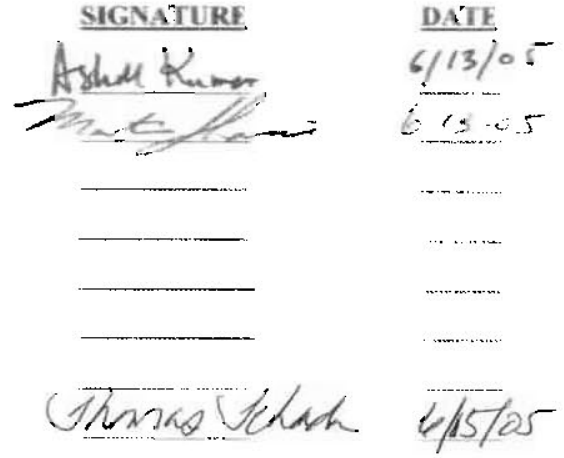

This s a Tribervece Project. Funds have beea requested for travel of Aur Force vend ivay represctitatives to participate in the evaluathon of licchnology implementation 
TRI SERVICE PROGRAM ARMY FACILITIES

\section{CORROSION PREVENTION AND CONTROL PROJECT PLAN}

Smart Fluorescent Coatings to Detect Corrosion in Severely Corrosive Environments at Vehicle Wash Facilities at Fort Bragg (RDT\&E,FY06)

\section{COORDDNATION SHEET}

ORGANOZATION
Project Manager
ERDC/CERL Branch Chief
Installation DPW POC
IMA Region
HQ IMA
HQ ACSIM
HQ AMC
Tri Service Facilities WIPT Chair

SIGNATURE $\quad \underline{\text { DATE }}$

Thervice Facilities WIPT Chair

This is a TriService Project. Funds have been requested for travcl of Air Forcc and Navy represcntatives to participate in the evaluation of technology implementation. 
TRI SERVICE PROGRAM

ARMY FACILITIES

CORROSION PREVENTION AND CONTROL PROJECT PLAN

Innovative Thermal Barrier Coatings to Prevent Corrosive Environmental Effects and

Improve Energy Efficiency in Heat Distribution Manholes - at Ft. Stewart and Ft. Bragg

\section{COORDINATION SHEET}

ORGANIZATION

Project Manager

ERDC/CERL Branch Chief

Installation DPW POC

IMA Region

HQ IMA

HQ ACSIM

HQ AMC

Tri Services Facilities WIPT Chair

\section{SIGNATURE}

DATE

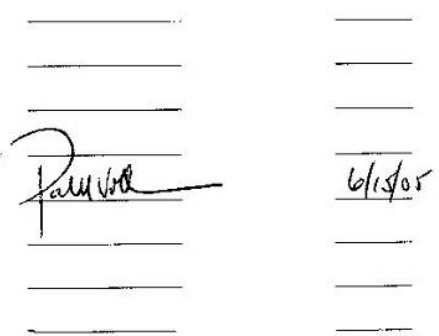

This is a Triservice Project . Funds have been requested for travel of Air Force and Navy representatives to participate in the cvaluation of technology implementation. 
TRI SERVICE PROGRAM

ARMY FACILITIES

CORROSION PREVENTION AND CONTROL PROJECT PLAN

Smart Fluorescent Coatings to Detect Corrosion in Severely Corrosive Environments at Vehicle Wash Facilities at Fort Bragg (RDT\&E,FY06)

6. COORDINATION SHEET

ORGANIZATION

Project Manager

ERDC/CERL Branch Chief

Installation DPW POC

IMA Region

HQ IMA

HQ ACSIM

HQ AMC

Tri Service Facilities WIPT Chair
SIGNATURE

$\underline{\text { DATE }}$

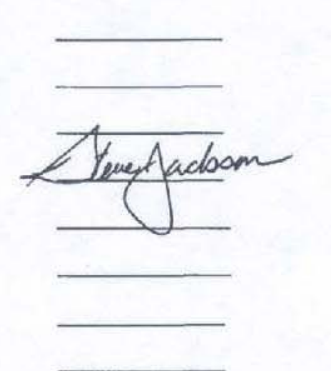

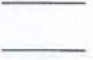

$6-13-2005$
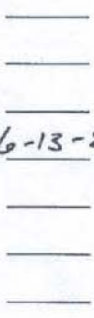

This is a TriService Project. Funds have been requested for travel of Air Force and Navy representatives to participate in the evaluation of technology implementation. 
TRI SERVICE PROGRAM

ARMY FACILITIES

\section{COIROSION PREVENTION AND CONTROL PROJECT PLAN}

Smarl Fluorescont Coatings to Detect Corrosion in Severely Corrosive Environments at Vehicle Wash Facilities at Fort Bragg (RDT\&E.FY06)

0. COOBDINATION SIIEET

OBSGANHATION

Projicl Mannger

IRnC/CIRE Branch Clier

Jistallation DSW POOC

IMA Keggion

II() IMA

IIO ACSIM

IIOAMC

Tii Service fincilities WIPT Chair

\section{SIGNATURE \\ DATE}
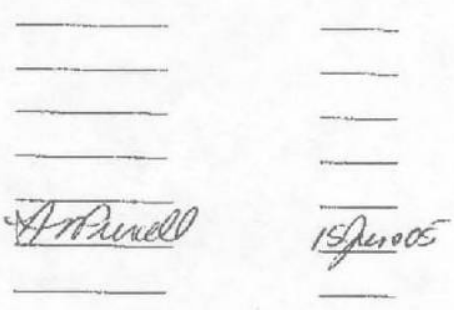

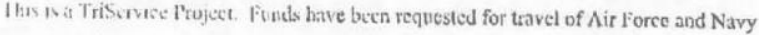
icpusentatives to participate in the cvaluation of technology implementation. 


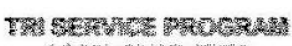

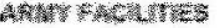

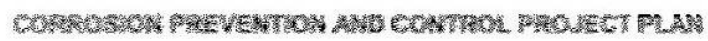

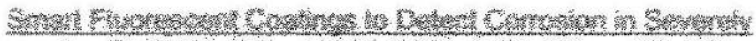

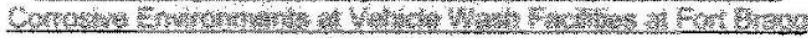

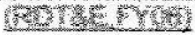

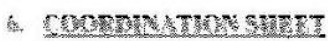

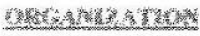

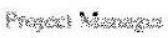

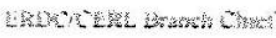

Iresaliation Les loc

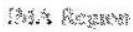

WOMA

WrV AESWH

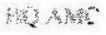

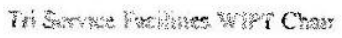

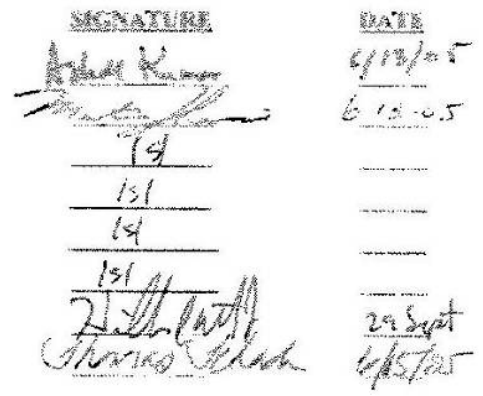

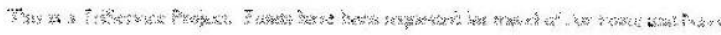

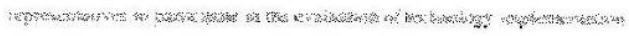


TRI SERVICE PROGRAM ARMY FACILITIES

CORROSION PREVENTION AND CONTROL PROJECT PLAN Smart Fluorescent and Self-healing Coatings for Severely Corrosive Environments at Vehicle Wash Facilities

at Fort Braga (RDT\&E, FY06)

\title{
7. APPENDICES
}

\author{
Appendix 1a. Potential ROI Calculations \\ (Based on Appendix B of OMB Circular A94)
}

Alternative 1: The Ft. Bragg Central Vehicle Wash (CVWF) inlet pipe to the grit settling chamber will requires replacement 8 years from now, at a cost of $\$ 15.8 \mathrm{M}$, plus the materials cost of coating the new pipe with smart fluorescent-self-healing coatings ( $\$ 410 \mathrm{~K})$, as shown under Baseline Costs as $\$ 16.21 \mathrm{M}$ in Year 8 .

Average annualized maintenance costs of the system is $\$ 35 \mathrm{~K}$, as shown under Baseline Costs. Additional costs are damage to Army vehicles due to corrosion, and downtime at $\$ 50 \mathrm{~K}$ from year 1 to year 8 . Also included in year 8 , as additional costs, is the $\$ 8.5 \mathrm{M}$ in corrosion of vehicles due to non-availability of the CVWF, therefore the total cost shown under New System Benefits/Savings in Year 8 is $\$ 8.55 \mathrm{M}$.

Alternative 2: Recoating the existing inlet pipes and components using smart self-healing-fluorescent based coatings in year 1 at a project cost of $\$ 1 \mathrm{M}$ is projected to extend the lives of the original coating systems by another 30 years. These coatings will show when maintenance is needed via fluorescence. Generally, require very little maintenance $(\$ 2,500)$ as shown under New System Costs. The downtime cost for coating the pipe in year 1 is minimal $(\$ 10 \mathrm{~K})$, as shown under New System Costs.

The additional cost of replacement of the inlet pipes and other components due to corrosion, and downtime (resulting in corrosion of vehicles) are avoided, as shown under New System Benefits/ Savings. The structures will again need recoating in year 38 .

After Year 8, the maintenance costs are the same, so no further analysis is needed. Comparing the two alternatives, the potential return-on-investment for Alternative 2 is projected to be 14.85 . 


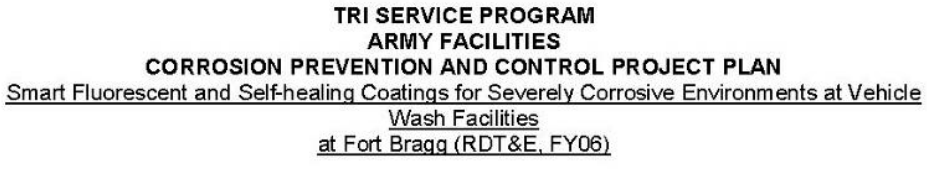

\section{Return on Investment Calculation}

\begin{tabular}{|c|c|c|c|c|c|c|c|}
\hline \multirow[b]{4}{*}{$\begin{array}{c}\text { A } \\
\text { Future } \\
\text { Year }\end{array}$} & \multicolumn{6}{|c|}{ Investment Required } & \multirow{2}{*}{$\begin{array}{r}1,000,000 \\
1485 \% \\
\end{array}$} \\
\hline & \multirow{2}{*}{\multicolumn{4}{|c|}{ Net Present Value of Costs and Benefits/Savings }} & 14.85 & Percent| & \\
\hline & & & & & 21,938 & $14,868,402$ & $14,846,465$ \\
\hline & $\begin{array}{c}\text { B } \\
\text { Baseline costs }\end{array}$ & $\begin{array}{c}c \\
\text { Baseline } \\
\text { Benefitss Savings }\end{array}$ & $\begin{array}{c}\text { D } \\
\text { New System } \\
\text { Costs }\end{array}$ & $\begin{array}{c}\text { E } \\
\text { News System } \\
\text { Benefits/Savings }\end{array}$ & $\begin{array}{c}F \\
\text { Present Value of } \\
\text { costs }\end{array}$ & $\begin{array}{c}G \\
f \begin{array}{c}G \\
\text { Present Value of } \\
\text { Savings }\end{array}\end{array}$ & $\begin{array}{c}\mathrm{H} \\
\text { Total Present } \\
\text { Value }\end{array}$ \\
\hline & $\frac{35,000}{3500}$ & & $\frac{10,000}{2501}$ & 50,000 & $9, \frac{9346}{3,90}$ & 79,441 & 70.095 \\
\hline & $\frac{35,000}{35000}$ & & $\frac{2,500}{2.500}$ & 50,000 & $\frac{2,184}{2041}$ & 74,239 & 72,056 \\
\hline & $\frac{35,000}{35,000}$ & & $\frac{2,501}{2,500}$ & $\frac{5,000}{50,000}$ & $\frac{2,041}{1,907}$ & $\begin{aligned} 69,3067 \\
64.847 \\
\end{aligned}$ & 62.959 \\
\hline & $\frac{35,000}{35,000}$ & & $\frac{2,500}{2500}$ & $\frac{50,000}{50000}$ & $\frac{1,789}{1.665}$ & 60,605 & $\frac{58,8230}{54.970}$ \\
\hline & $\frac{35.000}{35.000}$ & & $\frac{2.50}{\frac{2.50}{500}}$ & $\frac{5,0.000}{50.000}$ & $\frac{1.005}{1.5575}$ & $\frac{52.930}{50.90}$ & $\frac{31,373}{51,379}$ \\
\hline & $16,210,000$ & & & $8,550,000$ & 1,455 & $14,410,320$ & \\
\hline & & & & & & & \\
\hline & & & & & & & \\
\hline & & & & & & & \\
\hline & & & & & & & \\
\hline & & & & & & & \\
\hline & & & & & & & \\
\hline & & & & & & & \\
\hline & & & & & & & \\
\hline & & & & & & & \\
\hline & & & & & & & \\
\hline & & & & & & & \\
\hline
\end{tabular}




\author{
TRI SERVICE PROGRAM \\ ARMY FACILITIES \\ CORROSION PREVENTION AND CONTROL PROJECT PLAN \\ Smart Fluorescent and Self-healing Coatings for Severely Corrosive Environments at Vehicle \\ Wash Facilities \\ at Fort Bragg (RDT\&E, FY06)
}

APPENDIX 2 


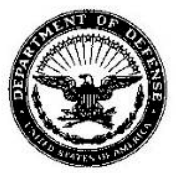

DAIM-FD
DEPARTMENT OF THE ARMY

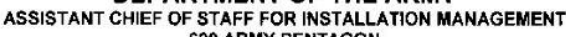

25 MAR 2005

S: 15 Oct 2005

MEMORANDUM FOR DIRECTOR, INSTALLATION MANAGEMENT AGENCY, 2511 JEFFERSON DAVIS HIGHWAY, ARLINGTON VA 22202-3926

SUBJECT: FY 06 Army Corrosion Control Program

1. OSD has tentatively allocated a total of $\$ 15.0 \mathrm{M}$ in FY 06 matching funds for implementation of corrosion prevention and control projects for equipment and facilities. The enclosed list of Army projects, totaling $\$ 13.3 \mathrm{M}$, will be presented for approval to OSD in April 05.

2. The Army programming target is not less than $\$ 10.0 \mathrm{M}$ of facility related projects in an effort to obtain a minimum of $\$ 5.0 \mathrm{M}$ of the OSD matching funds. To participate in OSD's funding augumentation, HQIMA will reserve \$5.0M in FY06 OMA funds, to be released to ERDC-CERL upon confirmation by this office that OSD matching funds are available. Further instructions on the actual distribution of funds will follow at that time.

3. POC for this action is Mr. David N. Purcell, or (703) 601-0371,

David.Purcell@hqda.army.mil.

4. Quality Facilities for Quality Soldiers!

FOR THE ASSISTANT CHIEF OF STAFF FOR INSTALLATION MANAGEMENT:

Encl

as

$\mathrm{CF}$

DACSIM

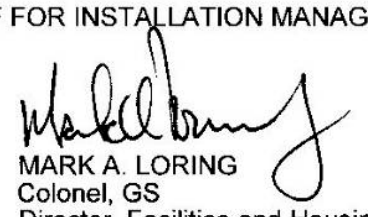

Colonel, GS

Director, Facilities and Housing 


\title{
Appendix B: Product Data Sheets
}

\author{
Ciba Specialty Chemicals
}

Coating Effects Segment

\section{Ciba ${ }^{\oplus}$ UVITEX ${ }^{\circledast}$ OB}

\section{Ciba}

\section{Fluorescent Whitening Agent}

\begin{tabular}{lc} 
Specific density at $20^{\circ} \mathrm{C}:$ & $1.26 \mathrm{~g} / \mathrm{cm}^{3}$ \\
& \\
Solubility ( $\mathrm{g} / 100 \mathrm{~g}$ solution) at $20^{\circ} \mathrm{C}$ : \\
\hline Acetone & 0.5 \\
Chloroform & 14 \\
Dimethylformamide & 0.8 \\
Dioxane & 2 \\
n-Hexane & 0.2 \\
Methanol & $? 0.1$ \\
Methylethylketone & 1.3 \\
Tricresylphosphate & 0.8 \\
Xylene & 5 \\
water & $? 0.01$
\end{tabular}

Application

UVITEX OB is recommended for applications such as:

- white and pastel tone paints where it intensifies the degree of whiteness

- clear coats and overprint varnishes where it is used to mask the yellowish self color and also to intensify the brilliance of white and colored base coats

- primer and/or topcoats where it is used as marker to identify voids, holidays and uneven coverage

- black and blue printing inks to increase their deep tone

- printing inks for quick identification, security and safeguard against forgeries (i.e. banknote)

- packaging inks as promotional tool or as tracer for packaging lines

- manufacture of fluorescent pigments/dyestuffs to reinforce the brightness of certain shades, particularly blue tones

- thermal dye diffusion paper to enhance paper whiteness

- film base for photographic paper

If UVITEX OB must be used in combination with a UV absorber, the absorption spectrum of the latter must leave an open window in the near UVA for the optical brightener.

Due to the intrinsic light fastness properties of optical brigtheners, UVITEX OB is recommended for indoor use only.

\begin{tabular}{lll}
\hline Recommended concentrations : & & \\
Clear coats and overprint varnishes & $0.02-0.1 \%$ & UVITEX OB \\
Marker in primers & $2.0-4.0 \%$ & UVITEX OB \\
\hline
\end{tabular}




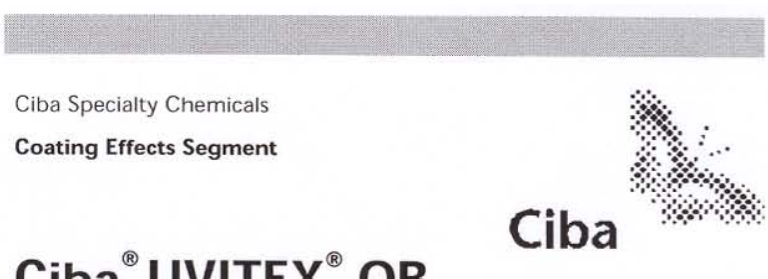

\section{Ciba ${ }^{\circledast}$ UVITEX ${ }^{\circledast}$ OB}

Fluorescent Whitening Agent

Concentrations are based on weight \% binder solids and depend on degree of desired brightening effect

White coatings

$0.5-5 \%$

UVITEX OB

Concentrations are based on $\%$ by weight of pigment and depend on the degree of desired whiteness

Safety and Handling

Important Notice
UVITEX OB should be handled in accordance with good industrial practice. Detailed information is provided in the Safety Data Sheet.

IMPORTANT: The following supersedes Buyer's documents. SELLER MAKES NO REPRESENTATION OR WARRANTY, EXPRESS OR IMPLIED, INCLUDING OF MERCHANTABILITY OR FITNESS FOR A PARTICULAR PURPOSE. No statements herein are to be construed as inducements to infringe any relevant patent. Under no circumstances shall Seller be liable for incidental, consequential or indirect damages for alleged negligence, breach of warranty, strict liability, tort or contract arising in connection with the product(s). Buyer's sole remedy and Seller's sole liability for any claims shall be Buyer's purchase price. Data and results are based on controlled or lab work and must be confirmed by buyer by testing for its intended conditions of use. The product(s) has not been tested for, and is therefore not recommended for, uses for which prolonged contact with mucous membranes, abraded skin, or blood is intended; or for uses for which implantation within the human body is intended. 


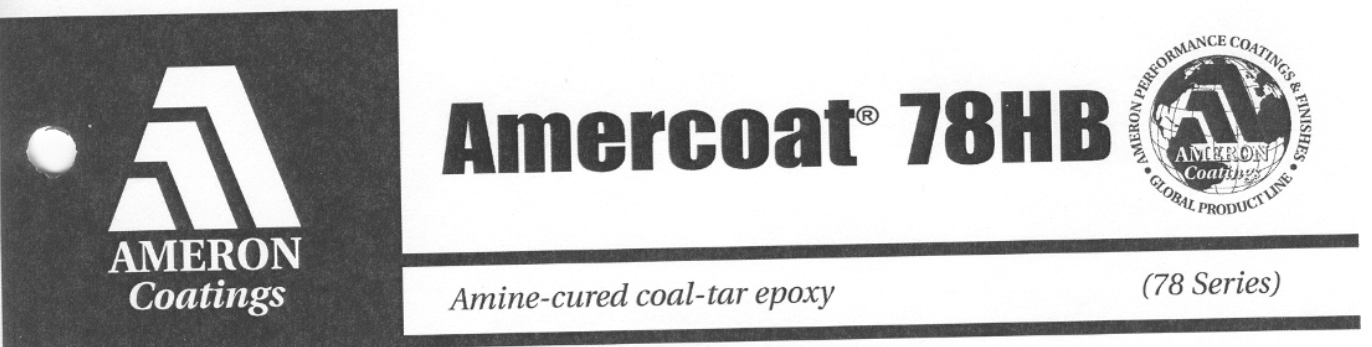

\section{Product Data}

- Protection in only one coat, eliminating intercoat adhesion problems of two-coat coal-tar epoxies

- One-coat application for significantly reduced labor costs - Superior application by airless and conventional spray

- For tank lining immersion or nonimmersion service

- Suitable for waste treatment plant service

Amercoat 78HB displays exceptional application versatility.

Easily applied in one-coat thicknesses of 16 mils ( 400 microns)

or more. Alternatively, two coats at 5 - 8 mils (125 - 200

microns) each may be applied if required by specification.

These features, combined with its high solids content and

broad spectrum or warer a high performance, economical Amercoa suitable for use over both steel and concrete.

\section{Typical Uses}

Marine structures, piling, bilges, ballast tanks, crude oil eargo/ballast tanks, ship bottoms: pipe coating and líning: industrial coating in power plants, oil production and refining plants, wastewater treatment plants. Lining for intermittent or continuous immersion in cride

\section{Systems Using Amercoat 78HB}

Amercoat $78 \mathrm{HB}$ normally does not require a primer or any additional topcoats. In the event a holding primer is required, Amercoat 370 may be used.

Dimetcote ${ }^{\circ} \mathrm{can}$ be used as a primer for Amercoat $78 \mathrm{HB}$ when the cathodic protection provided by an inorganic zinc is required. For immersion service, Amercoat 370 is recommended as a tiecoat between Dimetcote and Amercoat $78 \mathrm{HB}$.

Systems using Amercoat 78HB

$$
\begin{array}{lcc}
\multicolumn{1}{c}{\text { System }} & \multicolumn{2}{c}{\begin{array}{c}
\text { Nonimmersion } \\
\text { Splash/Spillage }
\end{array}} \\
\text { Amercoat 78HB } & \text { Immersion } & \text { Fumes } \\
\text { Amercoat 370/Amercoat 78HB } & \text { Yes } & \text { Yes } \\
\text { Dimetcote 9 Series/Amercoat 78HB } & \text { No } & \text { Yes } \\
\text { Dimetcote 9 Series/Amercoat 370/ } & & \text { Yes } \\
\text { Amercoat 78HB } & \text { Yes } & \text { Yes }
\end{array}
$$

\begin{tabular}{cc}
\multirow{2}{*}{$\begin{array}{c}\text { Sonimmersion } \\
\text { Smmersion }\end{array}$} & Fumes \\
Yes & Yes \\
Yes & Yes \\
No & Yes \\
Yes & Yes
\end{tabular}

\section{Application Data Summary}

For complete information on surface preparation, environmental conditions, application procedures, drying times,

equipment, and safety precautions refer to detailed application instructions. This product should be applied as recommended to obtain the maximum performance for which the material is formulated.

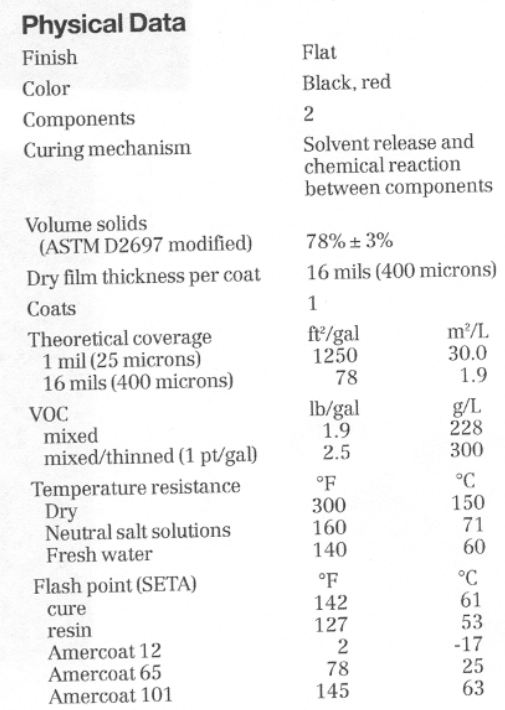

\section{Application Data}

Applied over

Prepared or primed steel or concrete

Surface preparation Abrasive blast or acid etch

Primer

Dimetcote 9 Series,

Amercoat 370

Method

Airless or conventional spray

Mixing ratio (by volume)

1 part cure to 19 parts resin

Pot life and drying time dependent on temperature.

Environmental conditions are critical for this class of coating. See application instructions.

Pot life (hours)

$$
\begin{array}{ccc} 
& { }^{\circ} \mathrm{F} /{ }^{\circ} \mathrm{C} & \\
90 / 32 & 70 / 21 & 50 / 10 \\
2 & 4 & 8
\end{array}
$$

Environmental conditions

Temperature

air ${ }^{\circ} \mathrm{F} \quad{ }^{\circ} \mathrm{C}$

$\begin{array}{lll} & 40 \text { to } 122 & 4 \text { to } 50 \\ \text { surface } & 40 \text { to } 120 & 4 \text { to } 49\end{array}$

Steel surface temperature must be at least $5^{\circ} \mathrm{F}\left(3^{\circ} \mathrm{C}\right)$ above dew point to prevent condensation. 


\section{Curing}

Can be exposed to most atmospheric conditions as soon as sufficiently hard to withstand the handling required.

Can be immersed in water where abrasion is not critical, such as in ships' ballast tanks or bilges, after 72 hours at $70^{\circ} \mathrm{F}\left(21^{\circ} \mathrm{C}\right)$. Full cure, where maximum chemical or abrasion resistance is required, takes 10 days at $70^{\circ} \mathrm{F}\left(21^{\circ} \mathrm{C}\right)$.

Note: Drying and curing times are dependent on temperature and thickness of coating.

\section{Safety Precautions}

Read each component's material safety data sheet before use. Mixed material has hazards of each component. Safety precautions must be strictly followed during storage, handling and use.

This product is for professional use only. Not for residential use.

\section{Warranty}

Ameron warrants its products to be free from defects in material and workmanship. Ameron's sole obligation and Buyer's exclusive remedy in connection with the products shall be limited, at Ameron's option, to either replacement of products not conforming to this Warranty or credit to Buyer's account in the invoiced amount of the nonconforming products. Any claim under this Warranty must be made by Buyer to Ameron in writing within five (5) days of Buyer's discovery of Ameron in writing with in no event later than the expiration of the applicable shelf life, or one year from the delivery date, the applicable shelf life, or one year from the delivery date, whichever is earlier. Buyer's failure to notify Ameron of such
nonconformance as required herein shall bar Buyer from recovery under this Warranty.

Ameron makes no other warranties concerning the product. No other warranties, whether express, implied, or statutory, such as warranties of merchantability or fitness for a

particular purpose, shall apply. In no event shall Ameron be liable for consequential or incidental damages.

Any recommendation or suggestion relating to the use of the products made by Ameron, whether in its technical literature, or in response to specific inquiry, or otherwise, is based on data believed to be reliable; however, the products and information believed to be reliable; however, the products and information are intended for use by Buyers having requisite skill and knowhow in the industry, and therefore it is for Buyer to satisfy itself shall be deemed that Buyer has done so, at its sole discretion and risk. Variation in environment, changes in procedures of use, or extrapolation of data may cause unsatisfactory results

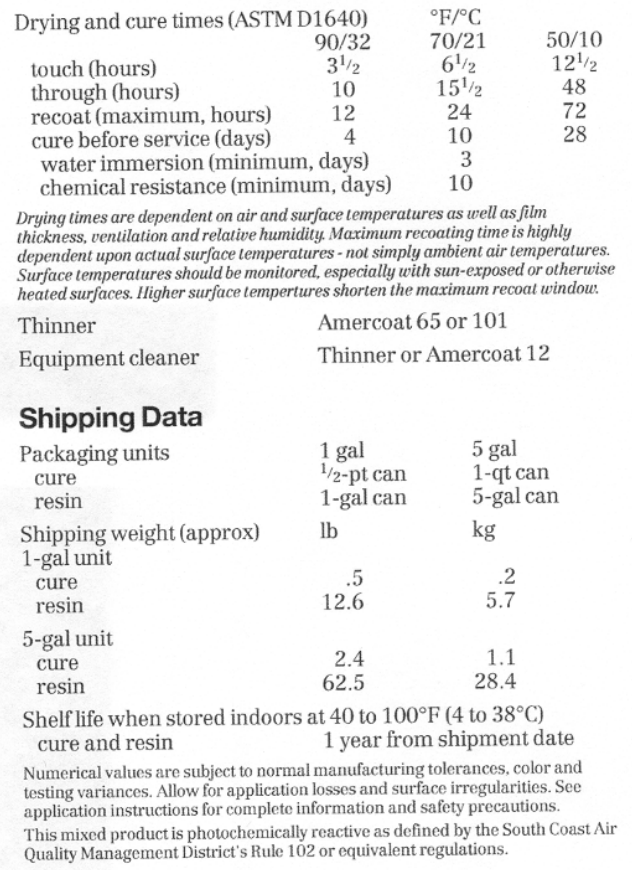

\section{Limitation of Liability}

Ameron's liability on any claim of any kind, including claims based upon Ameron's negligence or strict liability, for any loss or damage arising out of, connected with, or resulting from the use of the products, shall in no case exceed the purchase price allocable to the products or part there of which give rise to the claim. In no event shall Ameron be liable for consequential or incidental damages.

Due to Ameron's policy of continuous product improvement, the information contained in this Product Data/Application Instructions sheet is subject to change without notice. It is the Buyer's responsibility to check that this issue is current prior to using the product. For the most up-to-date Product Data/Application Instructions always refer to the Ameron International Performance Coatings \& Finishes website at www.ameroncoatings.com.

\footnotetext{
5 AMERON Ameron U.S.A. 1200 Bluegrass Lakes Parkway, Suite 100, Alpharetta, GA 30004 $\bullet$ (678) 393-0653 A Coatings
} 


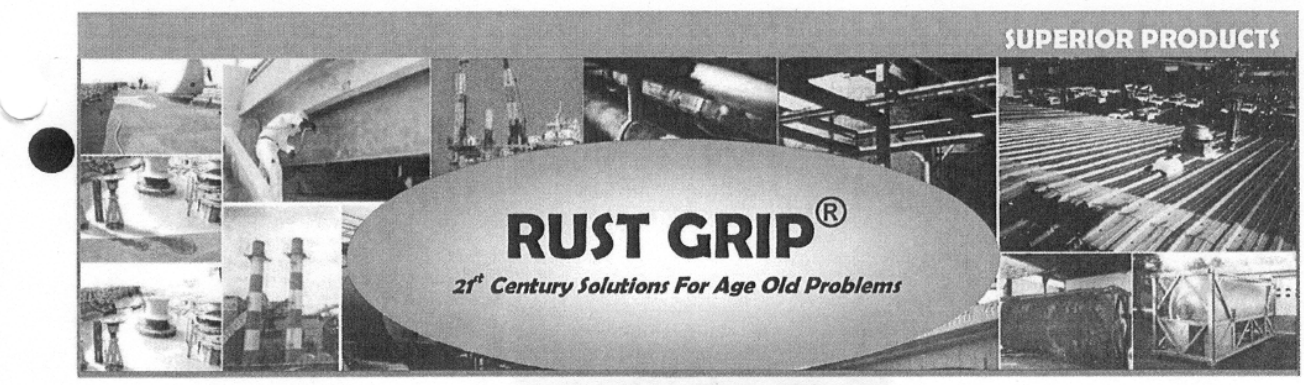

Technical Data Sheet ${ }_{(00 / 27 / 00)}$

DESCRIPTION

Rust Grip ${ }^{*}$ is a one-part polyurethane metallic pigmented coating that absorbs atmospheric moisture to cure. Upon curing, RUST GRIP $^{*}$ provides a protective coating of superior adhesion, flexibility and abrasion- and impact-resistance. It is resistant to chemical solvents and acid splash.

Rust Grip ${ }^{*}$ can be used as a primer or a one-coating system. It is patented (patent $\# 5,695,812$ ) as an encapsulant of lead-based paints and other toxic materials, including asbestos. Rust Grip ${ }^{*}$ can be applied over cleaned flash rust or most firmly bonded paints. In most cases, no near-white blasting is required.

\section{TYPICAL USES}

- As an encapsulant for lead-based paints, rust and other biohazardous materials

- As a protective coating on metal, concrete, wood, etc. to prevent deterioration

- As a single coat for bridges, oil platforms, roofs, etc. with minimal surface preparation

- As a moisture barrier to stop water penetration, contamination, and mold/mildew

\section{APPLICATION METHODS}

Surfaces should be clean, dry and sound; all dirt, salts, oil, tar, grease and film must be removed prior to application. Can be sprayed, brushed or rolled in 2 coats (20-30 minutes apart). Before using, stir thoroughly - without creating a vortex - to blend all metallic paste from the bottom. For specific instructions on surface preparation, mixing and application, refer to the SPI's application instructions for Rust Grip ${ }^{8}$.

NOTE: SURFACE MUST BE COMPLETELY DRY.

PHYSICAL DATA

- Solids: By weight $62.2 \%$ / By volume $51.37 \%$

- Cure Time @ $70 \mathrm{~F}(21 \mathrm{C}): 2$ hours to touch. Overcoat with Rust Grip $^{8}$ or other coatings immediately after surface is dry to the touch to achieve proper adhesion. Higher temperatures and humidity will shorten curing times, lower temperatures will slow curing. Must be overcoated within 2 hours or within 1 hour after reaching the dry-to-touch stage, or the surface must be lightly sanded to achieve good adhesion.

- Lead and Chromate Free

- Cures by reacting to moisture in the air

- Weight: $9.18 \mathrm{lbs}$. per gallon

- Surface Tensile Strength: $6,780+$ psi

- VOC Level: 414 grams/liter

- Impact Resistance: $200+$ psi front / 160+ psi back

- Shelf Life: Up to 3 years unopened under appropriate storage conditions (See MSDS).
TEST AND CERTIFICATIONS

1) Tensile Strength (6,780 psi after 3 weeks)

2) USDA approved

3) Marine approvals for salt water/maritime user:

4) DNV (Det Norske Veritas)

5) *ABS (American Bureau of Shipping)

6) *IMO (International Maritime Organization)

7) *US Coast Guard

8) Factory Mutual approval

9) E-108-00: Spread of flame on pitched roofs

10) (Class "A" non-combustible)

11) G85: Prohesion over rusted metal

12) Mildew Resistance - (ASTM D 3273, 3274)

13) Chemical Resistance (24 hours/12 reagents)

14) Flexibility (Mandrel Bend: ASTM D522) - 1/8"

15) Direct Impact Resistance (ASTM D2794)

15) Direct Impact Resistance (ASTM D
16) Adhesion (ASTM D 3359, D4541)

17) Adhesion (ASTM D3359, D4541)

18) Surface Burning Characteristics (E84)

19) Weathering (2000 hours ) - China

20) Biohazard Encapsulation Approval - (ASTM E1795)

SAFETY PRECAUTIONS

Do not use this product without first taking all appropriate -safety measures to prevent property damage and injuries. These measures may include, without limitation: proper ventilation, use of proper lamps, wearing of protective clothing and masks, tenting, and proper separation of application areas. This coating is flammable. Keep away from fire, or other sources of ignition. For more specific safety procedures, please refer to the Rust Grip ${ }^{\text {it }}$ Material Data Safety Sheet. KEEP OUT OF REACH OF CHILDREN.

MINIMUM SPREAD RATES (mil thickness)

Metal (non bridges) -8 mils wet / 4 mils dry

Concrete -10 mils wet / 5 mils dr

Wood -8 mils wet $/ 4$ mils dry

LIMITATION OF LIABLLITY: The information contained in this data sheet is based upon testes that we believe to be accurate and is intended for guidance only. All recommendations or suggestions relating to the use of the products made by SPI, whether in technical documentation, or in response to a specific enquiry, or otherwise, information are designed for users having the requisite knowledge and industrial skills. and the end-user has the responsibility to deternine the suitability of the product for its intended use.

SPI las no control over either the quality of condition of the substrate, or the many factors affecting the use and application of the product. Therefore, SPI does not accept any liability arising from loss, injury, or damage resulting from such use or the contents of his data sicen (miless ther o

The information contained in this data sheet is subject to modification as a result of practical experience and continuous product development. This data shect replaces and current prior to using the product. 


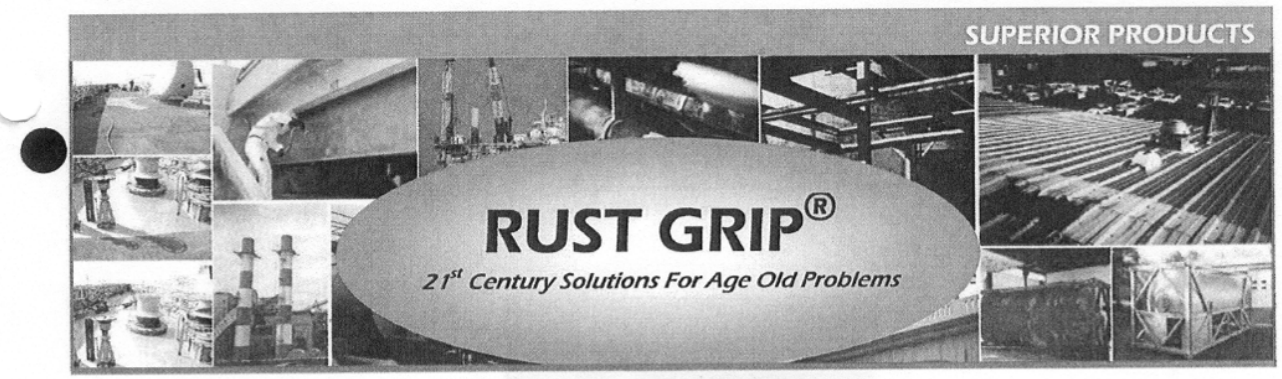

Application Instructions ${ }_{(00 / 16 / 06)}$

Rust Grip ${ }^{*}$ is a one-part, moisture-cured polyurethane that can be used as a primer, topcoat or encapsulant. It can be applied to metal, concrete, masonry and wood.

\section{SURFACE PREPARATION}

New construction (metal, concrete, masonry and wood):

1) Power wash surface $(3,500 \mathrm{psi})$ with citrus cleaner to remove dirt, oil tar, grease and film. In coastal areas, Chlor-Rid should replace the citrus cleaner.

2) Surface must be completely dry (if surface moisture persists, wipe down with Acetone prior to application).

NOTE: Flash rust on the substrate surface will not hinder the adhesion strength of Rust Grip ${ }^{*}$. Rust Grip ${ }^{* 6}$ can be applied directly over flash rust when completely dry.

Previously coated (metal, conerete, masonry and composite):

1) Power wash surface $(3,500 \mathrm{psi})$ with citrus cleaner to remove oose or flaking paint, and to clean the surface of dirt, oil, tar, grease and film. Chlor-Rid should also be used to remove salts.

2) Wipe down with Acetone to remove any loose particles and to completely dry the surface.

3) Surface must be completely dry before applying the coating.

4) If existing coating surface is glossed, sanding or roughing the surface must be done before application—no glossed surface.

NOTE: If pack rust, scale or bright glossy surfaces exist, they must be removed by grit blast, power tool or needle gun. Once removed, begin with Step 1 (power wash).

MIXING

1) Rust Grip can be mixed by hand or with a power drill using low

2) When the container is opened, the coating will be a yellowish green color. Mix continuously (no vortex) until the entire surface of the coating turns a silver gray color. Once the coating color has turned completely, mix for two more minutes making sure the paste is off of the bottom. (Metallics are visible when the coating is stirred properly.)

NOTE: Once container is opened, the product must be used or repackaged and sealed well in an unlined metal can. If left open, the product will harden in the container.

\section{POT LIFE}

Four hours at $70 \mathrm{~F}$. degrees, $60 \%$ humidity or higher.

TEMPERATURE

1) Store between $30 \mathrm{~F}$. and $100 \mathrm{~F}$. degrees according to hazmat

standards indicated on MSDS

2) Apply between $30 \mathrm{~F}$. and $100 \mathrm{~F}$. degrees.
APPLICATION

1) Rust Grip can be applied by brush (soft bristle), roller (1/4 inch nap) or spray (use a standard airless sprayer-3,000 psi or less-with a .015 tip).

2) In all applications (brush, roller or spray), use the cross-hatch method (side-to-side, then top-to-bottom) slowly to prevent pinholes.

3) If spraying, use half-speed and cross hatch to insure proper (I) spraying.

4) In all applications (brush, roller or spray), use the cross-hatch method (side-to-side, then top-to-bottom) slowly to prevent pinholes.

5) If encapsulating rust, lead-based paint, other bio-hazardous materials or bridges, brushing is the preferred application method. Apply the first coat by brush (keeping it very wet at all times), using the cross-hatch method. Go about 30 feet the return to the beginning and apply a second coat identical to the first. This method will insure the coating is worked into the pores and fully encapsulates the existing surface, while leaving enough coating over the surface to avoid pinholes.

6) Overcoat with Rust Grip ${ }^{*}$ or other coatings immediately after surface is dry to the touch to achieve proper adhesion. Higher emperatures and humidity will shorten curing times, lowe emperatures will slow curing. Must be overcoated within 2 hours or within 1 hour after reaching the dry-to-touch stage, or the surface must be lightly sanded to achieve good adhesion.

NOTE: The number of coats necessary and the thickness of each will be in accordance with the job specifications.

CURE TIME

1) Two hours to touch at $70 \mathrm{~F}$. degrees.

2) Fully cures in thirty days.

3) After three weeks, the coating will have a surface tensile strength of $6,750 \mathrm{psi}$. That number could easily double after four months.

CLEAN-UP EQUIPMENT

1) If breaks are taken, spray systems should be flushed with solvent.

2) After completion, spray system should be flushed and cleancd with solvent.

3) After completion, brushes and rollers should be discarded. 


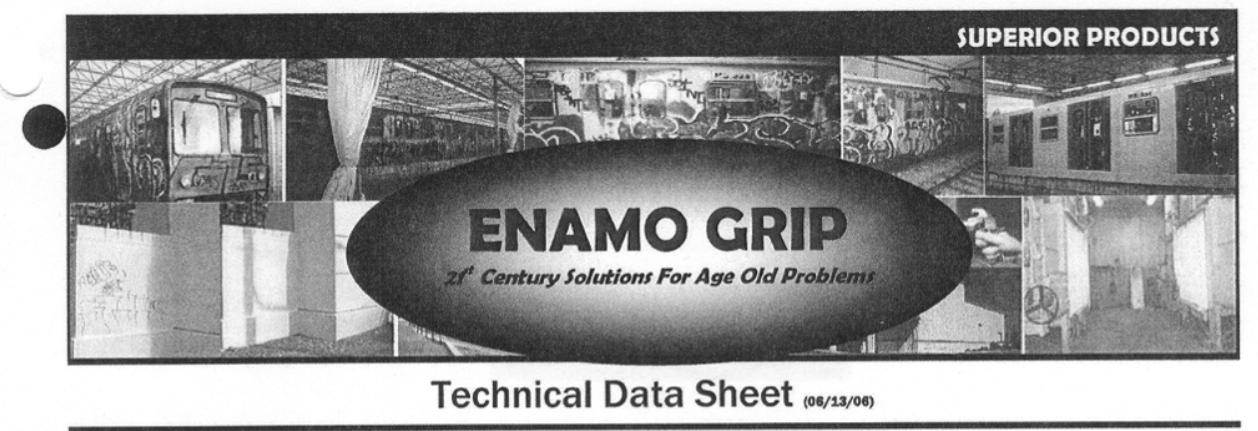

DESCRIPTION

ENAMO GRIP is a two-part polyurethane enamel that forms a uniquely hard and durable coating film, which demonstrates unsurpassed semi-gloss retention, color retention and chalk resistance when used in exterior applications. It is resistant to water and humidity, stains, acids, solvents, and chemicals, as well as having and impact resistance.

Although available in colors, ENAMO GRIP (Clear) provides exceptional graffiti resistance and protection. Krylon spray paints, magic markers, etc. can be removed completely with SPI's GRAFFIT CLEANER. ENAMO GRIP can withstand repeated incidents of graffiti removal as it is resistant to solvents. It can provide tremendous cost savings by eliminating blasting and re-painting of graffiti affecter surfaces on trains, buses, trams, and buildings.

The formula of resins in ENAMO GRIP will spread and self-level into an even, and smooth finish. No brush marks when applied by brush.

\section{TYPICAL USES}

$>$ For architectural and maintenance solutions that require the utmost

$>$ As a topcoat for RUST GRIP* and MOIST METAL GRIP;

$>$ As a coating system for graffiti protection;

As a floor covering where a tough, long-lasting finish is required. The coating has non-skid characteristics built into the formulation; $>$ Anywhere that a UV-resistant topcoat is required.

\section{APPLICATION METHODS}

ENAMO GRIP can be applied to metal, concrete, masonry, wood and other porous surfaces. The application can be by spray, brush or roller. For specific instructions on surface preparation, mixing an application, please refer to the SPI's application instructions for ENAMO GRIP.

MINIMUM SPREAD RATE (mil thickness

Metal: Apply at $250 \mathrm{sq}$ ftgallon

6.5 mils wet $/ 3$ mils dry

Concrete, Masonry: Apply two coats @ 200 sq ft/gal each coat

8 mils wet / 3.67 dry mils dry

\section{TESTS AND CERTIFICATIONS}

1) USDA Approved

2) Marine Approval for Salt Water/Maritime Uses $>$ US Coast Guard

ABS (American Bureau of Shipping)

IMO (International Marine Organization)

3) Flame Spread (ASTM E84) Class A Fire Rating

4) Abrasion (ASTM D4060)
FEATURES

- Solids: By volume: $45.9 \%$ By weight: $60.0 \%$

- Dry Time: One hour to touch, overcoat window is three hours, or longer

- Lead- and Chromate-free

- Cures by moisture in the air and heat reactivity

- Weight: $9.8 \mathrm{lbs}$ per gallon

- Vehicle Type: Aliphatic Polyurethane

- Shelf Life: Up to three years (unopened) under appropriate storag

conditions (See MSDS)

- VOC: Clear finish - 554 grams per liter, Color finish will range

between 446-526 grams per liter

- Impact Resistance: (Front) 160 psi / (Back) 100 psi

- Impact Resistance: (Front) $160 \mathrm{psi} /$ (Back) 100 pax Ratio: 1 part curing agent to 3 parts base

- Mix Ratio: 1 part curing agent to 3 parts base

- Pot Life: Four hours at 70F. degrees / One hour at 90 F. degrees

If temperature excecds

- Colors available with established minimum quantities

\section{SAFETY PRECAUTIONS}

Do not use this product without first taking all Do not use this product without first taking all appropriate safety measures to prevent property damage and injuries. These measures may include, without limitation: proper ventilation, use of proper lamps, wearing of protective clothin and masks, tenting and proper separation of application areas. Thi coating is flammable. Keep away from flame, fire, or other sources of ignition. For more specific safety procedures, please refer to the ENAMO GRIP Materials Safety Data Sheel. KEEP OUT OF REACH OF CHILDREN.

LIMITATION OF LIABILITY: The information contained in this data sheet is based upon tests that we believe to be accurate and is intended for guidance only.

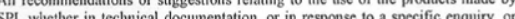
otherwise, are based on data which to the best of our knowledge is reliable. The products and information are designed for users laving the requisite knowiledge and industrial skills, and the end-user has the responsibility to determine the suitability of the product for its intended use.

SPI has no control over either the quality of condition of the substrate, or the many factors affecting the use and application of the product. Therefore, SPI does nol Whe ant tits of this data sheet (umless there are written agrements stating otherwise).

The information contained in this data sheet is subject to modification as a result of practical experience and continuous product development. This data sheet replaces and

annuls all previous issues and the user has the responsibility to ensure that this sheet is current prior to using the product. 


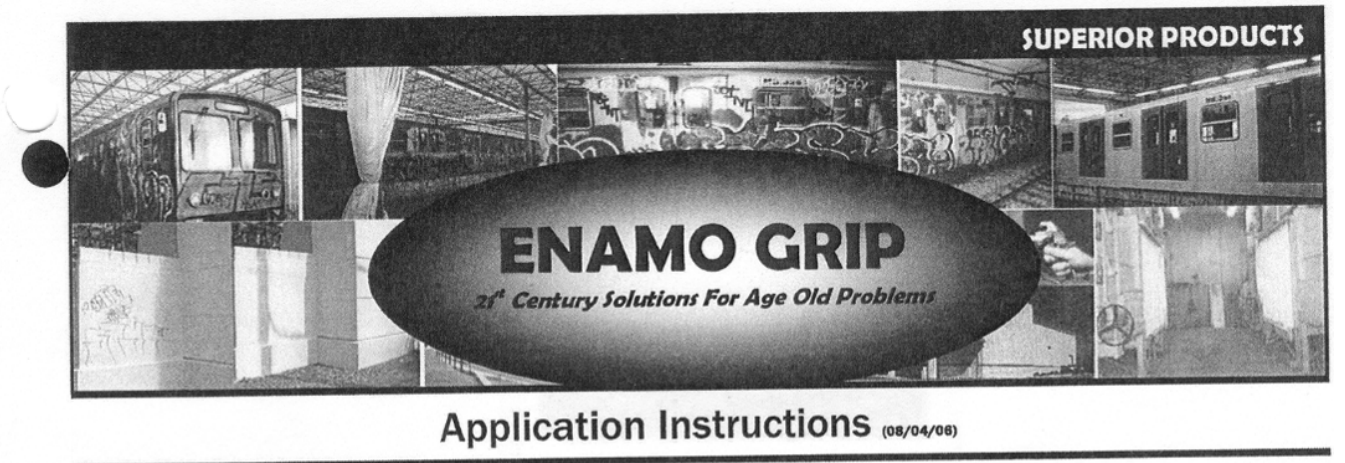

Enamo Grip is a two-part polyurethane enamel that forms a uniquely hard and durable coating film. This self-leveling coating is resistant to water, acids, solvent and impact. Enamo Grip is a one-coat system. Enamo Grip can be applied to metal, concrete, masonry and wood.

\section{SURFACE PREPARATION}

As a topcoat:

1) Surface must be clean and free of oil, tar, grease and film.

2) Surface must be completely dry before applying.

3) Enamo Grip must be applied during the prescribed overcoat window of the coating to which it will be applied.

4) If applied over an existing coating and this coating is glossed, it must be sanded and roughed before application, no gloss.

Can be applied as a one-coat system for graffiti protection (Enamo Grip in clear finish only).

MIXING

1) Open pail, mix base with curing agent 3:1 ratio

2) Mix by hand for two minutes.

3) If below $70 \mathrm{~F}$. degrees, allow to stand for 30 minutes.

4) Begin application; however, do not apply in direct sunlight. During the summer months, apply the coating in the morning or after 4:00 p.m.

\section{POT LIFE}

Four hours at $70 \mathrm{~F}$. degrees; two hours at $90 \mathrm{~F}$. degrees, once base and curing agent have been mixed.

\section{TEMPERATURE}

1) Apply between $40 \mathrm{~F}$. and $120 \mathrm{~F}$. degrees.

2) Store between $40 \mathrm{~F}$. and $120 \mathrm{~F}$. degrees according to hazmat standards indicated on MSDS.

\section{APPLICATION}

Enamo Grip can be applied by brush, roller or spray; however, the preferred method is by brush or roller:

1) If application is by brush, use a soft bristle brush.

2) If application is by roller, use a $1 / 4$ inch nap roller. Then use a brush any trapped air bubbles, if any.

3) If application is by spray, use a standard airless sprayer ( 2,800 psi or less) with a .024 tip.

NOTE: The number of coats and the thickness of each will be in accordance with the job specifications.

MINIMUM SPREAD RATES (mil thickness)

Porous Surfaces - Apply in 2 coats at $200 \mathrm{sq} \mathrm{ft}$ per gallon at 8 mils wet/3.67 mils dry.

Non-Porous Surfaces - Apply at $250 \mathrm{sq} \mathrm{ft}$ per gallon at 6.5 mils wet $/ 3$ mils dry.

\section{CURE TIME}

1) One hour to touch at $70 \mathrm{~F}$. degrees.

2) Overcoating window is three hours at $70 \mathrm{~F}$. degrees or longer.

3) Fully cures in ten days.

4) If temperature is over $90 \mathrm{~F}$. degrees, cure time and pot life is shortened to one hour.

\section{CLEAN-UP EQUIPMENT}

1) During breaks, spray system should be flushed with solvent.

2) After completion, spray systems should be flushed and cleaned with MEK or other comparable solvents.

3) After completion, brushes and rollers should be cleaned with MEK or other comparable solvents, stored and reused. 


\section{Appendix C: Economic Analysis of Overcoating and Smart Coatings}

\section{Assumptions and calculations}

\section{Overcoating versus repainting}

Four separate cost scenarios are presented assuming varying maintenance intervals and remaining structure service life. Costs are calculated on a total net present value (NPV) basis to reflect the true life-cycle cost of overcoating versus repainting a structure with pre-existing lead-based paint.

Alternative 1: Overcoating technology is implemented on steel structures at a cost of $\$ 2 / \mathrm{ft}^{2}$. The overcoat lasts 10 years and then must be repeated at 10 year intervals until the structure needs to be recoated at 30 years. The cost of overcoating is compared to repainting the structure at $\$ 10 / \mathrm{ft}^{2}$. The repainted structure must be touched up after 21 years $\left(\$ 0.50 / \mathrm{ft}^{2}\right)$ and again at 26 years $\left(\$ 1.00 / \mathrm{ft}^{2}\right)$. The structure is recoated entirely after 34 years. The remaining life of the structure is 50 years. Total NPV is calculated for each scenario and compared to determine a cost ratio of 2.19.

Alternative 2: Overcoating technology is implemented on steel structures at a cost of $\$ 2 / \mathrm{ft}^{2}$. The overcoat lasts 10 years and then must be repeated at 10 year intervals. The cost of overcoating is compared to repainting the structure at $\$ 10 / \mathrm{ft}^{2}$. The repainted structure must be touched up after 21 years $\left(\$ 0.50 / \mathrm{ft}^{2}\right)$ and again at 26 years $\left(\$ 1.00 / \mathrm{ft}^{2}\right)$. The remaining life of the structure is 30 years. Total NPV is calculated for each scenario and compared to determine a cost ratio of 2.89 .

Alternative 3: Overcoating technology is implemented on steel structures at a cost of $\$ 2 / \mathrm{ft}^{2}$. The overcoat lasts 15 years and then must be repeated at 15 year intervals until the structure needs to be repainted at 45 years. The cost of overcoating is compared to repainting the structure at $\$ 10 / \mathrm{ft}^{2}$. The repainted structure must be touched up after 21 years $\left(\$ 0.50 / \mathrm{ft}^{2}\right)$ and again at 26 years $\left(\$ 1.00 / \mathrm{ft}^{2}\right)$. The structure is recoated entirely after 34 years. The remaining life of the structure is 50 years. Total NPV is calculated for each scenario and compared to determine a cost ratio of 3.30. 
Alternative 4: Overcoating technology is implemented on steel structures at a cost of $\$ 2 / \mathrm{ft}^{2}$. The overcoat lasts 15 years and then must be repeated at 15 year intervals. The cost of overcoating is compared to repainting the structure at $\$ 10 / \mathrm{ft}^{2}$. The repainted structure must be touched up after 21 years $\left(\$ 0.50 / \mathrm{ft}^{2}\right)$ and again at 26 years $\left(\$ 1.00 / \mathrm{ft}^{2}\right)$. The remaining life of the structure is 30 years. Total net present value is calculated for each scenario and compared to determine a cost ratio of 3.75 .

\begin{tabular}{|c|c|c|c|c|}
\hline \multicolumn{5}{|c|}{ rernative } \\
\hline \multicolumn{5}{|c|}{ Repainting Scenario } \\
\hline \multicolumn{5}{|c|}{ Remaining Structural Life is 50 years } \\
\hline \multicolumn{5}{|c|}{ Mild Exposure Environment } \\
\hline & Current & NFV & NPV & Year \\
\hline repaint & $\$ 10.00$ & $\$ 10.00$ & $\$ 10.00$ & 0 \\
\hline touchup & $\$ 0.50$ & $\$ 0.93$ & $\$ 0.13$ & 21 \\
\hline touchup & $\$ 1.00$ & $\$ 2.16$ & $\$ 0.18$ & 26 \\
\hline repaint & $\$ 5.00$ & $\$ 13.66$ & $\$ 0.53$ & 34 \\
\hline TNPV & & & $\$ 10.84$ & \\
\hline
\end{tabular}

Overcoating Scenario

Remaining Structural Life is 50 years

Mild Exposure Environment

Overcoat Life is 10 years

$\begin{array}{lllll} & \text { Current } & \text { NFV } & \text { NPV } & \text { Year } \\ \text { overcoat } & \$ 2.00 & \$ 2.00 & \$ 2.00 & 0 \\ \text { overcoat } & \$ 2.00 & \$ 2.69 & \$ 1.04 & 10 \\ \text { overcoat } & \$ 2.00 & \$ 3.61 & \$ 0.54 & 20 \\ \text { repaint } & \$ 10.00 & \$ 24.27 & \$ 1.39 & 30 \\ \text { TNPV } & & & \$ 4.96 & \\ \text { CR=2.19 } & & & & \end{array}$

\section{Overcoating Scenario}

Remaining Structural Life is 30 years

Mild Exposure Environment

Overcoat Life is 10 years

$\begin{array}{lllll} & \text { Current } & \text { NFV } & \text { NPV } & \text { Year } \\ \text { overcoat } & \$ 2.00 & \$ 2.00 & \$ 2.00 & 0 \\ \text { overcoat } & \$ 2.00 & \$ 2.69 & \$ 1.04 & 10 \\ \text { overcoat } & \$ 2.00 & \$ 3.61 & \$ 0.54 & 20 \\ \text { TNPV } & & & \$ 3.57 & \end{array}$

$\mathrm{CR}=\mathbf{2 . 8 9}$ 
Alternative 3

Repainting Scenario

Remaining Structural Life is 50 years

Mild Exposure Environment

$\begin{array}{lllll} & \text { Current } & \text { NFV } & \text { NPV } & \text { Year } \\ \text { repaint } & \$ 10.00 & \$ 10.00 & \$ 10.00 & 0 \\ \text { touchup } & \$ 0.50 & \$ 0.93 & \$ 0.13 & 21 \\ \text { touchup } & \$ 1.00 & \$ 2.16 & \$ 0.18 & 26 \\ \text { repaint } & \$ 5.00 & \$ 13.66 & \$ 0.53 & 34 \\ \text { TNPV } & & & \$ 10.84 & \end{array}$

Overcoating Scenario

Remaining Structural Life is 50 years

Mild Exposure Environment

Overcoat Life is 15 years

$\begin{array}{lllll} & \text { Current } & \text { NFV } & \text { NPV } & \text { Year } \\ \text { overcoat } & \$ 2.00 & \$ 2.00 & \$ 2.00 & 0 \\ \text { overcoat } & \$ 2.00 & \$ 3.12 & \$ 0.75 & 15 \\ \text { overcoat } & \$ 2.00 & \$ 4.85 & \$ 0.28 & 30 \\ \text { repaint } & \$ 5.00 & \$ 18.91 & \$ 0.26 & 45 \\ \text { TNPV } & & & \$ 3.28 & \end{array}$

$\mathrm{CR}=3.30$
Alternative 4

Repainting Scenario

Remaining Structural Life is 30 years

Mild Exposure Environment

$\begin{array}{lllll} & \text { Current } & \text { NFV } & \text { NPV } & \text { Year } \\ \text { repaint } & \$ 10.00 & \$ 10.00 & \$ 10.00 & 0 \\ \text { touchup } & \$ 0.50 & \$ 0.93 & \$ 0.13 & 21 \\ \text { touchup } & \$ 1.00 & \$ 2.16 & \$ 0.18 & 26 \\ \text { TNPV } & & & \$ 10.31 & \end{array}$

Overcoating Scenario

Remaining Structural Life is 30 years

Mild Exposure Environment

Overcoat Life is 15 years

$\begin{array}{lllll} & \text { Current } & \text { NFV } & \text { NPV } & \text { Year } \\ \text { overcoat } & \$ 2.00 & \$ 2.00 & \$ 2.00 & 0 \\ \text { overcoat } & \$ 2.00 & \$ 3.12 & \$ 0.75 & 15 \\ \text { TNPV } & & & \$ 2.75 & \end{array}$

$\mathrm{CR}=3.75$

\section{Smart coating versus standard coatings}

It is difficult to quantify the potential savings of improved application and acceptance inspection as well as periodic inspection. However, significant cost savings can be expected. An example which can be used to illustrate the costs related to smart coatings versus standard coatings is potable water tanks. The design life of coating systems for lining potable water storage tanks is 40-years for a two coat epoxy system. Owners are inured to 
accepting service lives of just 10 to 15 years. In other words there is a great disparity between the service received and the potential service of the coating. Improved inspection can go a long way towards narrowing that gap. Two alternative scenarios are considered.

Alternative 1: Smart fluorescing coatings are installed to the inside of a water tank with another 40 years of expected use. The tank needs to be relined every 15 years using standard coatings, but only every 40 years with smart coatings. The installed costs of smart coatings and standard coatings are $\$ 8.67 / \mathrm{ft}^{2}$ and $\$ 7.63 / \mathrm{ft}^{2}$ respectively. Total net present value is calculated for each scenario and compared to calculate a cost ratio of 1.21.

Alternative 2: Smart self-healing coatings are installed to the exterior of a pipe with another 30 years of expected service. Smart coatings are touched up after 21 years $\left(\$ 0.50 / \mathrm{ft}^{2}\right)$ and 26 years $\left(\$ 1.00 / \mathrm{ft}^{2}\right)$. Standard coatings are applied and need to be replaced every 12 years and are touched up once at 9 years $\left(\$ 1 / \mathrm{ft}^{2}\right)$. The installed costs of smart coatings and standard coatings are $\$ 8.67 / \mathrm{ft}^{2}$ and $\$ 7.63 / \mathrm{ft}^{2}$ respectively. The cost of microcapsules is assumed to be just $10 \%$ of the current market cost. Total net present value is calculated for each scenario and compared to calculate a cost ratio of 1.30 . 


\section{C2. Smart coatings versus standard coatings Cost Ratio(CR).}

\section{Alternative 1}

Standard Paints Scenario

Remaining Structural Life is 40 years

Water Tank Interior

Standard Coating Life is 15 years

$\begin{array}{lllll} & \text { Current } & \text { NFV } & \text { NPV } & \text { Year } \\ \begin{array}{lllll}\text { paint } \\ \# 1\end{array} & \$ 7.63 & \$ 7.63 & \$ 7.63 & 0 \\ \begin{array}{l}\text { paint } \\ \# 2\end{array} & \$ 7.63 & \$ 11.89 & \$ 2.85 & 15 \\ & & & & \\ \text { TNPV } & & & \$ 10.48 & \end{array}$

\section{Smart Coatings Scenario}

Remaining Structural Life is 40 years

Water Tank Interior

Smart Coating Life is 40 years

$\begin{array}{lllll} & \text { Current } & \text { NFV } & \text { NPV } & \text { Year } \\ \text { smart } & & & & \\ \# 1 & \$ 8.67 & \$ 8.67 & \$ 8.67 & 0 \\ & & & & \\ \text { TNPV } & & & \$ 8.67 & \end{array}$

$\mathrm{CR}=1.21$

\section{Alternative 2}

Standard Paints Scenario

Remaining Structural Life is 30 years

Exterior of Pipe

Standard Coating Life is 12 years

$\begin{array}{lllll} & \text { Current } & \text { NFV } & \text { NPV } & \text { Year } \\ & & & & \\ \text { paint \#1 } & \$ 7.63 & \$ 7.63 & \$ 7.63 & 0 \\ & & & & \\ \text { touchup } & \$ 1.00 & \$ 1.30 & \$ 0.55 & 9 \\ & & & & \\ \text { paint \#2 } & \$ 7.63 & \$ 10.88 & \$ 3.47 & 12 \\ & & & & \\ \text { TNPV } & & & \$ 11.65 & \end{array}$

Smart Coatings Scenario

Remaining Structural Life is 30 years

Mild Exposure Environment

Overcoat Life is 10 years

$\begin{array}{lllll} & \text { Current } & \text { NFV } & \text { NPV } & \text { Year } \\ \begin{array}{lllll}\text { smart } \\ \# 1\end{array} & \$ 8.67 & \$ 8.67 & \$ 8.67 & 0 \\ \begin{array}{l}\text { touch } \\ \text { up }\end{array} & \$ 0.50 & \$ 0.93 & \$ 0.13 & 21 \\ \begin{array}{l}\text { touch } \\ \text { up }\end{array} & \$ 1.00 & \$ 2.16 & \$ 0.18 & 26 \\ \text { TNPV } & & & \$ 8.98 & \\ \text { CR }=1.30 & & & & \end{array}$




\section{Appendix D: Environmental, Health, and Safety Information}

\section{Environmental, health, and safety practices for overcoating}

Surface contaminants may be removed by power washing or hand washing. Power washing pressures should be limited such that substantial amounts of lead-containing paint are not removed. Wash water should be collected and tested for lead contamination. For elevated work or work over water, suspended netting may provide adequate environmental protection provided this practice is acceptable to local regulators. Hand washing minimizes the amount of waste generated and may be selected on this basis. Hand wash water is readily collected on ground tarps because of the relatively small volume.

Wash water exhibiting the hazardous characteristic must be disposed of as a hazardous waste. Filtering solids from the water may be sufficient to reduce the hazardous characteristic. Waste water from power washing averages $100-200$ gallons per $1,000 \mathrm{ft}^{2}$ of surface cleaned. Waste water from hand washing averages $10-20$ gallons per $1000 \mathrm{ft}^{2}$ of surface cleaned.

Vacuum-shrouded power tools are recommended for preparing corroded areas and to remove loose coating. Vacuum shrouds reduce worker exposure to lead-containing dust and reduce the chance of environmental releases. Ground tarps should be used with vacuum-shrouded tools.

Health and safety requirements are generally the same for overcoating projects as for other industrial maintenance painting projects and include fall protection, flammable liquid precautions, hearing conservation, eye protection, and respiratory protection. Additional requirements may be necessary depending on whether workers are exposed to lead above the action level during surface preparation activities. Half-face respirators with an Assigned Respiratory Factor (APF) of 10 are recommended for use during cleaning with vacuum assisted power tools. A greater degree of respiratory protection may be required if vacuum assist is not employed. Personal air monitoring (PAM) should be conducted at the outset of any project involving the removal of lead-containing paint to ensure that workers are adequately protected. 
Residual dust produced during power tool cleaning must be removed from the surface prior to overcoating. Wiping down surfaces with rags wet with water or solvent is recommended as it reduces worker exposures to leadcontaining dust. When solvents are used they should have a high flash point.

Table D1 summarizes the recommended environmental and worker protection practices.

Table D1. Summary of recommended worker health and environmental protection practices.

\begin{tabular}{|l|l|l|}
\hline Procedure & Environmental Protection & Worker Health Protection \\
\hline Contaminant Removal & $\begin{array}{l}\text { Collect wash and rinse waters on ground } \\
\text { tarps and test for lead. Filter water if } \\
\text { appropriate. } \\
\text { Use nets for debris collection as a } \\
\text { minimum for elevated work. }\end{array}$ & Hearing and eye protection \\
\hline Surface Preparation & Vacuum shrouded power tools & $\begin{array}{l}\text { Respirators with minimum APF } \\
\text { of 10. Hearing and eye } \\
\text { protection. }\end{array}$ \\
\hline Dust Removal & Wet rags to prevent dust dispersion & NA \\
\hline Overcoat Application & NA & $\begin{array}{l}\text { Respirators as necessary. Eye } \\
\text { protection. }\end{array}$ \\
\hline
\end{tabular}

Environmental, health, and safety practices for smart coatings

Health and safety requirements are generally the same for smart coating projects as for other industrial maintenance painting projects and include fall protection, flammable liquid precautions, hearing conservation, eye protection, and respiratory protection. Additional requirements would be necessary if workers were exposed to lead above the action level during surface preparation activities. Table D2 summarizes the recommended environmental and worker protection practices.

Table D2. Summary of recommended worker health and environmental protection practices.

\begin{tabular}{|l|l|l|}
\hline Procedure & Environmental Protection & Worker Health Protection \\
\hline Surface Preparation & $\begin{array}{l}\text { Abrasive blasting with ground and/or } \\
\text { suspended tarps }\end{array}$ & $\begin{array}{l}\text { Respiratory, hearing and eye } \\
\text { protection. }\end{array}$ \\
\hline Dust Removal & $\begin{array}{l}\text { Vacuum or blow down with ground and/or } \\
\text { suspended tarps }\end{array}$ & Respiratory and eye protection \\
\hline $\begin{array}{l}\text { Smart Coating } \\
\text { Application }\end{array}$ & $\begin{array}{l}\text { The applied coating meets established } \\
\text { standards for volatile organic content. }\end{array}$ & $\begin{array}{l}\text { Respirators as necessary. Eye } \\
\text { protection. Skin protection. }\end{array}$ \\
\hline
\end{tabular}




\section{Safety}

In accordance with the Manta Safety Program all employees were drug screened, fit tested for respiratory protection equipment and trained by the Manta competent person in the use of hazardous material MSDS and special equipment.

Safety Audits and Tool Box Safety meetings were conducted weekly by Manta Field and Office Supervision to evaluate potential risks and hazards (KARRS). These programs were conducted per Manta's Industrial Safety Program and Fort Bragg Safety Policy to eliminate potential accidents during normal work procedures. 


\title{
Appendix E: Suggested Implementation Guidance
}

\section{Proposed Draft UFGS language for overcoating}

\author{
SECTION 09900 \\ OVERCOATING
}

1. GENERAL

1.1 REFERENCES

The publications listed below form a part of this specification to the extent referenced. The publications are referred to in the text by basic designation only.

AMERICAN NATIONAL STANDARDS INSTITUTE (ANSI)

$\begin{array}{cl}\text { ANSI Z87.1 } & \begin{array}{l}\text { (1989; Errata; Z87.19; R 1999) } \\ \text { Occupational and Educational Eye } \\ \text { and Face Protection } \\ \text { (1990) Emergency Eyewash and } \\ \text { ANSI Z358.1 }\end{array} \text { AMERICAN SOCIETY FOR TESTING AND MATERIALS (ASTM) } \\ \text { (1995; R 1995) Mineral Spirits } \\ \text { ASTM D 235 }\end{array}$

40 CFR 262

Standards Applicable to Genera-

40 CFR 262.22

tors of Hazardous Waste

Number of Copies 
40 CFR 263

40 CFR 355

49 CFR 171, Subchapter C
Standards Applicable to Transporters of Hazardous Waste Emergency Planning and Notification Hazardous Materials Regulations

ENGINEERING MANUALS (EM) EM 385-1-1

(1996) U.S. Army Corps of Engineers Safety and Health Requirements Manual

NATIONAL FIRE PROTECTION ASSOCIATION (NFPA) NFPA 70 (1999) National Electrical Code

NATIONAL INSTITUTE FOR OCCUPATIONAL SAFETY AND HEALTH (NIOSH)

NIOSH Pub No. 98-119

(1998, $4^{\text {th }}$ Ed., $2^{\text {nd }}$ Supplement) NIOSH Manual of Analytical Methods

SSPC: THE SOCIETY FOR PROTECTIVE COATINGS (SSPC) SSPC Guide 6 (1997) Containing Debris Generated During Paint Removal operations

SSPC SP 1 (1982) Solvent Cleaning SSPC SP 3 (1982, Editorial Changes 1995) Power Tool Cleaning

1.2 LUMP SUM PRICE

1.2.1 Painting:

1.2.1.1 Payment

Payment will be made for costs associated with "Painting", which includes full compensation for furnishing all materials, equipment, and labor required to paint the deluge tank in accordance with this section.

1.2.1.2 Unit of Measure

Unit of measure: lump sum.

\section{3SUBMITTALS}

Government approval is required for submittals with a "G" designation; submittals having an "FIO" designation are for information only. The following shall be submitted:

SD-08 Statements

Qualifications and Experience; G.

The Contractor shall submit certification pursuant to paragraph QUALIFICATIONS for all job sites.

Accident Prevention Plan; G.

The Contractor shall submit an Accident Prevention Plan in accordance with the requirements of Section 01 of EM 385-1-1. The plan shall include, but is not limited to, each of the topic areas listed in Appendix A therein and the requirements of paragraph SAFETY AND HEALTH PROVISIONS; each topic shall be developed in a concise manner to include management and operational aspects. 
Respiratory Protection Program; G.

The Contractor shall submit a comprehensive written respiratory protection program in accordance with 29 CFR 1910.134, 29 CFR 1926.62, and Section 05.E of EM 385-1-1.

Medical Surveillance Plan; G. The Contractor shall submit a Medical Surveillance Plan as required in paragraph MEDICAL STATUS and provide a statement from the examining physician indicating the name of each employee evaluated and any limitations which will preclude the employee from performing the work required. The statement shall include the date of the medical evaluation, the physician's name, signature, and telephone number.

Worker Protection Plan; G.

The Contractor shall submit a Worker Protection Plan in accordance with the requirements of 29 CFR 1926.62. The plan shall address all necessary aspects of worker protection and shall include activities emitting lead, means to achieve compliance, alternative technologies considered, air monitoring program, implementation schedule, work practice program, administrative controls, multicontractor site arrangements, and jobsite inspections.

Environmental Compliance Plan; G. The Contractor shall submit an Environmental Compliance Plan. The submitted plan shall address all aspects of establishing and demarcating regulated areas, ventilation/containment system performance verification, and reporting of accidental releases.

Waste Classification, Handling, and Disposal Plan; G. The contractor shall submit a Waste Classification, Handling, and Disposal Plan in accordance with the requirements of 40 CFR 261 and 40 CFR 262 and paragraph Waste Classification, Handling, and Disposal.

Containment Plan; G.

The Contractor shall submit a plan for containing debris generated during paint removal operations in accordance with the requirements of paragraph Containment. The plan shall include drawings, load-bearing capacity calculations, and wind load calculations. 
Inspection and Operation Records; G.

The Contractor shall submit records of inspections and operations performed in accordance with paragraph INSPECTION. Submittals shall be made on a daily basis.

1.4 QUALIFICATIONS

Qualifications and experience shall comply with the following.

\subsubsection{Certified Professional}

The competent and qualified person shall have successfully completed an EPA or state accredited lead-based paint abatement Supervisor course specific to the work to be performed and shall possess current and valid state and/or local government certification, as required.

\subsection{SAFETY AND HEALTH PROVISIONS}

Work shall be performed in accordance with the requirements of 29 CFR 1910, 29 CFR 1926, EM 385-1-1, and other references as listed herein. Matters of interpretation of the standards shall be submitted to the contracting officer for resolution before starting work. Where the regulations conflict, the most stringent requirements shall apply. Paragraph SAFETY AND HEALTH PROVISIONS supplements the requirements of EM 385-1-1, paragraph (1). In any conflict between section 01 of EM 385-1-1 and this paragraph, the provisions herein shall govern.

\subsubsection{Cleaning with Solvents}

\subsubsection{Personal Protective Equipment}

Personal protective equipment shall be provided where required by 29 CFR 1910.146 and in accordance with 29 CFR 1910, subpart I.

\subsubsection{Paint Application}

\subsubsection{Ignition Sources}

Ignition sources, to include lighted cigarettes, cigars, pipes, matches, or cigarette lighters shall be prohibited in area of solvent cleaning, paint storage, paint mixing, or paint application.

\subsection{MEDICAL STATUS}

Prior to the start of work and annually thereafter, all contractor employees working with or around paint systems, thinners, blast media, those required to wear respiratory protective equipment, and those who will be exposed to high noise levels shall be medically evaluated for the particular type of exposure they may encounter. Medical records shall be maintained as required by 29 CFR 1910.20. For lead-based paint removal, the medical requirements of 29 CFR 1926.62 shall also be included.

\subsection{CHANGE IN MEDICAL STATUS}

Any employee whose medical status has changed negatively due to work related chemical and/or physical agent exposure while working with or around paint systems and thinners, blast media, or 
other chemicals shall be evaluated by a physician, and the Contractor shall obtain a physicians statement as described in paragraph MEDICAL STATUS prior to allowing the employee to return to those work tasks. The Contractor shall notify the contracting officer in writing of any negative changes in employee medical status and the results of the physician's reevaluation statement.

\subsection{ENVIRONMENTAL PROTECTION}

The Contractor shall comply with the following environmental protection criteria.

1.8.1 Waste Classification, Handling, and Disposal

The Contractor shall be responsible for assuring the proper disposal of all hazardous and nonhazardous waste generated during the project. Hazardous waste shall be placed in properly labeled closed containers and shall be shielded adequately to prevent dispersion of the waste by wind or water. Any evidence of improper storage shall be cause for immediate shutdown of the project until corrective action is taken. Nonhazardous waste shall be stored in closed containers separate from hazardous waste storage areas. All hazardous waste shall be transported by a licensed transporter in accordance with 40 CFR 263 and 49 CFR 171, Subchapter $\mathrm{C}$. All nonhazardous waste shall be transported in accordance with local regulations regarding waste transportation. In addition to the number of manifest copies required by 40 CFR 262.22, one copy of each manifest will be supplied to the Contracting officer prior to transportation.

\subsubsection{Containment}

The Contractor shall contain debris generated during paint removal operations in accordance with the requirements of SSPC Guide 6, Class 2P. The Contractor may use vacuum shrouded power tools and ground tarps in lieu of class 2P containment.

1.9 PAINT PACKAGING, DELIVERY, AND STORAGE

Paints shall be processed and packaged to ensure that within a period of one year from date of manufacture, they will not gel, liver, or thicken deleteriously, or form gas in the closed container. Paints, unless otherwise specified or permitted, shall be packaged in standard containers not larger than 5 gallons, with removable friction or lug-type covers. Paints that can be harmed by exposure to cold weather shall be stored in ventilated, heated shelters. All paints shall be stored under cover from the elements and in locations free from sparks and flames.

\section{PRODUCTS}

\subsection{Paints}

\section{MOISTURE CURE URETHANE OVERCOAT SYSTEM DESCRIPTION}




\section{Moisture Cure Polyurethane Overcoat System}

General Description. This paint system consists of commercially available moisture cure polyurethane primer, intermediate, and topcoat products containing solvent, pigment, and additives as necessary to meet the stated requirements. Products comprising a system shall all be produced by the same manufacturer. The topcoat shall be an aliphatic moisture cure polyurethane. Intermediate and topcoat paints shall be single pack products. Primers shall be either one or two pack products containing zinc or zinc and micaceous iron oxide. The system shall be suitable for overcoating aged alkyd coatings as well as properly prepared bare steel. Wide latitude is afforded the formulator provided the products meet the specified requirements. The paints shall not contain added lead, cadmium, chromium, or chlorinated solvents. The products shall be suitable for application at temperatures as low as $45^{\circ} \mathrm{F}$ and up to 95-percent relative humidity. Thinning shall be permitted up to a maximum of 10-percent by volume unless otherwise limited by the manufacturer.

Requirements. The coatings shall comply with the following requirements:

(1) Working Properties. The paints shall be readily applied by brush, roller, or spray when tested in accordance with FED-STD-141, Methods 4321, 4331, and 4541. The paints shall not streak, run, or sag during or after application.

(2) Dry Time. When applied at the manufacturer's maximum recommended dry film thickness and tested in accordance with ASTM D 1640, dry to recoat times shall not be greater than 4- and 6-hours for the primer and intermediate coats respectively and the topcoat shall dry setto-touch in not more than 2-hours. 
(3) Weight Solids Zinc. The percent zinc in the dried primer shall not be less than 60-percent by weight.

(4) Volume Solids. When determined in accordance with ASTM D 2697 the volume solids of intermediate and topcoat products shall not be less than 60-percent.

(5) Pot Life. Material applied from an open one gallon container maintained at $77^{\circ} \mathrm{F}$ and 40 - to 60-percent relative humidity shall meet the requirements of Working Properties after 3-hours.

(6) Flash Point. When determined in accordance with ASTM D 3278 the flash point of the paints shall not be less than $85^{\circ} \mathrm{F}$.

(7) Adhesion. When determined in accordance with ASTM D 3359 Method B the adhesion of the untopcoated primer shall be $5^{\mathrm{B}}$.

(8) Gloss. When determined in accordance with ASTM D 523 the 6o-degree specular gloss of the topcoat shall be 20 to 50 units (semigloss) or 50 to 85 units (gloss).

(9) VOC. When determined in accordance with EPA Method 24 the maximum VOC as supplied and thinned shall by 340 and $420 \mathrm{~g} / \mathrm{L}$ respectively.

(10) Color. The topcoat color shall conform to the specified FEDSTD-595 color number or other color as specified on the schedule.

(11) Corrosion Resistance. When tested in accordance with the following protocol the test panels coated with the system shall show no blistering or rust when evaluated in accordance with ASTM D 714 and D 610 respectively. The upper limit of the mean maximum undercutting at the $95 \%$ confidence level shall not be greater than $4.0 \mathrm{~mm}$. 
(a) Test Panel Preparation. Test panels shall be ASTM A 36 steel measuring $3 \times 6 \times 0.125$ inches. Prior to applying the paint systems the test panels shall be solvent and blast cleaned in accordance with SSPCSP 1 and SP 5. A nonmetallic blast media shall be used to impart an angular profile of between 1.5 and 2.5 mils.

(b) Paint Application. The coatings shall be spray applied using the manufacturer's recommended equipment and application parameters. Unless otherwise designated by the manufacturer the dry time between coats shall be 24 hours.

(c) Coating Thickness. Dry film thicknesses shall be measured and recorded for each coat of paint on each test panel using a magnetic dry film thickness gage calibrated and used in accordance with ASTM D 1186. Unless otherwise specified the average dry film thickness of each coat on each panel shall be the manufacturer's recommended thickness \pm $20 \%$. For coatings with a recommended dry film thickness range, the manufacturer's recommendation shall be assumed to be the median of the range. Test panels not meeting the dry film requirements shall not be used.

(d) Drying. Coated test panels shall be allowed to air dry under standard laboratory conditions for a minimum of 7 days prior to testing.

(e) Scribing. Prior to exposure, two scribes each six centimeters long shall be made through the coating to the substrate at 45-degrees to the long axis of the test panels. The scribes shall be equally spaced from each other and from the edges of the panels such that they are centered on the upper and lower halves of the panels. Scribing shall be performed with the tool specified in ASTM D1654. 
(f) Cyclic Corrosion Testing. The corrosion resistance of the coating system shall be evaluated by ASTM D 5894. Test panels shall be exposed in the UV exposure cabinet to begin the first cycle. Triplicate panels for each coating system shall be exposed for a total of 2688 hours.

(g) Test Panel Evaluation and Data Reporting. Each test panel shall be evaluated at the end of the specified exposure period for rusting, blistering, and undercutting at the scribe in accordance with ASTM D 610, D 714, and D 1654 respectively, except that for undercutting the coating shall be completely removed adjacent to the scribe to the extent that it is necessary to reveal the entire area subject to undercutting. Degree of rusting, blister size, density and location, and maximum undercutting on each side of each scribe shall be reported for each test panel.

\subsection{THINNERS}

Thinner shall be as specified by the coating manufacturer.

\section{EXECUTION}

\subsection{CLEANING AND PREPARATION OF SURFACES TO BE PAINTED}

3.1.1 Cleaning of Surfaces

All surfaces to be painted shall be cleaned before applying paint. Cleaning shall be performed by hand scrubbing surfaces using a solution of detergent and household bleach in water applied with an abrasive pad. Surfaces are adequately clean when all surface dirt and most staining is removed. The scrubbed surfaces then shall be rinsed with clean potable water.

\subsubsection{Preparation of Surfaces}

After cleaning, surfaces that will be coated with PAINTING SYSTEM A shall be power tool cleaned in accordance with the requirements of SSPC-SP 3. Only areas with visible corrosion or loose paint must be power tool cleaned. The surfaces to be power tool cleaned (approximately 2000 square feet) have an SSPC VIS 2 rust rating of 5G (a general distribution of rust over 1- to 3percent of the surface).

\subsubsection{Solvent Clean}

After cleaning and preparation all surfaces shall be solvent cleaned in accordance with SSPC-SP 1 using mineral spirits or other low toxicity solvents having a flash point above 100 degrees F. Clean cloths and clean fluids shall be used. 


\subsubsection{General}

The finished coating shall be free from holidays, pinholes, bubbles, runs, drops, ridges, waves, laps, excessive or unsightly brush marks, and variations in color, texture, and gloss. Each paint coat shall be applied in a manner that will produce an even, continuous film of uniform thickness. Edges, corners, crevices, seams, joints, welds, rivets, corrosion pits, and other surface irregularities shall receive special attention to ensure that they receive an adequate thickness of paint.

\subsubsection{Mixing and Thinning}

Paints shall be thoroughly mixed, strained where necessary, and kept at a uniform composition and consistency during application. Where necessary to suit conditions of the surface temperature, weather, and method of application, the paint may be thinned immediately prior to use, using the type and quantity of thinner recommended by the coating manufacturer. Paint that has deteriorated in any manner to a degree that it cannot be restored to essentially its original condition by customary fieldmixing methods shall not be used and shall be removed from the project site.

\subsubsection{Atmospheric and Surface Conditions}

Paint shall be applied only to surfaces that are above the dew point temperature and that are completely free of moisture as determined by sight and touch. Paint shall not be applied to surfaces upon which there is detectable frost or ice. Except as otherwise specified, the temperature of the surfaces to be painted and of air in contact therewith shall be not less than 20 degrees $F$ during paint application nor shall paint be applied if the surfaces can be expected to drop to 20 degrees $F$ or lower before the film has dried to a reasonably firm condition. Paint shall not be applied to surfaces heated by direct sunlight or other sources to temperatures that will cause detrimental blistering, pinholing, or porosity of the film.

\subsubsection{Time between Surface Preparation and Painting}

Surfaces that have been cleaned and/or otherwise prepared for painting shall be primed as soon as practicable after such preparation has been completed but, in any event, prior to any deterioration of the prepared surface.

\subsubsection{Method of Paint Application}

Paint shall be applied by brush and roller. Special attention shall be directed toward ensuring adequate coverage of edges, corners, crevices, welds, and similar surface irregularities.

\subsubsection{Coverage and Film Thickness}

Wet film thickness or spreading rates for each coat shall be as specified by the coating manufacturer.

\subsubsection{Progress of Painting Work}

Where field painting on any type of surface has commenced, the complete painting operation, including prime and finish coats, on that portion of the work shall be completed as soon as practicable, without prolonged delays. Sufficient time shall elapse 
between successive coats to permit them to dry properly for recoating, and this period shall be modified as necessary to suit adverse weather conditions. Paint shall be considered dry for recoating when it feels firm, does not deform or feel sticky under moderate pressure of the finger, and the application of another coat of paint does not cause film irregularities such as lifting or loss of adhesion of the undercoat. All coats of all painted surfaces shall be unscarred and completely integral at the time of application of succeeding coats.

3.2.8 Protection of Unpainted Surfaces

Walls, equipment, fixtures and all other items in the vicinity of the surfaces being painted shall be maintained free from damage by paint or painting activities. Paint spillage and painting activity damage shall be promptly repaired.

\subsection{INSPECTION}

The Contractor shall inspect, document, and report all work phases and operations on a daily basis. As a minimum the daily report shall contain the following:

a. Inspections performed, including the area of the structure involved and the results of the inspection.

b. Surface preparation operations performed, including the area of the structure involved, the mode of preparation, the kinds of solvent, and power tools employed, and whether contract requirements were met.

c. Thinning operations performed, including thinners used, and thinner/paint volume ratios.

d. Application operations performed, including the area of the structure involved, mode of application employed, ambient temperature, substrate temperature, dew point, relative humidity, type of paint with batch numbers, elapsed time between surface preparation and application, elapsed time for recoat, condition of underlying coat, number of coats applied, and if specified, measured dry film thickness or spreading rate of each new coating.

\subsection{PAINTING SCHEDULES}

MCU OVERCOAT SYSTEM

Items or surfaces to be coated:

SURFACE

PREPARATION TOPCOAT

SP 3 Power Tool Cleaning Topcoat

\section{PRIMER INTERMEDIATE}

MCU Primer MCU Intermediate MCU 


\section{Proposed draft UFGS language for fluorescing coating}

Note: Fluorescing coating technology should be incorporated into UFGSo9 9713.16 (January 2007) INTERIOR COATING OF WELDED STEEL WATER TANKS and UFGS-09 97 13.17 (January 2007) THREE COAT EPOXY INTERIOR COATING OF WELDED STEEL PETROLEUM FUEL TANKS. The text in bold type is intended to supplement the information contained in the existing documents without the deletion of any existing test.

USACE / NAVFAC / AFCESA / NASA UFGS-09 9713.16 (January 2007)

Preparing Activity: NAVFAC Superseding

UFGS-09 9713.16 (July 2006)

UNIFIED FACILITIES GUIDE SPECIFICATIONS

References are in agreement with UMRL dated January 2008

SECTION TABLE OF CONTENTS

DIVISION 09 - FINISHES

SECTION 099713.16

INTERIOR COATING OF WELDED STEEL WATER TANKS

$$
\text { 01/07 }
$$

2.2 COATING SYSTEM

$* * * * * * * * * * * * * * * * * * * * * * * * * * * * * * * * * * * * * * * * * * * * * * * * * * * * * * * * * * *$

NOTE: Include bracketed text for new construction only.

$* * * * * * * * * * * * * * * * * * * * * * * * * * * * * * * * * * * * * * * * * * * * * * * * * * * * * * * * * * *$ 
Alternate systems or products will not be considered. All primer, intermediate, and topcoat materials shall be manufactured by one manufacturer. [The entire coating system is intended to be applied in the field. Alternatively, surface preparation may be accomplished in the shop, following all temperature, humidity, and testing requirements listed herein, followed by an application of a hold-primer. Upon completion of field fabrication, all shop-applied coatings shall be removed, surfaces prepared to SSPC SP 10, and the specified coating system applied. Adjust all shop preparation to avoid conflicts with final surface preparation requirements.]

[2.2.1 NSF Certified Polyamide Epoxy Coating System][2.2.2 MIL-DTL24441 Epoxy System for Potable Water Tanks]

$* * * * * * * * * * * * * * * * * * * * * * * * * * * * * * * * * * * * * * * * * * * * * * * * * * * * * * * * * * * * * * * * * *$

NOTE: Choose the NSF Certified Polyamide Epoxy coating System where required. Remove Table I when NSF coating specified. The intermediate epoxy coat may be an NSF61 certified product containing an optically active pigment (OAP). OAP containing coatings facilitate inspection when a black light is used to look for holidays and pinholes in the finish coat.

$* * * * * * * * * * * * * * * * * * * * * * * * * * * * * * * * * * * * * * * * * * * * * * * * * * * * * * * * * * * * * * * * * *$

Select a commercially available, three coat polyamide epoxy coating system that is certified in accordance with NSF 61 for contact with potable water in water storage tanks of the size being coated. The coating system shall be suitable for application in three even coats of 50-100 microns 3-5 mils dry film thickness (DFT), for a total minimum of 225 microns 9 mils DFT.

$* * * * * * * * * * * * * * * * * * * * * * * * * * * * * * * * * * * * * * * * * * * * * * * * * * * * * * * * * * * * * * * * * *$

NOTE: Choose this system, MIL-DTL-24441 Type III (/20 and /22), for potable water where certification to NSF 61 is not required. Edit Table I to match. The intermediate epoxy coat may be manufactured to either contain or receive an additive in the field containing an optically active pigment (OAP). OAP containing coatings facilitate inspection when a black light is used to look for holidays 
and pinholes in the finish coat. Follow the manufacturer's guidelines for using the additive.

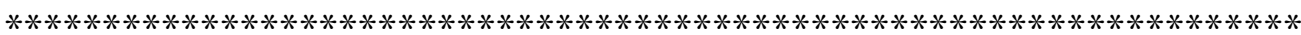

The epoxy coating materials shall be approved by the Naval Sea Systems Command and listed on their current Qualified Products List (QPL) for the specified materials.

\subsubsection{Epoxy Primer Coat}

Epoxy polyamide, MIL-DTL-24441/20 (Formula 150, Type III, Green).

\subsubsection{Epoxy Intermediate Coat}

Epoxy polyamide, MIL-DTL-24441/22 (Formula 152, Type III, White (Tinted)). Tint to approximately FED-STD-595 color number 27778 parchment using pigment dispersions prepared for epoxy paint tinting. Manufacturer shall tint material and appropriately label. All other requirements of this Military Specification apply.

\subsubsection{Epoxy Topcoat}

Epoxy polyamide, MIL-DTL-24441/22 (Formula 152, Type III, White). ][2.2.3 MIL-DTL-24441 Epoxy System for Non-potable Water Tanks

$* * * * * * * * * * * * * * * * * * * * * * * * * * * * * * * * * * * * * * * * * * * * * * * * * * * * * * * * * * * * * * * * * *$

NOTE: Choose this system, MIL-DTL-24441 Type IV

(/29 and /31), for non-potable water. Type IV materials are not suitable for potable water due to Benzyl alcohol. Edit Table I to match. The intermediate epoxy coat may be manufactured to either contain or receive an additive in the field containing an optically active pigment (OAP). OAP containing coatings facilitate inspection when a black light is used to look for holidays and pinholes in the finish coat. Follow the manufacturer's guidelines for using the additive. 
The epoxy coating materials shall be approved by the Naval Sea Systems Command and listed on their current Qualified Products List (QPL) for the specified materials.

\subsubsection{Epoxy Primer Coat}

Epoxy polyamide, MIL-DTL-24441/29 (Formula 150, Type IV, Green).

\subsubsection{Epoxy Intermediate Coat}

Epoxy polyamide, MIL-DTL-24441/31 (Formula 152, Type IV, White (Tinted)). Tint to approximately FED-STD-595 color number 27778 parchment using pigment dispersions prepared for epoxy paint tinting. Manufacturer shall tint material and appropriately label. All other requirements of this Military Specification apply.

\subsubsection{Epoxy Topcoat}

Epoxy polyamide, MIL-DTL-24441/31 (Formula 152, Type IV, White). All other requirements of this Military Specification apply.

\subsubsection{Holiday Testing}

No sooner than 48 hours after application of the topcoat, perform holiday testing in accordance with the low voltage wet sponge method of NACE SP0188 or if optically active pigment is used in the intermediate coat use a black light to inspect for holidays. Use a low voltage wet sponge to verify that the holiday extends to the steel substrate. Repair holidays per paragraph entitled "Procedure for Holiday and Spot Repairs of Newly Applied Coating." 
USACE / NAVFAC / AFCESA UFGS-09 9713.17 (January 2007)

Preparing Activity: NAVFAC Superseding

UFGS-09 97 13.17 (July 2006)

UNIFIED FACILITIES GUIDE SPECIFICATIONS

References are in agreement with UMRL dated January 2008

SECTION TABLE OF CONTENTS

DIVISION 09 - FINISHES

SECTION 099713.17

THREE COAT EPOXY INTERIOR COATING OF WELDED STEEL PETROLEUM FUEL TANKS

01/07

2.2 COATING SYSTEM

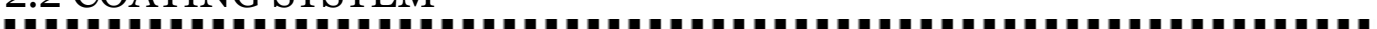

NOTE: Include bracketed text for new construction only.

$* * * * * * * * * * * * * * * * * * * * * * * * * * * * * * * * * * * * * * * * * * * * * * * * * * * * * * * * * * * * * * * * * * *$

Alternate systems or products will not be considered. All primer, intermediate, and topcoat materials shall be manufactured by one manufacturer. [The entire coating system is intended to be applied in the field. Alternatively, surface preparation may be accomplished in the shop, following all temperature, humidity, and testing requirements listed herein, followed by an application of a hold-primer. Upon completion of field fabrication, all shop-applied coatings shall be removed, surfaces prepared to SSPC SP 10, and the specified coating system applied. Adjust all shop preparation to avoid conflicts with final surface preparation requirements.] 
2.2.1 Epoxy Primer, Intermediate, and Topcoats

The epoxy coating materials shall be approved by the Naval Sea Systems Command and listed on their current Qualified Products List (QPL) for the specified materials.

\subsubsection{Epoxy Primer Coat}

Epoxy polyamide, MIL-DTL-24441/29 (Formula 150, Type IV, Green).

\subsubsection{Epoxy Intermediate Coat}

Epoxy polyamide, MIL-DTL-24441/31 (Formula 152, Type IV, White (Tinted)). Tint to approximately FED-STD-595 color number 27778 parchment using pigment dispersions prepared for epoxy paint tinting. Manufacturer shall tint material and appropriately label. All other requirements of this Military Specification apply. The intermediate epoxy coat may be manufactured to either contain or receive an additive in the field containing an optically active pigment (OAP). OAP containing coatings facilitate inspection when a black light is used to look for holidays and pinholes in the finish coat. Follow the manufacturer's guidelines for using the additive.

\subsubsection{Epoxy Topcoat}

Epoxy polyamide, MIL-DTL-24441/31 (Formula 152, Type IV, White).

\subsubsection{Holiday Testing}

No sooner than 48 hours after application of the topcoat, perform holiday testing in accordance with the low voltage wet sponge method of NACE SP0188 or if optically active pigment is used in the intermediate coat use a blacklight to inspect for holidays. Use a low voltage wet sponge to verify that the holiday extends to the steel substrate. Repair holidays per paragraph entitled "Procedure for Holiday and Spot Repairs of Newly Applied Coating." 


\title{
Appendix F: Smart Fluorescent and Self- Healing Coatings for Steel Utilities at Army Installations
}

\author{
SMART FLUORESCENT AND SELF-HEALING COATINGS FOR \\ STEEL UTILITIES AT ARMY INSTALLATIONS
}

\author{
Ashok Kumar and L. D. Stephenson \\ U. S. Army Engineer Research \& Development Center (ERDC) \\ Construction Engineering Research Laboratory (CERL) \\ Champaign, IL
}

\begin{abstract}
A smart coating system that provided a means of detecting areas where corrosion can initiate was demonstrated and implemented on an Army Installation's central vehicle wash facility CVWF) grit settling chamber water inlet pipe. Optically active additives were incorporated into the primer of a commercially available epoxy coating system and tested in the laboratory. Following successful testing, these coating systems were implemented on the inlet pipe. The coatings fluoresce under ultraviolet (UV) light inspection to reveal areas where coatings have developed holidays in the top coat, or areas of incomplete coverage, which exhibit brighter luminosity than surrounding areas. In addition, laboratory tested microcapsules containing film formers, corrosion inhibitors, and marker dyes were mixed into paint as a dry powder at the time of application, and applied to critical areas of the pipe surfaces. The microcapsules break open if the coating is damaged and spill out their contents to protect and mark the damaged areas until they can be repaired after UV inspection. The early identification of coating damage will allow for more timely maintenance repairs to be performed before the surface is destroyed by corrosion.
\end{abstract}




\section{INTRODUCTION}

\section{Central Vehicle Wash Facilities}

Following training exercises, Army vehicles must be cleaned and decontaminated to prevent corrosion and ensure long-term dependability. To that end, many large Army Installations have central vehicle wash facilities (CVWF), which are used to wash soil and mud off Army vehicles, so that concentration cell corrosion will not result. The water used in the CVWF is recycled as shown in Figure 1. Dirty water is pumped from the CVWF wash basin (1) to a grit settling chamber (2), where large particles settle to the bottom, and the oil and grease that float to the top, are skimmed off. The water is then pumped to a holding pond (3), and afterwards to a filter bed (4), consisting of 1 meter of graded sand, where the fine particle are filtered out. The clean water is pumped to a second holding pond (5), and finally back to the CVWF wash basin.

One large Army installation in the Southeast had identified severe corrosion problems at Central Vehicle Wash Facility (CVWF). The $0.65 \mathrm{~m}$ diameter inlet pipe for the grit chamber was being corroded due to its proximity to the water in the wash basin. If left uncorrected, the pipe would have been destroyed by corrosion (Figure 2). Maintenance delays would eventually result in pitting, which occurs when complete coating failure has occurred and irreversible corrosion damage begins. Without this coating system, the CVWF inlet pipe would continue to deteriorate, and the facility would be forced to shut down more frequently for repairs, in which case the benefits of washing vehicles to enhance their resistance to corrosion will not be realized. Since there is no other similar facility available at this Installation, Army vehicles will not be able to have mud removed underneath. In this case, concentration cell corrosion will develop, because the corrodants are held next to the metal of the vehicle. Removal of mud by the CVWF prevents this from happening.

About 20 other Army Installations have similar facilities that suffer similar problems. In addition, similar corrosion problems are present at vehicle wash facilities at other installations in the Tri-services. Thus, the proposed project has far-reaching impact, because the removal of mud from vehicles mitigates corrosion. 


\section{BACKGROUND}

Conventional coating systems do not provide for a method of early identification of coating failures due to corrosion issues. Current corrosion detection methods typically consist of visually identifying failures after extensive disbonding of the coating system from the substrate has occurred. At this stage, the coating system is normally so severely damaged that total removal and recoat is the only solution. This results in extensive maintenance costs and extended down times, a constant burden to operational facilities.

In order to address these problems, smart fluorescent self-healing coatings were used that have dual functionality built into the primer. These coatings can simultaneously: (1) provide warning of where the coating has been damaged via fluorescence and release of marker dyes, and (2) selfrepair the damaged areas. The use of these smart fluorescent and selfhealing coatings would provide the benefits of making inspection easier and restoring the CVWF to its optimum operating condition, as well as reduced maintenance, and increased safety not only for the CVWF, but for the vehicle that use the facility.

\section{Fluorescent Coatings}

Fluorescent coatings contain additives that fluoresce under ultraviolet (UV) light inspection to reveal areas where coatings have developed holidays, areas of incomplete coverage, and areas where corrosion has initiated under the coating. The fluorescent coating proposed uses a variation of non-destructive testing (NDT) to produce a visual condition that dramatically increases a workers ability to "see" film coverage defects. This is accomplished by the incorporation of a photo-luminescent "tag" in several layers of epoxy and polyurethane coatings of an applied system. Observation of changes in fluorescence allows the operator to easily locate film detects even in welds, corners, edges, crevices, or wherever there is a dramatic change in surface contour, due to corrosion.

The utilization of fluorescent additives in coating systems has been in use in the marine industry to extend the life of ballast tanks., ${ }^{1,2}$ They are used for the inspection of applied coatings for holidays both during and after application.3, 4 With the fluorescent additives in the primer, areas where coatings have developed holidays in the top coat, or areas of incomplete 
coverage, which exhibit brighter luminosity than surrounding areas. Prior to application of the topcoat, areas of brighter than normal luminosity tend to indicate higher than expected dry film thickness (DFT); duller than normal luminosity indicates lower than expected DFT. After application of a topcoat, the fluorescence should disappear; areas where the fluorescence is still present are indicative of a lower than normal topcoat thickness. Organic dust and grit show as speckled bright spots under the UV light, but with practice, they are easily identified as such. To eliminate any possibility of confusing surface contaminants with other defects, the painted surface should be wiped clean prior to UV inspection.

The average worker with 20/20 vision can usually locate a defect $0.5 \mathrm{~mm}$ in size. UV fluorescence allows the same worker to locate defects $0.1 \mathrm{~mm}$ in size or smaller, even in low-light conditions. 3

\section{EXPERIMENTAL LABORATORY INVESTIGATION}

\section{Fluorescent OAA Additives}

Steel coupons $(7.5 \mathrm{~cm} \mathrm{X} 22.5 \mathrm{~cm})$ panels were coated with waterborne epoxy primer to 125 microns that had a commercially available optically active additive (OAA), viz., 4,4 -bis (2-sulfostyryl)-biphenyl disodium salt, mixed in at one-volume percent of liquid primer at the time of application. The absorption and emission spectrum is shown in Figure 3 and indicate indicates absorption of UV light (275-400 $\mathrm{nm}$ ) and emission primarily in the visible violet to blue range. (400-500nm). Steel coupons were then top-coated with 25 to 75 microns of water borne epoxy primer, using drawdown apparatus. A 35 watt UV-A lamp (275-400 nm) was used to illuminate the samples.

The analysis of the images under fluorescent illumination requires some practice, and the use of such coatings with known defects is strongly suggested. Dust and other small particles on the surface of the coatings fluoresces brightly, and one must learn to differentiate from actual defects in the coatings.

As can be seen in Figure 4, the primer with OAA shows much brighter luminosity (bright blue white color compared to the darker dull color of the primer coat without the OAA, thus allowing differentiating of coatings that are too thinly applied from coatings of normal thickness, since the OAA 
will be seen under UV illumination through a thin coating, as shown in Figure 5. Defects in the topcoat, such as scratches are seen glowing brightly at A in Figure 6, along with a few small areas indicating lower than normal thickness at B.

\section{Microcapsule Additives}

"Self-healing" coatings are a relatively new technology, recently developed by U.S. Army Engineer Research and Development Center (ERDC) Construction Engineering Research Laboratory (CERL).5,6,7,8 Self-healing coatings are made by incorporating microcapsules (6o - 150 microns in diameter) that contain film-formers and corrosion inhibitors into commerciallyavailable paint primers at the time of coating application. When the coating is scratched, the microcapsules break and release their corrosion inhibitors and film formers, which protect the underlying steel substrates from corrosion, and repair some of the coating damage. Typical urea formaldehyde (UF) microcapsules (6o microns average size) are shown in Figure 7a. In addition, the microcapsules contain conventional dyes and fluorescent dyes that will be released to mark damaged areas, as shown in Figure $7 \mathrm{~b}$. These marker dyes will show maintenance personnel which areas of the coating require repair, while the film formers and corrosion inhibitors provide interim protection. A typical optical micrograph of a cross section of self-healing coated with microcapsules in the primer is shown in Figure 8 , and reveals a relative well-dispersed microcapsule mixture. The microcapsule additives are used in the coating systems that are applied to the critical corrosive areas, such as joints and welds of the pipe.

\section{FIELD DEMONSTRATION OF FLUORESCENT AND SELF HEALING COATINGS}

Pre-application inspection of the pipe to be coated revealed that surface rust was present over approximately $60 \%$ of the pipe exterior, and that the existing paint film exhibited severe chalking. An analysis of paint chips revealed no lead present above actionable levels. The work flow for the coating process, including surface preparation is given in Table 1. The existing coating was thin in several areas, exposing steel to environment and further corrosion. Existing coatings in critical areas such as welds, elbows, couplers, bolts and pipe stands exhibited signs of cracking, peeling and corrosion. 


\section{Surface Preparation and Coating Activities}

In order for the CVWF to remain operational while the recoating process was carried out, only one side of the grit settling chamber was shut down, at a time, as shown in Figure 9. The surface preparation process included the following: (1) Low-pressure water washing to remove surface contaminants; (2) Abrasive blasting to remove all existing coating material and corrosion; and (3) Application of coating systems with fluorescent additives and self healing microcapsules mixed in at the time of application.

\section{Contaminant Removal}

Surface contamination was removed prior to abrasive blasting activities being performed. Surface contaminates were removed by a combination power washing and hand washing. Power washing was performed at between the ranges of 1,500 to 4,000 psi. All surrounding surfaces were protected from surface preparation activities and coating application. The surrounding areas were protected with tarps, enclosures, and containments, as shown in Figure 9.

Surface preparation consisted of abrasive blasting to Near White Metal Blast (SSPC-SP10). The surface profile was 50 to 75 micron profile as measured by a press-on-film tape \& micrometer. Blast media was $12 / 40$ or 20/40 grit size or equivalent. This surface preparation method removed all rust and old existing coating materials. Spent media was collected and disposed of in accordance with local environmental requirements.

\section{Application of New Coating Systems}

Coal tar epoxy coatings were applied using roller and brush in two coats to the entire surface of the piping structure at a dry film thickness of approximately 25 to 100 microns dry-film thickness (DFT) per coat, as measured by magnetic gages. The first coat consisted of epoxy coal tar primer with fluorescent additive. As in the case of the laboratory investigation, the fluorescent additive was mixed in as a dry powder at one-volume percent of epoxy coal tar primer (See Figure 10). After this primer was cured, UV light was used to inspect for film defects. The UV light allowed for identification of defects 10 microns in size or smaller. If defects were located, they were immediately repaired (Figure 11). Future damage to the coating sys- 
tem can be detected by the use of the UV light method during routine maintenance inspections.

At critical areas such as joints, welds, edges, or bolts, a special stripe coat of epoxy coal tar is applied. This application includes the mixing of microcapsule dry powder additive in the epoxy coal tar product. Self healing coatings with microcapsules will provide coatings with additional special properties, including self-healing capabilities, corrosion resistance, and passive sensing via fluorescent additives that allow for UV inspection and dyes in microcapsules that are released when the coating is damaged..

A final protective membrane of epoxy coal tar without additives was applied in two coats to the entire surface of the piping structure at a dry film thickness of approximately 75 to 100 microns DFT. The entire finished system was 250 microns to 400 microns DFT (Figure 12).

\section{CONCLUSIONS}

This research has shown that coating defects, such as pinholes and cracks are visible under UV light inspections of paint systems incorporating fluorescent additives. Laboratory research has revealed that optically active additives did not interfere with the ease of paint application, nor with the efficacy of the coating, Laboratory research on coatings with known defects provided practice for analyzing fluorescent images. Field application of the fluorescent coatings with self-healing microcapsules revealed that the optically active additives are effective for identification of areas of inadequate coverage, which were subsequently repaired.

It is believed that the use of these fluorescent additives will ensure a longer period of maintenance free service, reduce re-work and reduce paint usage, which in turn will reduce VOC emission from the site. Easier and improved inspections are expected to allow for identification of defects and repairs to the coating system at an early stage, and will prevent more expensive repairs which would otherwise occur over the lifetime of the facility.

\section{REFERENCES}

1. MIL-PRF-23236C: "Performance Specification": Coatings Systems for Ship Structures, U. S. Dept of Defense (2003) (http://assist.daps.dia.mil). 
2. Burkhurst, M, and Bowry, E., Paper T-44: "An Optically Active Coating System for Coatings Ballast Tanks," The Paint \& Coatings Expo 2005, Pittsburgh, PA: SSPC: The Society for Protective Coatings (2005).

3. SSPC-TU 11 Society for Protective Coatings Technology Update No. 11, "Inspection of Fluorescent Coating Systems," October 1, 2006.

4. Johnson, R. E. and Agarwala, V. S., Rajan, K. S., Singh, A., Durrett, M. G., "Fluorescent Materials Utilized as Early Warning Sensors for Corrosion of Aluminum Alloy Surfaces," CORROSION/99, Paper 505, National Association of Corrosion Engineers (NACE), Houston, TX (1999).

5. United States Patent no. 7,192,993, March 20, 2007, "Self-healing coating and microcapsules to make same” Ashok Kumar, et. al.

6. L.D. Stephenson, Ashok Kumar, Timothy D. Race, L.D. Stephenson, Ashok Kumar, and Steve Williams, "Surface-Tolerant Coatings for Aircraft Hangars, Flight Control Tower, and Deluge Tanks at Fort Campbell, ":ERDC/CERL TR-07-24, U. S. Army Engineer Research \& Development Center (ERDC) Construction Engineering Research Laboratory (CERL) Champaign, IL (2007).

7. Kumar, Ashok and Stephenson, L. D., "Accelerated Testing of Self-Healing Coatings," Corrosion 2003, Paper No. 03221, National Association of Corrosion Engineers (NACE) Conference, San Diego, CA, March 2003.

8. Kumar, Ashok and Stephenson, L. D., "Self Healing Coatings," Proceedings: Corrosion 2002, Paper No. 02158, National Association of Corrosion Engineers Conference, Denver, CO, April 2002.

Table 1. CVWF inlet pipe coating work flow.

\begin{tabular}{|l|l|}
\hline $\begin{array}{l}\text { Cleaning and Surface } \\
\text { Preparation }\end{array}$ & $\begin{array}{l}\text { Pressure Wash to remove surface contamination at 1,500 to } \\
4,000 \text { psi. Abrasive blast to Near White Metal SSPC10 }\end{array}$ \\
\hline Environmental Controls & Impermeable ground tarps, or plastic \\
\hline Primer & $\begin{array}{l}\text { Coal Tar Epoxy 78HB with Fluorescent additive; two coats at 75 to } \\
00 \text { microns dry thickness/coat }\end{array}$ \\
\hline Primer at Critical Areas & $\begin{array}{l}\text { Coal Tar Epoxy 78HB with Microcapsule additive; one coat at 75 } \\
\text { to } 100 \text { microns dry film thickness }\end{array}$ \\
\hline Finish Coat & $\begin{array}{l}\text { Coat Tar Epoxy 78HB; two coats at } 75 \text { to } 100 \text { microns dry } \\
\text { thickness/coat }\end{array}$ \\
\hline
\end{tabular}



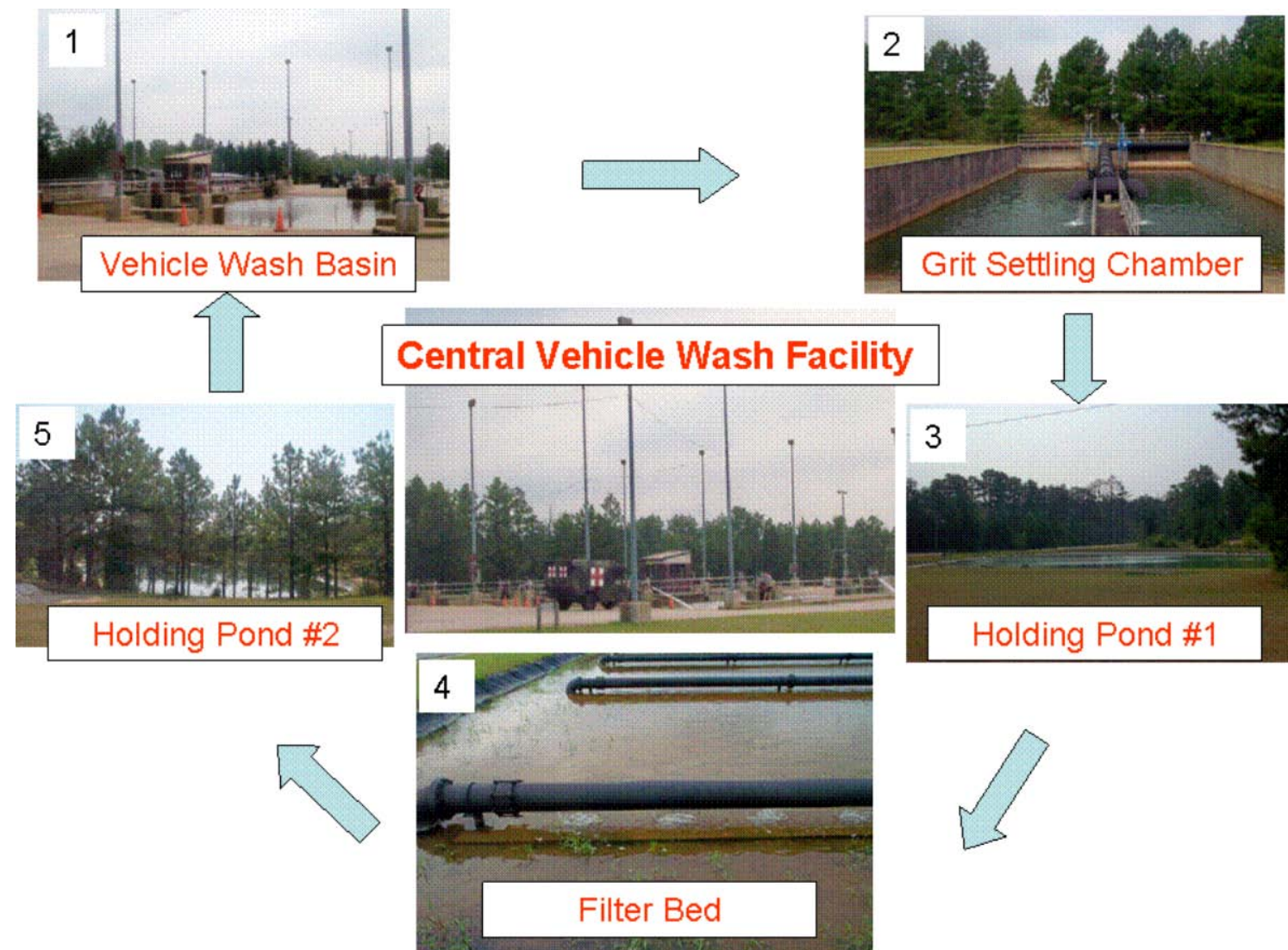

Figure 1. Typical central vehicle wash facility (CVWF) water cycle.

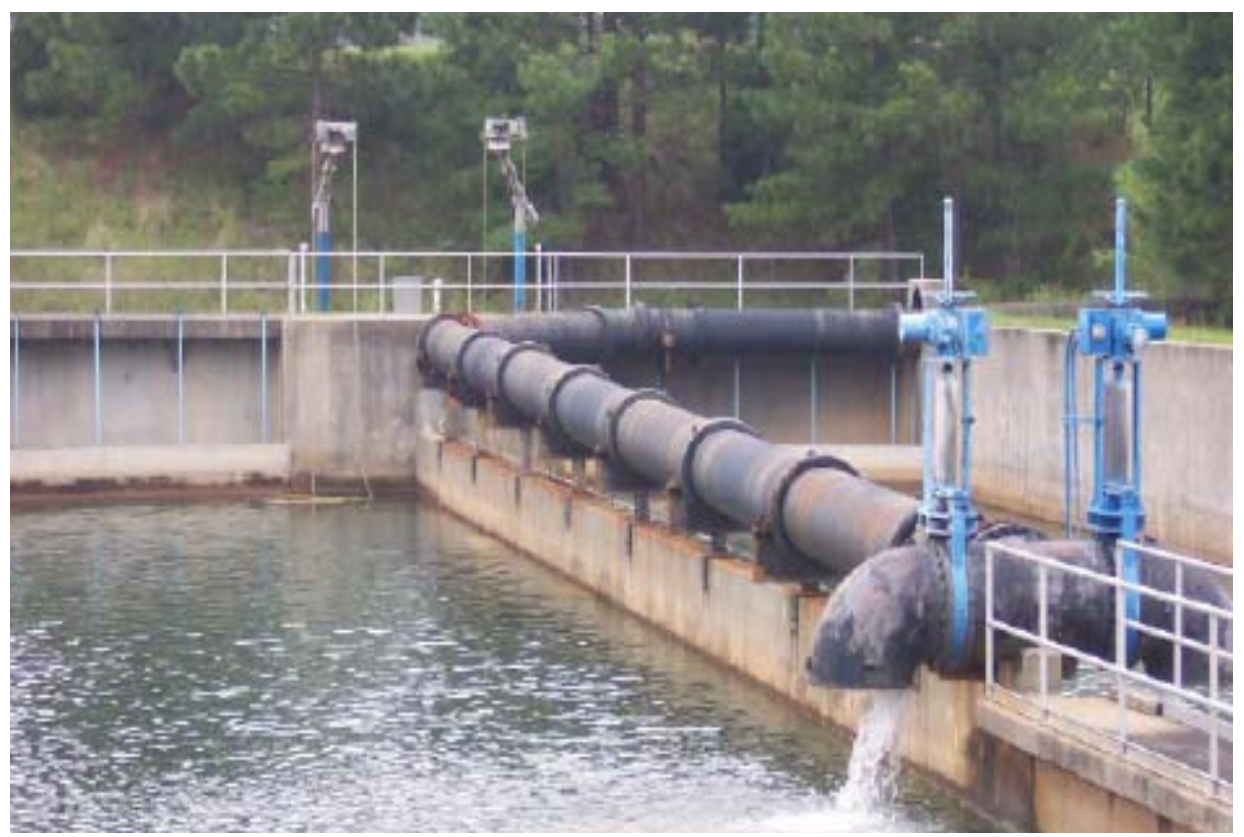

Figure 2. Corroded inlet pipe at the CVWF grit settling chamber. 


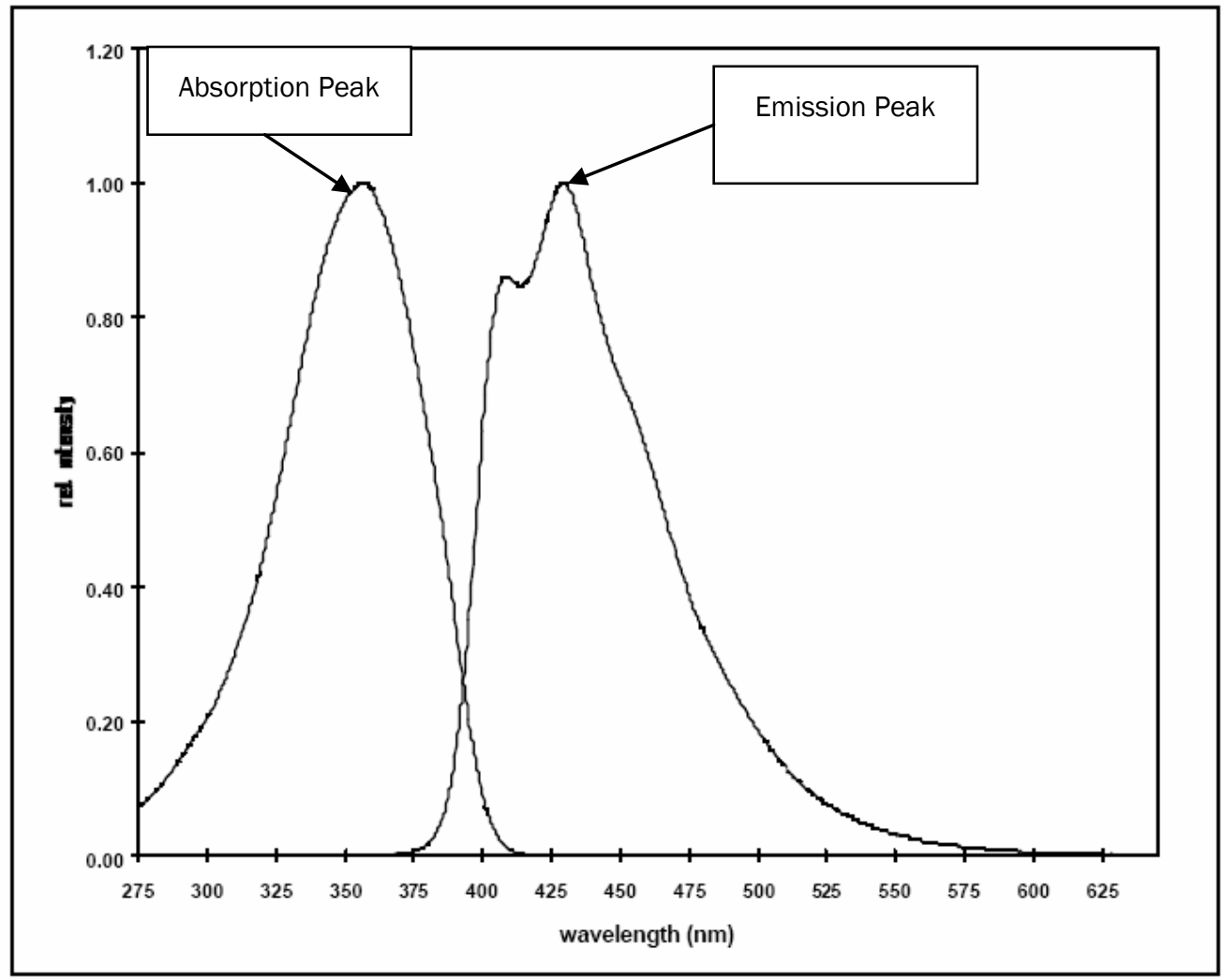

Figure 3. Absorption and emission spectrum of optically active additive (OAA) 4,4 -bis (2sulfostyryl)-biphenyl disodium salt.

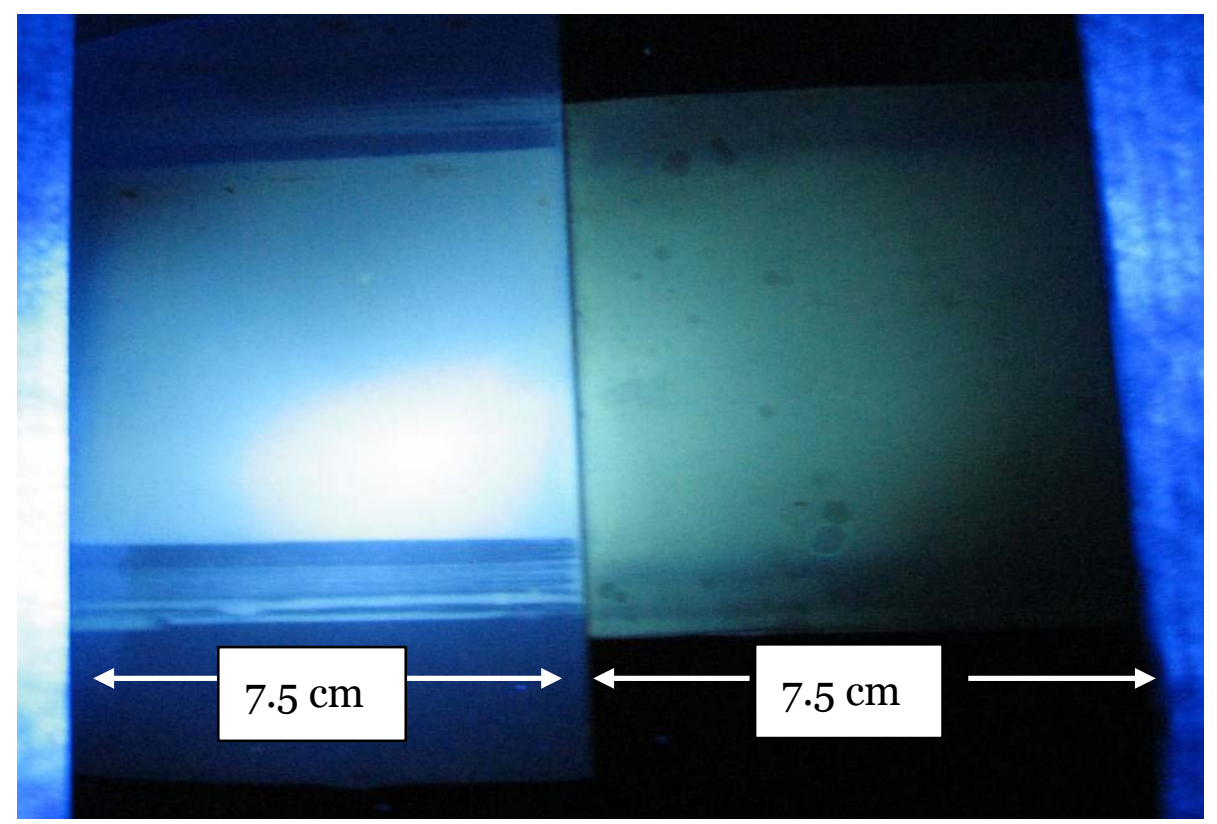

Figure 4. Steel coupons coated with water borne epoxy primer. The primer with OAA mixed in (left) shows much brighter luminosity compared to the primer without OAA (right). 

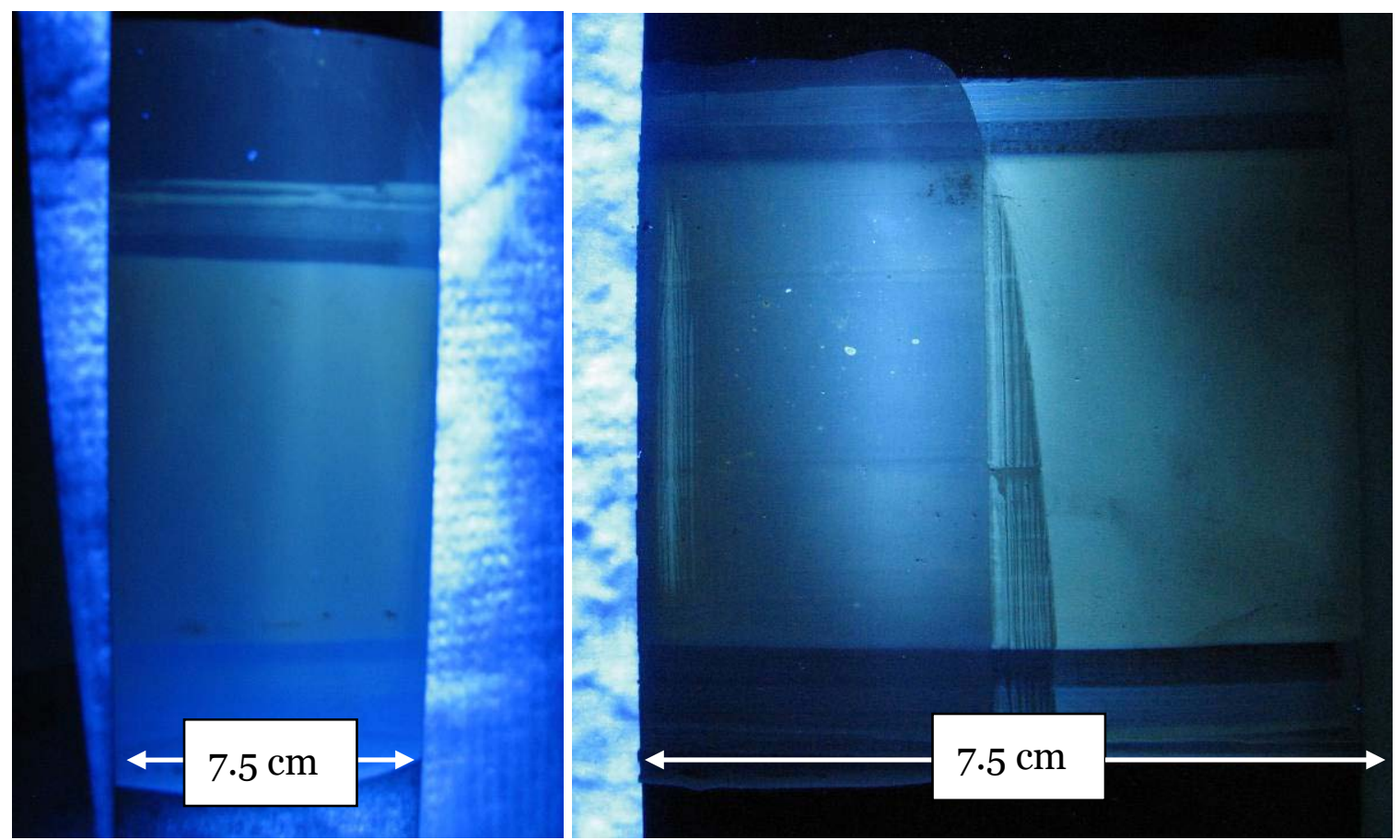

Figure 5. Steel coupons coated with water borne epoxy coatings. Left: thick topcoat applied. Middle: topcoat thinly applied (OAA will be seen under UV illumination through a thin coating). Right: Primer with OAA mixed in, but without topcoat.

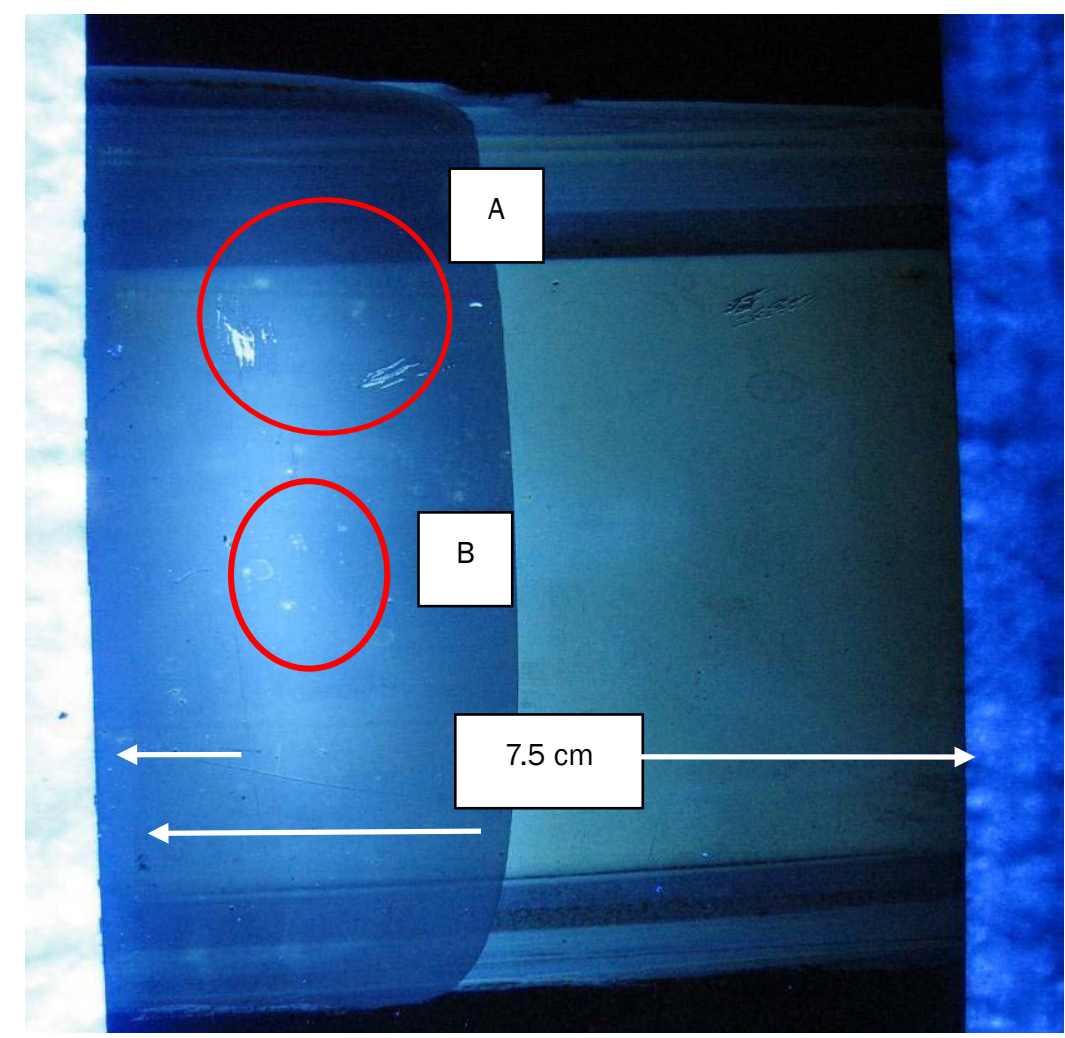

Figure 6. Left: Steel coupon topcoated. Defects in the topcoat, such as scratches are seen glowing brightly at A in Fig. 6 , along with a few small areas indicating lower than normal thickness at B. Right: Primer with OAA mixed in, but without topcoat. 


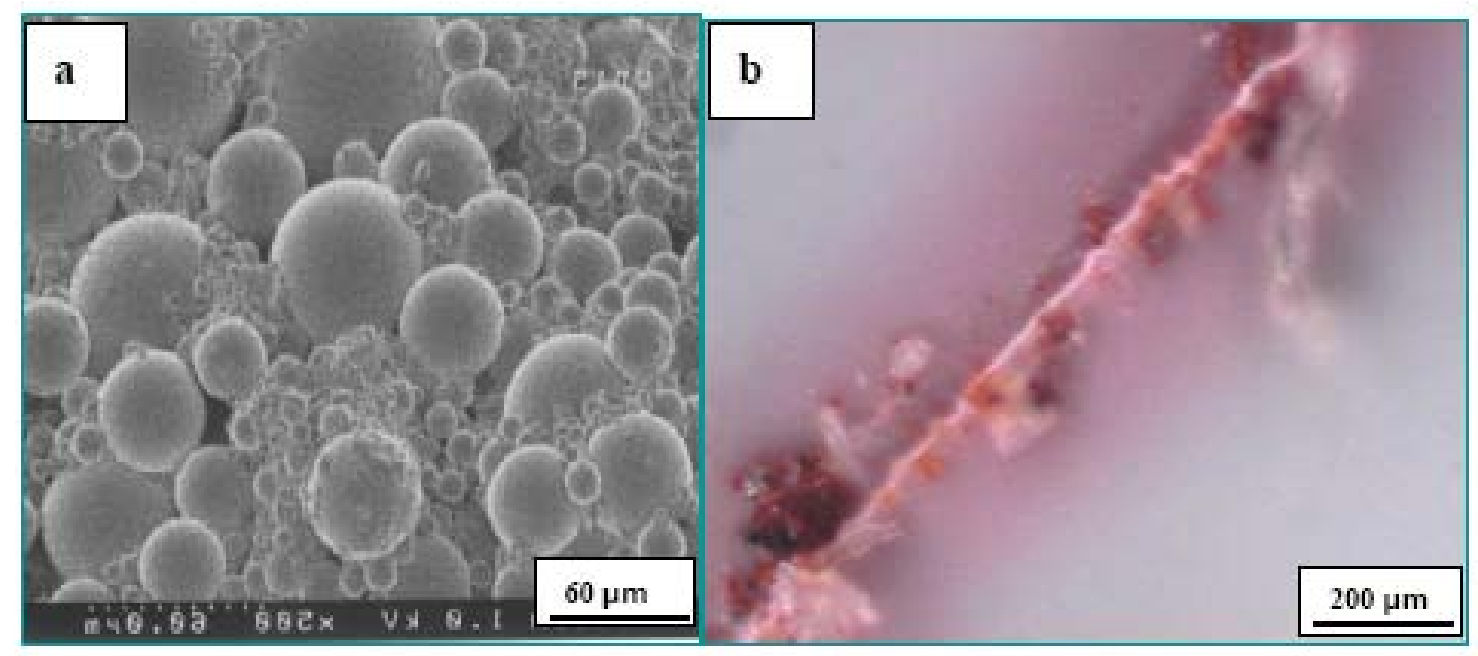

Figure 7. Self-Healing Coatings (a). Microcapsules containing film-formers and corrosion inhibitors (b) Self-healing microcapsule release film-formers and corrosion inhibitors when the coatings are damaged.

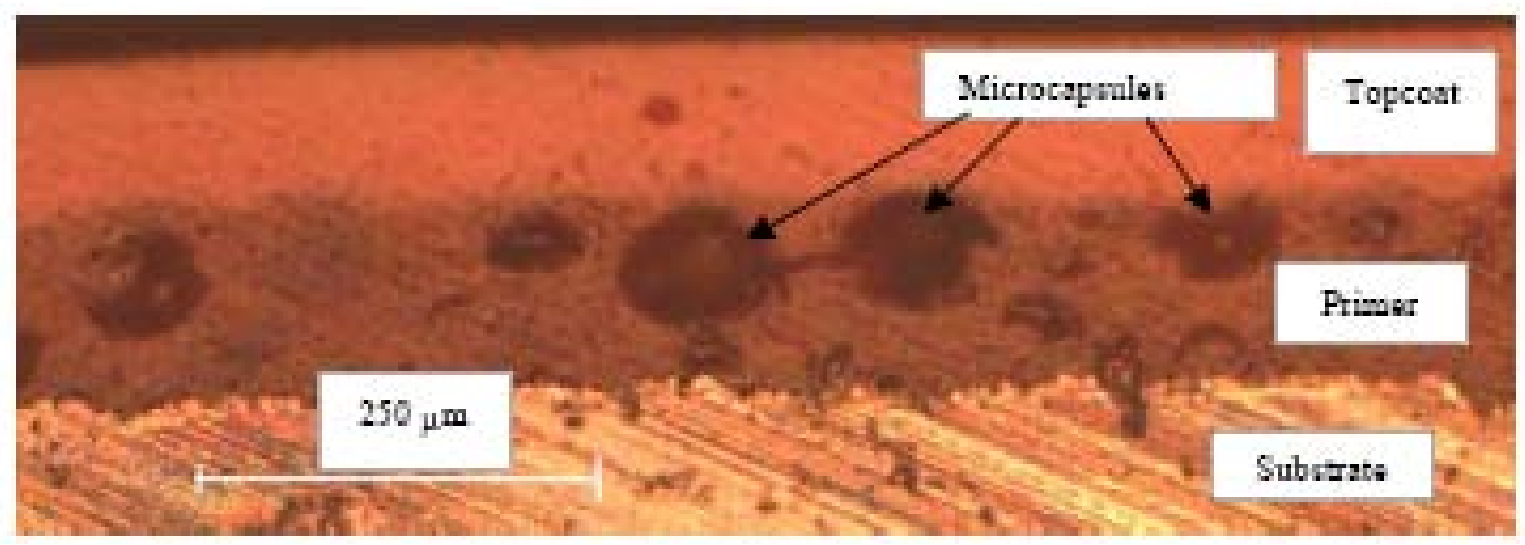

Figure 8. Cross section micrograph of self-healing coatings showing microcapsules in the primer. 


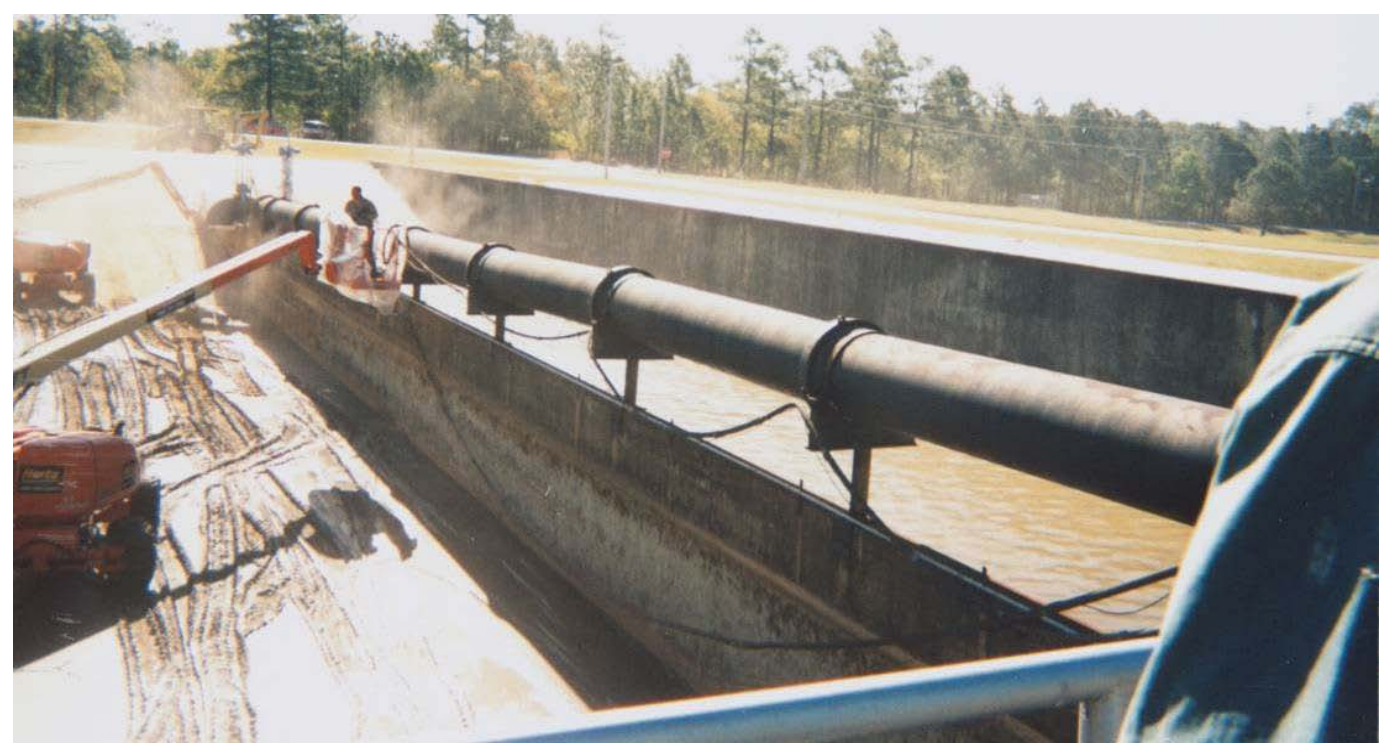

Figure 9. Surface preparation of the inlet pipe of CVWF grit settling chamber prior to coating with smart coatings.

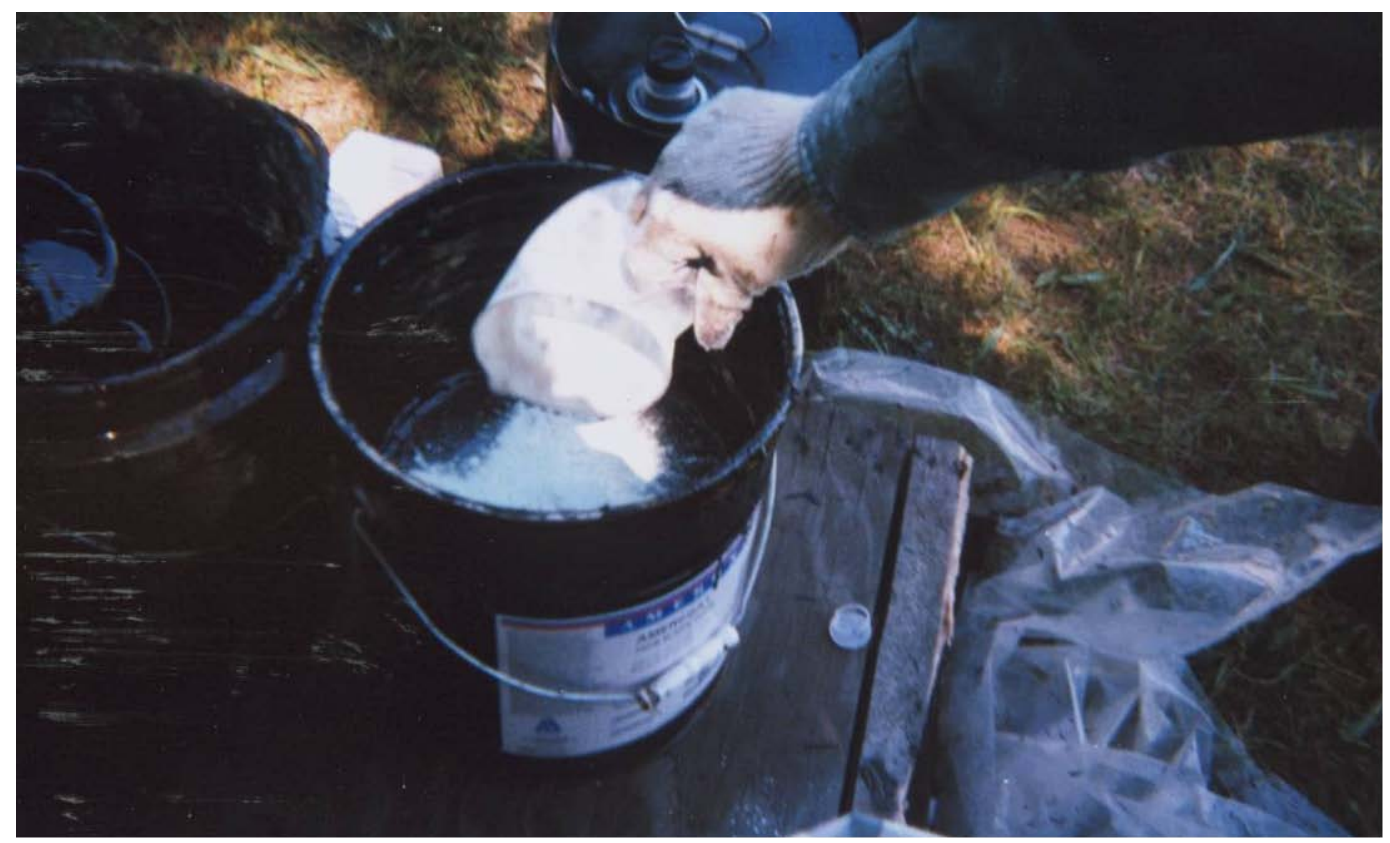

Figure 10. Mixing of fluorescent additives into coal tar epoxy formulation, prior to application. 

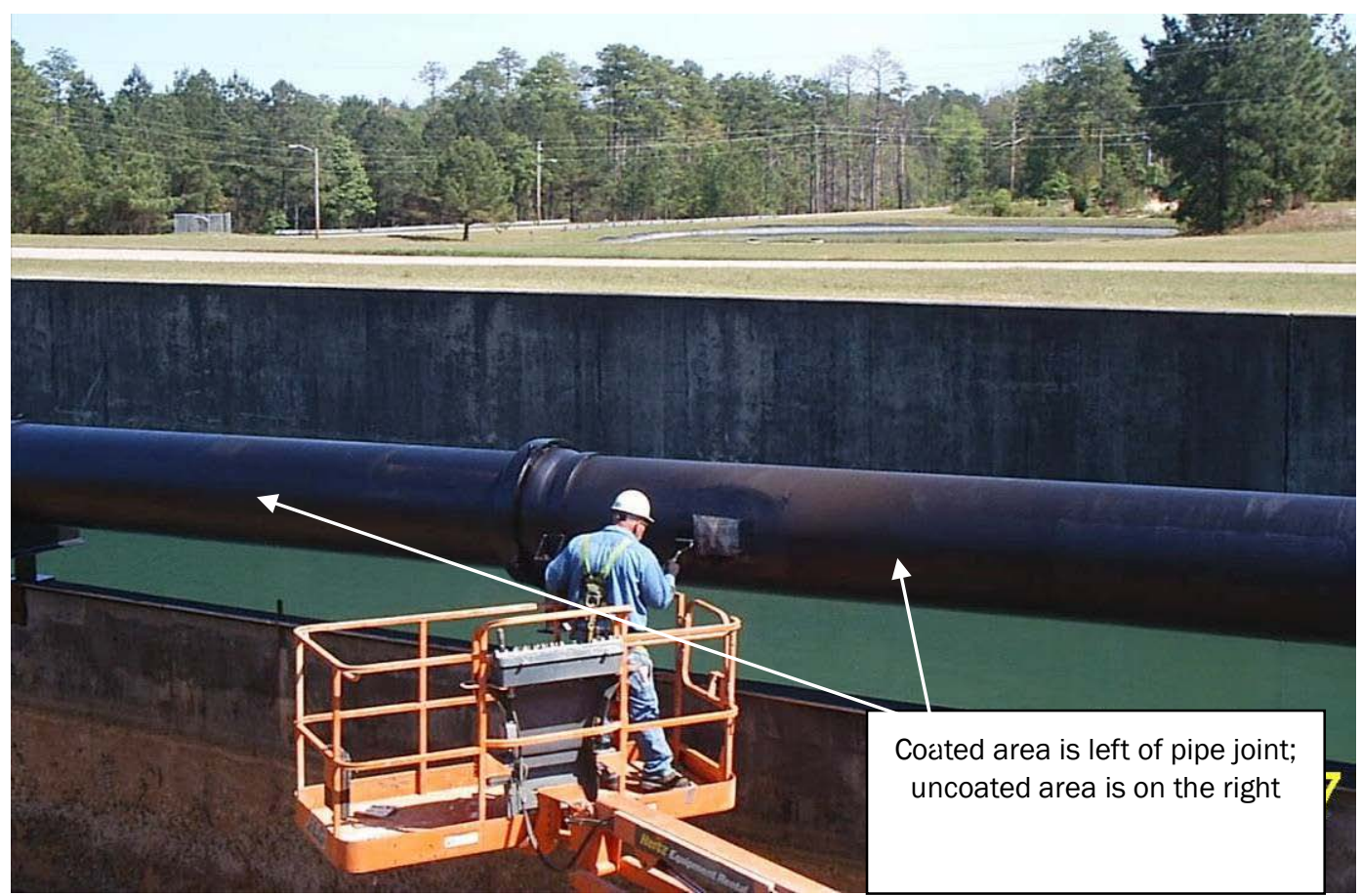

Figure 11. Inlet pipe of CVWF grit settling chamber being coated with coal tar epoxy that with self healing and fluorescent additives.

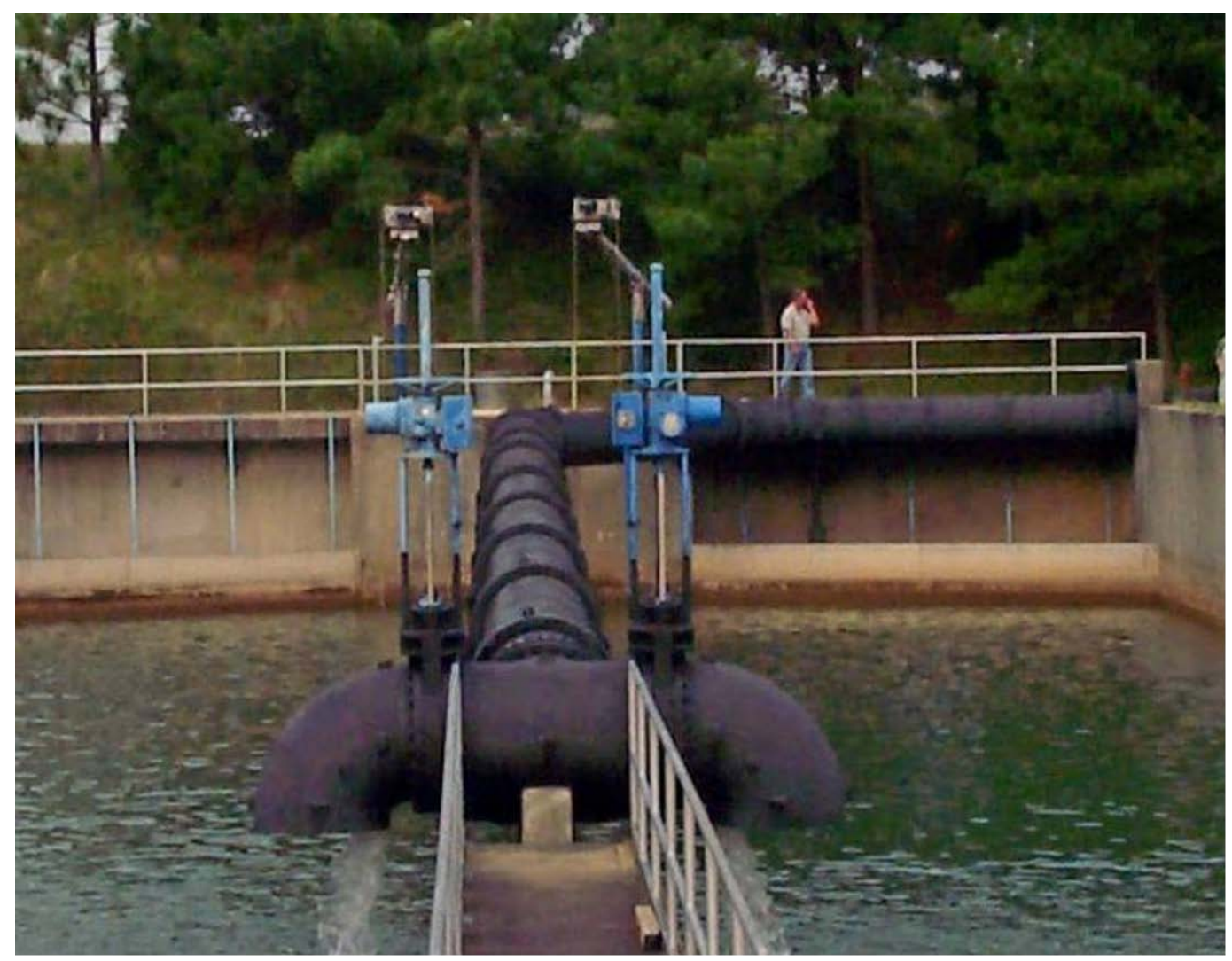

Figure 12. Inlet pipe of CVWF grit settling chamber with new coal tar epoxy coating that incorporates fluorescent additives and self-healing coatings. 


\title{
Appendix G: Smart Coatings Condition Assessment Report
}

\author{
Technology Demonstration Follow-up Report \\ Smart Fluorescent and Self Healing Coatings for \\ Severely Corrosive Environments at Vehicle Wash
}

Facilities

Contract No. W9132T-06-D-0001

Delivery Order 0009

Prepared by

Mandaree Enterprise Corporation

812 Park Drive

Warner Robins, GA 31088

Phone: 478-329-8233

Fax: 478-329-8946

6 May 2009 


\section{Background}

Conventional coating systems normally do not provide for a visual method of early identification of impending coating failures due to corrosion or surface damage other than obvious coating blisters or discolorations "bleeding" through the topcoat. Current corrosion detection methods typically consist of visually identifying failures after disbonding/blistering of the coating system from the substrate has occurred. At that stage, the coating system is normally so severely damaged that more expensive coating touchup requirements are needed.

ERDC/CERL's approach incorporated the use of proven method of mechanical surface preparation of water blasting and abrasive blasting to remove coatings and corrosion. The project test cadre then modified the standard primers with a novel fluorescing material additive (CIBA $®$ UVITEX® OB Fluorescent Whitening Agent, Ciba Specialty Chemicals, Inc - now part of BASF) that would be readily visible when exposed to ultraviolet (UV) "black light". The use of commercially available fluorescent additives mixed in the conventional coating systems provides the applicator and inspector a capability to quickly identify any discontinuities, voids, and other defects and repair these areas.

Additionally, self-healing coatings have been developed by ERDC/CERL and were incorporated in the pipe coating system. These corrosion inhibiting, self-healing microcapsules contain the materials listed in Table G1.

Table G1. Composition of microcapsules.

\begin{tabular}{|l|l|}
\hline $\begin{array}{l}\text { Microcapsule } \\
\text { Description }\end{array}$ & $\begin{array}{l}\text { EM000808A } \\
\text { (urea-formaldehyde shell, 60-150 micron diameter) }\end{array}$ \\
\hline Diluent & $\begin{array}{l}\text { Therminol 66 (modified partially hydrogenated terphenol) } \\
18.5 \text { Percent by Weight }\end{array}$ \\
\hline Diluent & $\begin{array}{l}\text { Santicizer 148 } \\
\text { (Isodecyl diphenyl phosphate) } \\
19.4 \text { Percent by Weight }\end{array}$ \\
\hline Film-Former & $\begin{array}{l}\text { phenolic varnish } \\
55.3 \text { Percent by Weight }\end{array}$ \\
\hline Antioxidant & $\begin{array}{l}\text { butylated hydroxytoluene (BHT) } \\
0.43 \text { Percent by Weight }\end{array}$ \\
\hline Anticorrosion Agent & $\begin{array}{l}\text { Irgacor 153 (alkylammonium salt of (2-benzothiazolylthio) succinic } \\
\text { acid in xylene preparation, 6.1 Percent by Weight }\end{array}$ \\
\hline
\end{tabular}


ERDC-CERL developed the microcapsules so the protective film formers would be released when they are ruptured by damage to the area on which they were applied. The film-forming material in the microcapsules would then spread over and seal the damaged area.

As noted in the Manta, Inc., Interim Report (undated) and final project report dated January 2008, the test cadre's inspection of the CVWF identified severe corrosion problems of the two-foot diameter inlet pipe for the grit chamber. A major corrosion issues contributing factor was the location of the pipe to the water in the wash basin which contains runoff from the vehicle wash and rinse operations.

As noted in the Manta reports, surface rust was present over approximately $60 \%$ of the pipe exterior (see Figure G1). Coating mil thickness had degraded to a point exposing steel to environment and further corrosion. Existing coatings in critical areas such as welds, elbows, couplers, bolts and pipe stands exhibited signs of cracking, peeling and corrosion. Severe chalking was also occurring. The Manta project lab analysis of existing coating material identified "lead" levels below action levels. Appropriate action was taken to contain and properly dispose of the contaminated waste per local, state, and federal requirements.

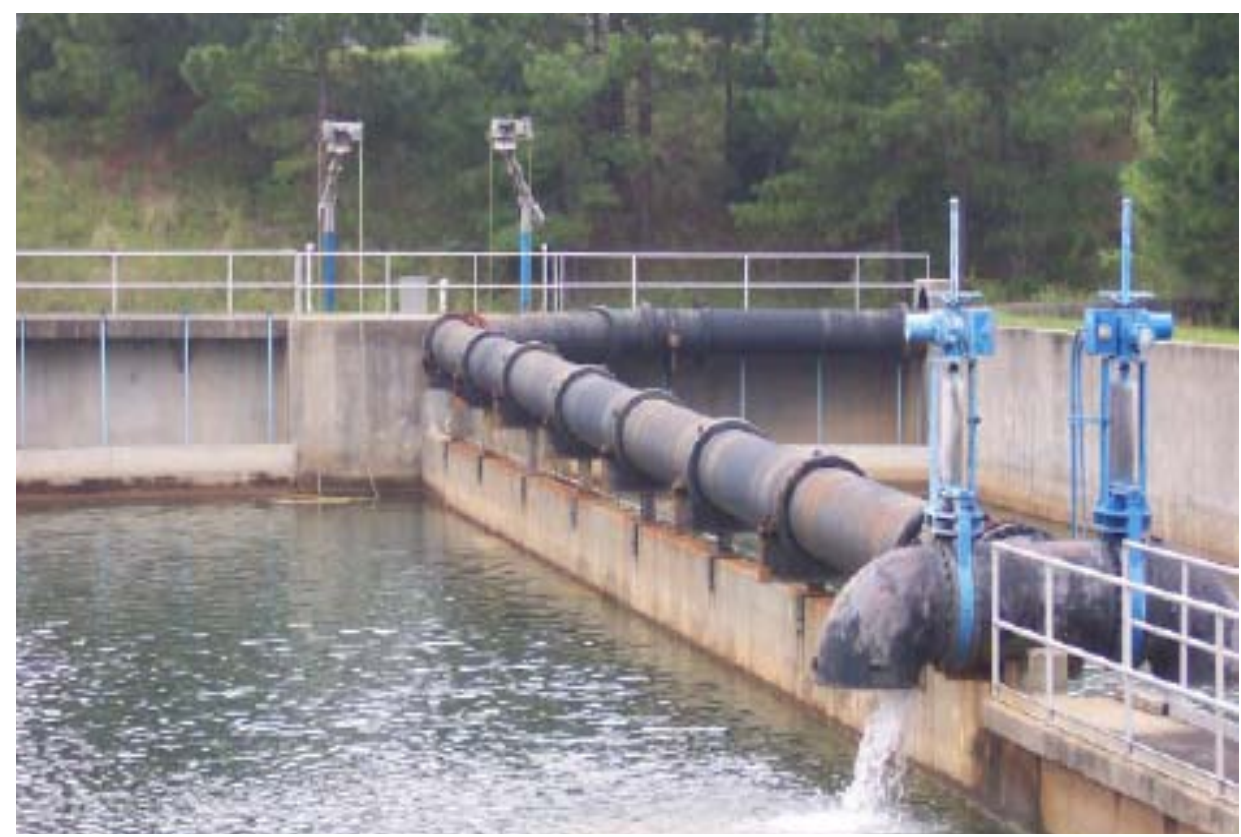

Figure G1. CVWF inlet pipe, May 2007.

The Manta test cadre water blasted, abrasive blasted, primed and painted the CVWF inlet pipe in May 2007. Specific coating preparation and appli- 
cation methods, materials, and processes can be found in MEC's final project report to ERDC-CERL, "DoD Corrosion Prevention and Control Program Technology Demonstration: Smart Fluorescent and Selfhealing Coating for Severely Corrosive Environments at Vehicle Wash Facilities", dated January 2008.

\section{Current site assessment}

On 23 April 2009, Mr. Michael Surratt (MEC) met with Mr. Russ Hayes, Directorate of Public Works, Fort Bragg, NC to conduct a follow-up site assessment of the coatings at the CVWF location. The CVWF drain pipes are shown in Figure G2.

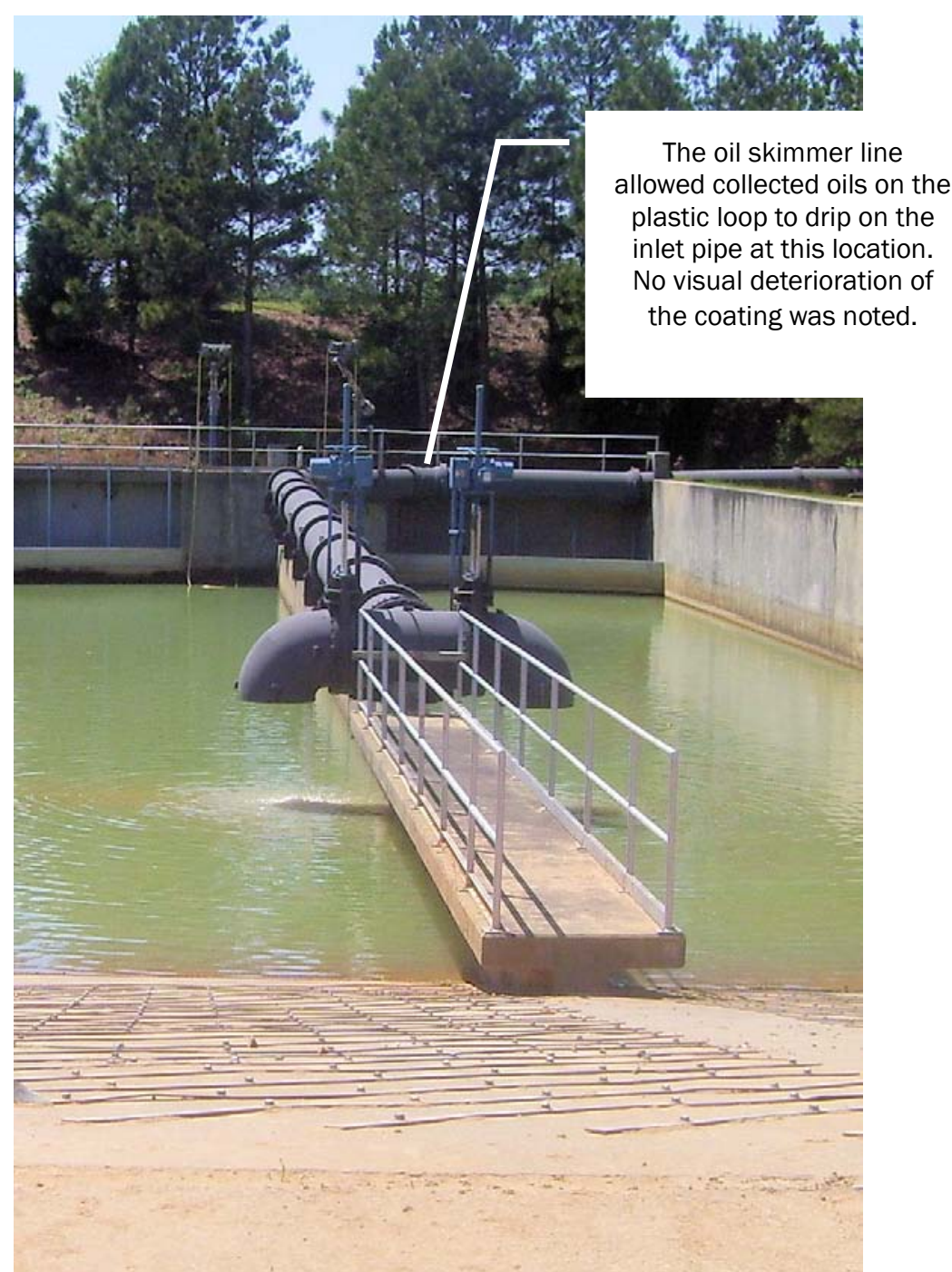

Figure G2. Fort Bragg CVWF inlet piping, 23 May 2009. 
Mr Surratt and Mr. Hayes inspected the CVWF inlet piping and sand filtration drain fields 09387, O9386, and O9385. With the exception of surface coating fading, as would be expected with an epoxy type coating system when exposed to UV radiation, the coating system was sound, no defects or surface corrosion or coating blisters were noted. We did note a small area on the inlet pipe under the oil skimmer line collection point (Figure 2) that was oil soaked and appeared to be overflow from the collection basin but the oil did not appear to affect the coating. We did not accomplish any destructive inspections on any areas of the inlet pipe or drain field pipes to verify the fluorescence or self healing properties of damaged coatings.

Attempts were made to identify any possible coating defects using UV light, however as expected the UV light was ineffective in sunlight. Mr. Surratt returned to the CVWF at night and rechecked the areas previously noted. No defects were noted. Figure $\mathrm{G}_{3}$ typifies the appearance of the piping painted in May 2007 with the test coatings.

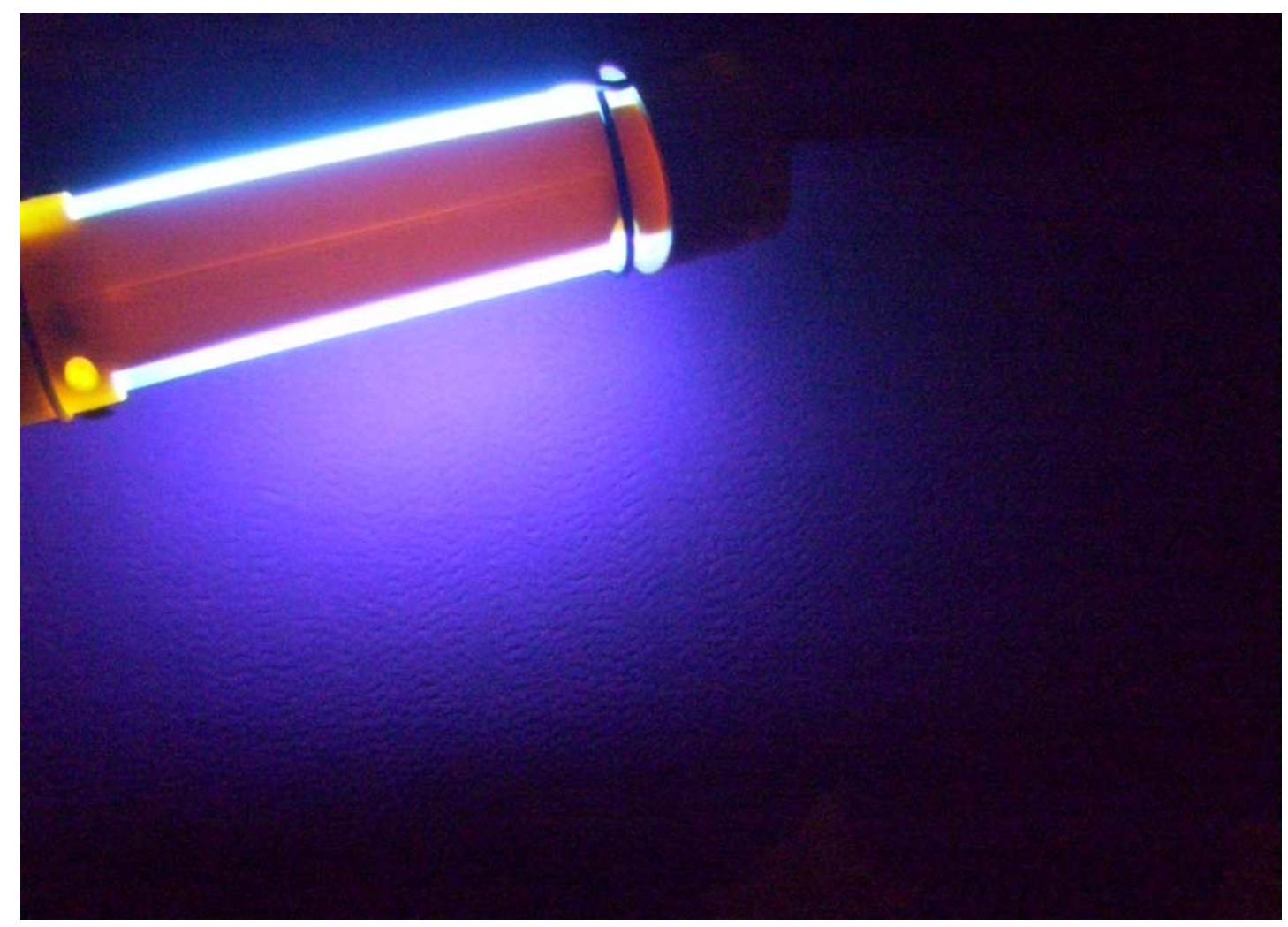

Figure G3. Typical inspection results using UV light at night. 


\section{Recommendations}

Based on the data provided in the interim and final reports, mixing and application of the modified coatings would not require specialized training. However, the identification of the microcapsule self healing coating and UV fluorescing material is very limited and it subsequent use(s) is not commonly known in the industrial painting community.

MEC recommends changes are made to Unified Facilities Criteria (UFC) 3190-06, Protective Coatings and Paints, (dated 01-16-2004) to incorporate the test materials and provide instructions for mixing, application, and UV inspection procedures in the appropriate sections of the document. That would ensure the material identification, mixing, and application information is maintained and utilized when project engineers develop tailored Unified Facility Guide Specifications. As this is a Tri-Service document, recurring procurement demands placed on the fluorescing additives and self-healing microcapsule manufacturers should drive a lower unit cost improving the overall facility infrastructure life cycle cost returnon-investment. 


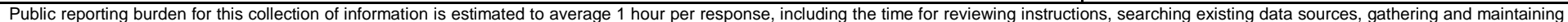

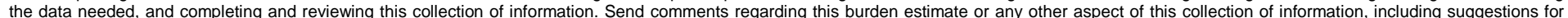

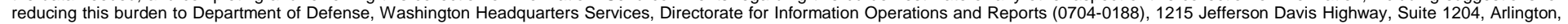

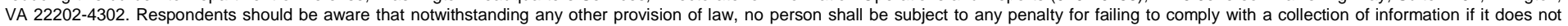
display a currently valid OMB control number. PLEASE DO NOT RETURN YOUR FORM TO THE ABOVE ADDRESS.

\begin{tabular}{l|l} 
1. REPORT DATE (DD-MM-YYYY) & 2. REPORT TYPE
\end{tabular} August 2009 Final

4. TITLE AND SUBTITLE

Demonstration of Smart Fluorescent and Self-Healing Coatings for Severely Corrosive

Environments at Vehicle Wash Facilities

3. DATES COVERED (From - To)

5a. CONTRACT NUMBER

5b. GRANT NUMBER

5c. PROGRAM ELEMENT NUMBER

Corrosion Prevention and Control

6. AUTHOR(S)

Dr. Ashok Kumar, Dr. L. D. Stephenson, Timothy D. Race, and Tony Bochniak

5d. PROJECT NUMBER

CPC FAR-02

5e. TASK NUMBER

MIPR6FCERB1020, MIPR6H6AG3CPC1

5f. WORK UNIT NUMBER

7. PERFORMING ORGANIZATION NAME(S) AND ADDRESS(ES)

U.S. Army Engineer Research and Development Center

8. PERFORMING ORGANIZATION REPORT

NUMBER

ERDC/CERL TR-09-31

Construction Engineering Research Laboratory

P.O. Box 9005

Champaign, IL 61826-9005

9. SPONSORING I MONITORING AGENCY NAME(S) AND ADDRESS(ES)

10. SPONSOR/MONITOR'S ACRONYM(S)

U.S. Army Installation Management Command

Engineering Office, Directorate of Public Works (IMPW-E)

2511 Jefferson Davis Hwy. NUMBER(S)

Arlington, VA 22202

\section{DISTRIBUTION / AVAILABILITY STATEMENT}

Approved for public release; distribution is unlimited.

\section{SUPPLEMENTARY NOTES}

Additional Task Number is MIPR6HMBHDE097

\section{ABSTRACT}

This project demonstrated the following cost-effective paint maintenance procedures: utilization of smart coatings containing fluorescing compounds, self-healing microcapsules, and purpose-formulated surface tolerant coatings to overcoat existing paints. Smart coatings incorporate microcapsules and fluorescing compounds which are mixed into paint at the time of application. Microcapsules instill the coating with self-healing, corrosion resistance, and passive sensing capabilities. Fluorescing compounds improve the coating service life by faster and better inspections, early identification of problems, and timely repairs.

The overcoating process does not require extensive surface preparation, and can be significantly less expensive than other maintenance practices, particularly when the existing coating contains lead or other hazardous materials.

The smart coatings were demonstrated on pipes used in a water-handling system for a central vehicle wash facility. The overcoating procedure was demonstrated on two types of structures: steel tanks and corrugated steel hangars. It is recommended that these technologies be implemented as standard practice for coating of steel structures for the Army and DoD.

\section{SUBJECT TERMS}

corrosion prevention and control, coatings, fluorescing compounds, maintenance, self-healing microcapsules

16. SECURITY CLASSIFICATION OF:

\section{a. REPORT}

Unclassified

\section{b. ABSTRACT}

Unclassified

\section{c. THIS PAGE}

Unclassified
17. LIMITATION OF ABSTRACT
18. NUMBER OF PAGES

132 19a. NAME OF RESPONSIBLE PERSON

19b. TELEPHONE NUMBER (include area code) 